\title{
Alteração hidrotermal e fluidos mineralizantes no alvo Jerimum de Baixo, Campo Mineralizado do Cuiú-Cuiú, Província Aurífera do Tapajós: um estudo baseado em petrografia, inclusões fluidas e química mineral
}

\author{
Hydrothermal alteration and mineralizing fluids in the Jerimum de \\ Baixo prospect, Cuiú-Cuiú Goldfield, Tapajós Gold Province: a study \\ based on petrography, fluid inclusions and mineral chemistry \\ Helder Thadeu de Oliveira ${ }^{1,2}$ (1), Régis Munhoz Krás Borges ${ }^{1,2,3}$ (1), Evandro Luiz Klein ${ }^{2,5}$ (1), \\ Claudio Nery Lamarão ${ }^{1,3}$ (1), Gisele Tavares Marques ${ }^{3,4}$ (D), Rafael Guimarães Correa Lima ${ }^{1,2}$ (1) \\ 'Universidade Federal do Pará - UFPA, Instituto de Geociências, Programa de Pós-Graduação em Geologia e Geoquímica - IG/ \\ PPGG, Rua Augusto Corrêa, 1, CEP 66075-110, Belém, PA, BR (helderthadeu@outlook.com; \\ munhoz@ufpa.br; lamarao@ufpa.br; rg.correalima@gmail.com) \\ ¿Universidade Federal do Pará - UFPA, Grupo de Pesquisa em Geologia \\ Econômica - GPGE, Belém, PA, BR (evandro.klein@cprm.gov.br) \\ ${ }^{3}$ Universidade Federal do Pará - UFPA, Grupo de Pesquisa Petrologia de \\ Granitoides - GPPG, Belém, PA, BR (gisageo15@yahoo.com.br) \\ ${ }^{4}$ Universidade Federal do Pará - UFPA, Instituto de Geociências, Laboratório de Microanálises, Belém, PA, BR \\ ${ }^{5}$ Serviço Geológico do Brasil - CPRM, Brasília, DF, BR
}

Recebido em 31 de dezembro de 2017; aceito em 04 de dezembro de 2018

\begin{abstract}
Resumo
O alvo Jerimum de Baixo está localizado no Campo Mineralizado do Cuiú-Cuiú, região central da Província Aurífera do Tapajós, Cráton Amazônico. O alvo abrange rochas de composição monzogranítica portadoras de biotita rica em Fe, essencialmente isotrópicas e que foram de fraca a fortemente hidrotermalizadas. Cloritização, sericitização, sulfetação, silicificação e carbonatação são os tipos de alteração mais importantes. A clorita hidrotermal é do tipo chamosita e foi formada entre 261 e $315^{\circ} \mathrm{C}$. A mica branca apresenta composição fengítica. A mineralização é representada por vênulas de quartzo com baixo teor de sulfetos (pirita + pirrotita \pm calcopirita \pm galena \pm esfalerita) em que o ouro ocorre livre e em zonas mais fragilizadas e alteradas, geralmente associado à pirrotita. $\mathrm{O}$ estudo petrográfico e microtermométrico de inclusões fluidas hospedadas em quartzo de vênulas definiu inclusões aquocarbônicas, carbônicas e aquosas. Os fluidos com $\mathrm{CO}_{2}$ representam o provável fluido mineralizador e foram gerados por processos de separação de fases entre 280 e $380^{\circ} \mathrm{C}$. Uma posterior infiltração e processos de mistura com fluidos meteóricos são indicados para os fluidos aquosos mais tardios. Separação de fases, modificações nas condições do $\mathrm{pH}$ e interação fluido/rocha foram os mecanismos importantes para a precipitação do $\mathrm{Au}$, que se deu em nível rúptil-dúctil da crosta (entre 2 e $6 \mathrm{~km}$ ). O conjunto de dados até aqui disponíveis indicam para o alvo Jerimum de Baixo uma filiação metalogenética similar a de depósitos auríferos relacionados à intrusão.
\end{abstract}

Palavras-chave: Província Tapajós; Alteração hidrotermal; Mineralização aurífera; Inclusões fluidas; Química mineral.

\begin{abstract}
The Jerimum de Baixo gold target is located in the Cuiú-Cuiú goldfield, Tapajós Gold Province, Amazonian Craton. The target is composed by isotropic monzogranitic rocks with Fe-rich biotite, which is slightly-to-strongly altered by hydrothermal fluids. Chloritization, sericitization, sulfidation, silicification and carbonatization are the most important types of hydrothermal alteration. The chloritization is represented by Fe-rich chlorite (chamosite type), that was mostly formed between 261 and $315^{\circ} \mathrm{C}$. White mica takes up fengitic compositions. The mineralization is represented by quartz-rich veinlets with low content of sulfides (pyrite + pyrrhotite \pm chalcopyrite \pm galena \pm sphalerite) in which the gold occurs as freemilling particles and in fractured, brecciaed and altered zones, where gold is associated with pyrrhotite. The petrographic and microthermometric study of fluid inclusions hosted in quartz veinlets defined aqueous-carbonic, carbonic and aqueous fluids. The $\mathrm{CO}_{2}$-bearing inclusions represent the probable mineralizing fluid, and are interpreted as produced by phase
\end{abstract}


separation process (effervescence) between 280 and $380^{\circ} \mathrm{C}$. The aqueous fluids are late to the mineralization and represent posterior and consecutives events of infiltration and mixture with meteoric fluids. Phases separation, modifications in $\mathrm{pH}$ conditions and interaction fluid/rock were important mechanisms for the precipitation of gold that took place in the brittle-ductile zone of the continental crust (between 2 and $6 \mathrm{~km}$ ). The available data set pointed out a metallogenetic affiliation, similar to that of intrusion-related gold deposits, to Jerimum de Baixo.

Keywords: Tapajós Province; Hydrothermal alteration; Gold mineralization; Fluid inclusions; Chemistry mineral.

\section{INTRODUÇÃO}

A Província Aurífera do Tapajós (PAT) é localizada na parte sudoeste do Estado do Pará, Brasil, porção central do Cráton Amazônico, e abrange uma área de aproximadamente $140 \mathrm{mil} \mathrm{km} \mathrm{km}^{2}$. Os vários registros de ocorrências primárias, supergênicas e aluvionares, bem como de alguns depósitos auríferos, tornaram a PAT um importante alvo de exploração por companhias mineradoras durante as últimas seis décadas. Alguns dos jazimentos auríferos mais importantes estão alojados em depósitos primários, tais como Tocantinzinho, São Jorge, Bom Jardim, Cuiú-Cuiú e Ouro Roxo. De acordo com os modelos metalogenéticos propostos, há diversas classes de depósitos na província, dos tipos relacionado à intrusão (intrusion-related gold deposit - IRGD), epitermais, orogênicos e pórfiros (Juliani et al., 2005; Santos et al., 2001; Veloso et al., 2013; Villas et al., 2013).

O Campo Mineralizado do Cuiú-Cuiú (CMCC) se situa próximo da porção central da PAT e reúne dois depósitos e alguns prospectos cuja produção histórica foi estipulada entre 46 e 62 toneladas de ouro (McMahon, 2011). Inicialmente atribuída a processos orogenéticos (Klein et al., 2001), estudos mais recentes apontam para a mineralização deste campo uma filiação ligada a um sistema magmático-hidrotermal (relacionado à intrusão?), em que a granitogênese Parauari seria um potencial responsável pelas soluções portadoras dos metais (Araújo, 2014; Assunção e Klein, 2014; Coutinho, 2008; Queiroz e Klein, 2012; Silva Junior et al., 2012, 2013).

$\mathrm{O}$ alvo Jerimum de Baixo, inserido no contexto do CMCC, não dispunha ainda de informações metalogenéticas, como características dos fluidos mineralizantes e seus produtos mineralógicos em termos composicionais. O presente trabalho aborda a caracterização e gênese do alvo Jerimum de Baixo, com base em estudos petrográficos, de inclusões fluidas (IF) e de química mineral, e complementa o acervo de dados existentes sobre a geologia e metalogênese do CMCC.

\section{CONTEXTO GEOLÓGICO}

\section{Geologia regional}

APAT se insere no contexto geológico do Cráton Amazônico (Figura 1). Localiza-se na porção centro-norte do Escudo
Brasil Central (Almeida et al., 1981) e integra a província geocronológica Tapajós-Parima (Santos et al., 2000, 2006). Sua evolução geológica (2033 - $1780 \mathrm{Ma})$, ainda em debate, baseia-se em principalmente dois modelos geotectônicos: eventos acrescionários de cinco arcos magmáticos a uma borda continental, desenvolvidos ao longo de dois eventos orogênicos entre 2040 e $1880 \mathrm{Ma}$, seguidos por um período pós-orogênico, entre 2050 e 1877 Ma (Santos et al., 2000, 2001, 2004); ou um único evento orogênico colisional de um arco magmático contra um continente (cerca de $2000 \mathrm{Ma}$ ), seguido de subsequentes pulsos magmáticos tardi- a pós-orogênicos e posterior magmatismo intraplaca com o estabelecimento de um ambiente extensional, entre $1880 \mathrm{Ma}$ e $1780 \mathrm{Ma}$, respectivamente (Vasquez et al., 2008).

A formação metassedimentar Castelo dos Sonhos é composta de metaconglomerados e metarenitos auríferos depositados em sistemas fluvial e lacustres entre 2011 e 2050 Ma e foi recentemente incluída na área da PAT (Klein et al., 2017; Queiroz et al., 2015). A evolução orogênica, propriamente dita, da PAT é registrada pelas rochas do Grupo Jacareacanga e Complexo Cuiú-Cuiú. O primeiro reúne associações metavulcanossedimentares $(\sim 2010 \mathrm{Ma})$ metamorfisadas sob condições de fácies xisto-verde a anfibolito (Santos et al., 2001). O Complexo Cuiú-Cuiú (2033$2005 \mathrm{Ma}$ ), por sua vez, consiste em gnaisses de variadas composições, anfibolito e granitoides cálcico-alcalinos de composição predominantemente granodiorítica a tonalítica (Klein et al., 2001; Santos et al., 2000, 2001). Ambas representariam uma associação relacionada a um ambiente de arco magmático (Santos et al., 2004; Vasquez et al., 2008). Ainda no contexto de arco, estariam incluídas as vulcânicas félsicas e piroclásticas da Formação Comandante Arara (2022 - 2012 Ma; Vasquez et al., 2014) e as vulcânicas cálcico-alcalinas de alto K a shoshoníticas da Formação Vila Riozinho (2002 - 1998 Ma; Lamarão et al., 2002).

Após o ápice do evento colisional, zonas de cisalhamento transcorrentes de direção NW-SE desenvolveram-se e controlaram o posicionamento de intrusões tardi-orogênicas da Suíte Intrusiva Creporizão (2000 - $1951 \mathrm{Ma}$; Santos et al., 2001; Silva Junior et al., 2015; Vasquez et al., 2000). Essa unidade reúne granitoides cálcio-alcalinos de médio a alto $\mathrm{K}$, pera- a metaluminosos e com feições ígneas bem preservadas (Vasquez et al., 2002). 
Após um intervalo de aproximadamente $50 \mathrm{Ma}$, grandes eventos plutônicos e vulcânicos ocorreram na PAT, representados pelo magmatismo cálcico-alcalino de alto K das suítes intrusivas Tropas (1907 - 1892 Ma; Santos et al., 2004) e Parauari (1890 - 1885 Ma; Santos et al., 2001; Silva Junior et al., 2015). O primeiro é composto de rochas de composição tonalítica e granodiorítica pouco deformadas, enquanto o último abrange rochas tonalíticas

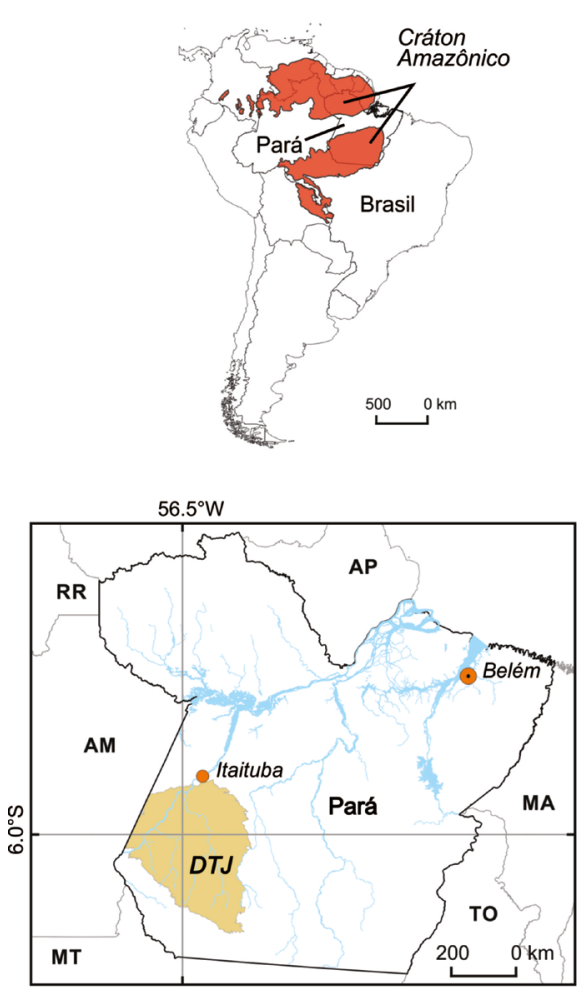

Convenções

DTJ - Domínio Tapajós DIX - Domínio Iriri-Xingu

\begin{tabular}{|c|c|}
\hline & Falha/fratura \\
\hline 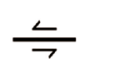 & $\begin{array}{l}\text { Falha transcorrente } \\
\text { sinistral }\end{array}$ \\
\hline $\bar{\gamma}$ & $\begin{array}{l}\text { Falha transcorrente } \\
\text { destral }\end{array}$ \\
\hline$\Lambda$ & Falha compressional \\
\hline$\perp$ & Falha extensional \\
\hline$\odot$ & Capital \\
\hline & Sede municipal \\
\hline & Rios e igarapés \\
\hline BR-163 & Estrada \\
\hline & $\begin{array}{l}\text { Limite de domínios } \\
\text { tectônicos (Sm-Nd) }\end{array}$ \\
\hline
\end{tabular}

Figura 1. Mapa geológico do Domínio Tapajós (cujos limites são similares aos da Província Aurífera do Tapajós) com indicação da localização do Campo Mineralizado do Cuiú-Cuiú, área de estudo.

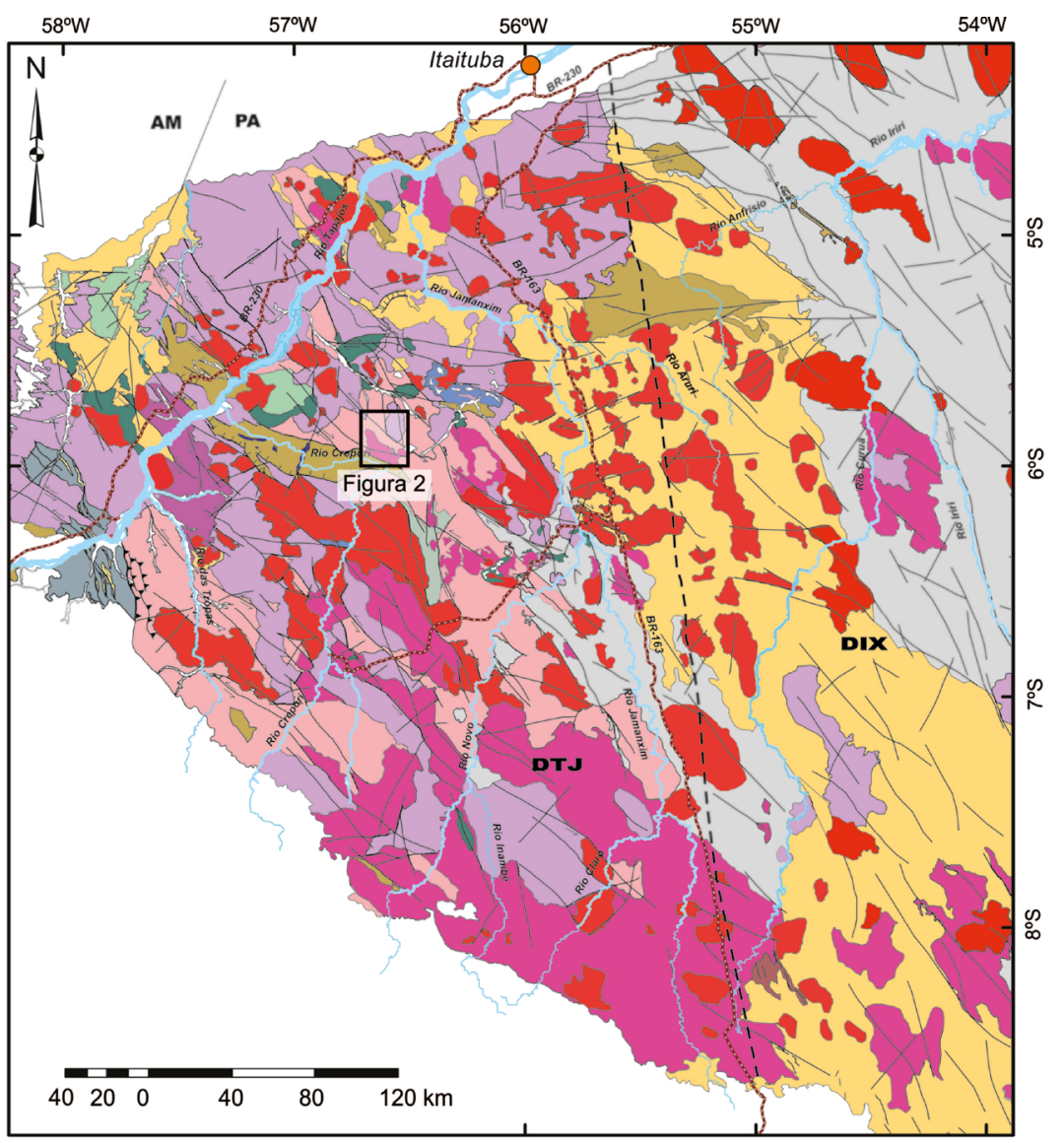

Unidades litoestratigráficas

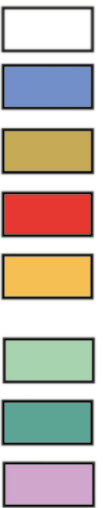

Cobertura Cenozoica

Suíte Intrusiva Cachoeira Seca

Formação Buiuçu

Suíte Intrusiva Maloquinha

Grupo Iriri e Formação Novo Progresso

Formação Bom Jardim

Suíte Intrusiva Ingarana

Suíte Intrusiva Parauari

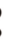

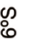

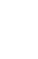


a sienograníticas com feições dúcteis pouco expressivas, possivelmente associadas a uma série de intrusivas básicas (Suíte Intrusiva Ingarana) e efusivas básicas e intermediárias (por exemplo, Formação Bom Jardim). Santos et al. (2001, 2004) interpretam as suítes Tropas e Parauari como produtos de ambiente de arco continental, ao mesmo tempo que Vasquez et al. (2008) propõem um cenário pós-orogênico para a sua formação. Klein et al. (2012) aventam ainda que pelo menos a Suíte Intrusiva Parauari pode estar relacionada ao início de sistema de rift intracontinental, o Silicic Large Igneous Province (SLIP) Uatumã.

Um evento extensional parcialmente posterior produziu um volumoso magmatismo alcalino do tipo A (1895 $1864 \mathrm{Ma}$ ), agrupado na Suíte Intrusiva Maloquinha e nas rochas piroclásticas e vulcânicas do Grupo Iriri (Lamarão et al., 2002; Santos et al., 2004; Vasquez et al., 2008), e as rochas sedimentares da Formação Novo Progresso. O estabelecimento de rifts continentais paleoproterozoicos na província culminou com a sedimentação siliciclástica da Formação Buiuçu. A PAT ainda experimenta algum magmatismo máfico intracontinental, reconhecida na Suíte Intrusiva Cachoeira Seca (1198 - $1174 \mathrm{Ma}$; Santos et al., 2002), antes de encerrar sua evolução geológica com a formação de depósitos cenozoicos.
De acordo com Juliani et al. (2014), a metalogenia aurífera do Domínio Tapajós, embora pouco consensual, tem sido relacionada a:

(i) modelos magmático-hidrotermais, incluindo os Intrusion Related Gold Deposits (Assunção e Klein, 2014; Borges et al., 2009; Queiroz e Villas, 2015; Villas et al., 2013), os epitermais (high- e low-sulfidation) (Jacobi, 1999; Juliani et al., 2005; Tokashiki et al., 2015) e os do tipo pórfiro (EcheverriMisas et al., 2013; Juliani et al., 2012; Santos et al., 2013);

(ii) modelos metamórfico-hidrotermais, correspondentes aos depósitos de ouro orogênico (Coutinho et al., 2000; Klein et al., 2004; Veloso et al., 2013).

A Formação Castelo dos Sonhos, que hospeda depósito aurífero homônimo, interpretada no contexto geológico da PAT, acrescenta a classe paleoplacer à metalogenia da PAT.

\section{Geologia do Campo Mineralizado do Cuiú-Cuiú}

A região do $\mathrm{CMCC}$, onde está localizado o alvo Jerimum de Baixo (Figura 2), tem como unidade mais antiga o Complexo Cuiú-Cuiú (2033 - 2005 Ma), que reúne metagranitoides (quartzo diorito a monzogranito) de granulação média a grossa, porfiríticos a equigranulares e gnaisse

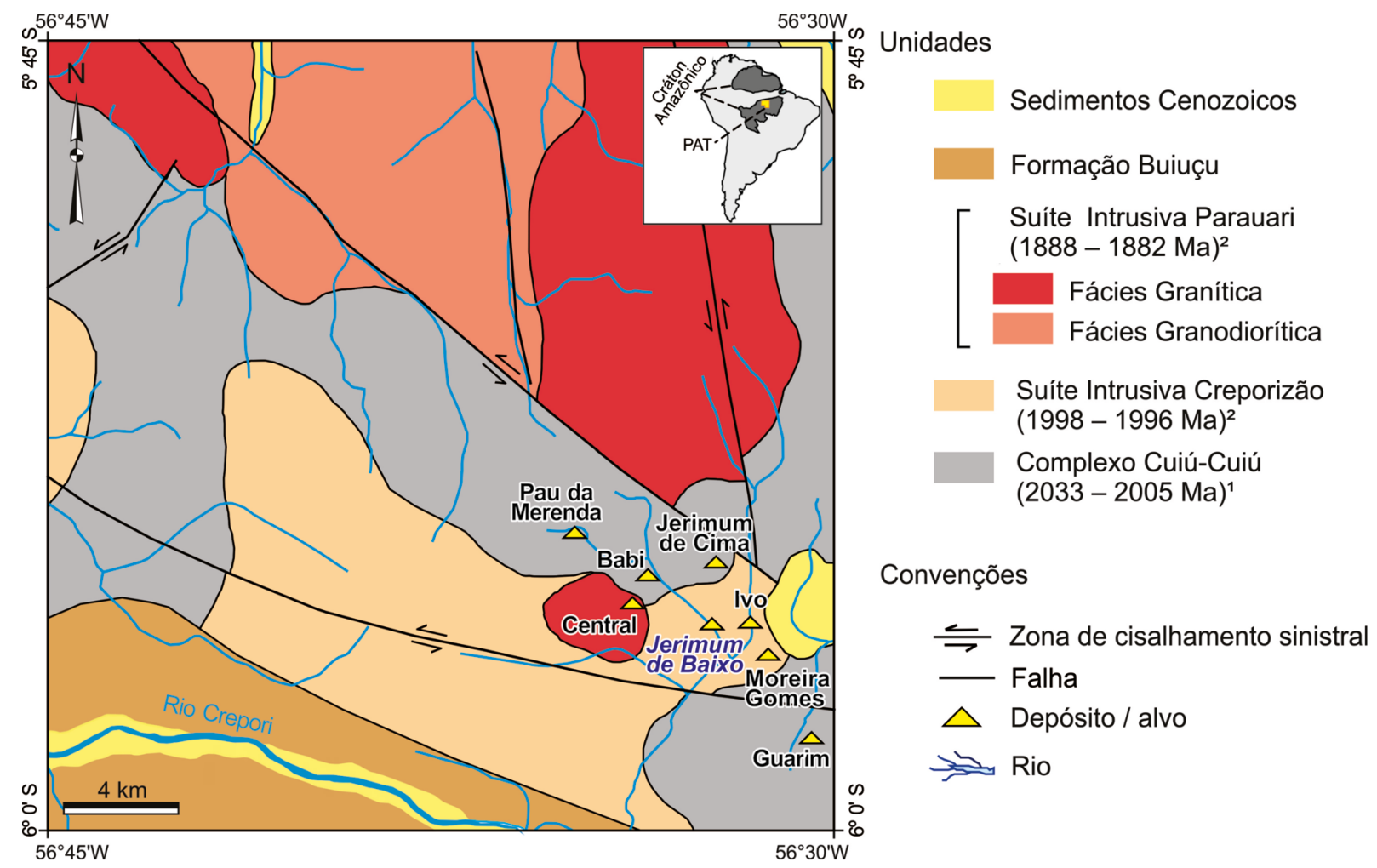

Idades: ${ }^{1}$ Santos et al. (2001); ${ }^{2}$ Silva Junior et al. (2015).

Fonte: modificado de Moura et al., 2014.

Figura 2. Mapa geológico da região de Cuiú-Cuiú com a localização do alvo Jerimum de Baixo, entre outros jazimentos. 
metamorfisado sob condições de fácies anfibolito de grau médio a alto (Bahia e Quadros, 2000; Klein et al., 2001). $\mathrm{Na}$ sequência, colocaram-se intrusões cálcico-alcalinos de médio a alto $\mathrm{K}$ atribuídas às suítes intrusivas Creporizão e Parauari (1997 \pm 1 Ma e $1885 \pm 3$ Ma, respectivamente, idade de cristalização $\mathrm{Pb}-\mathrm{Pb}$ em zircão por evaporação; Silva Junior et al., 2015). A primeira compreende tonalito a monzogranito de granulação média a grossa e sem trama dúctil importante. A segunda consiste em granitoides com discretas zonas de cisalhamento e se manifesta em duas fácies distintas (Bahia e Quadros, 2000; Vasquez et al., 2000): uma majoritariamente granodiorítica e outra em que predominam monzogranito e sienogranito. A porção sul/ sudoeste do campo é recoberta por rochas siliciclásticas e vulcanoclásticas da Formação Buiuçu (Bahia e Quadros, 2000; Bahia et al., 2001).

O CMCC reúne dois depósitos (Moreira Gomes e Central) e vários prospectos que, litoestratigraficamente, estão hospedados nas unidades cristalinas (isto é, o Complexo Cuiú-Cuiú e as suítes intrusivas Creporizão e Parauari; Assunção e Klein, 2014; Moura et al., 2014; Silva Junior et al., 2015). O conjunto de jazimentos é controlado, sobretudo, estruturalmente e está disposto entre duas grandes falhas de orientação predominante WNW-ESE (com inflexões até E-W) e movimentação sinistral, hospedado em uma zona de cisalhamento NW-SE de grande escala (McMahon, 2011). A mineralização de ouro no CMCC está hospedada em veios de quartzo em zonas fortemente sericitizadas e sulfetadas (McMahon, 2011). Em geral, o conteúdo em sulfeto é baixo $(<2 \%)$, mas as zonas com teores elevados ( $>10 \mathrm{~g} / \mathrm{t}$ de $\mathrm{Au}$ ) estão associadas àquelas mais ricas em sulfetos. Na escala de depósito, as zonas mineralizadas apresentam formas irregulares e parecem ser bem desenvolvidas em granitoides cataclasados/brechados.

Idades modelo $\mathrm{Pb}-\mathrm{Pb}$ em sulfetos obtidas nos depósitos Moreira Gomes e Central e no alvo Pau da Merenda são muito próximas de ca. 1,86 Ga (Silva Junior et al., 2015), o que aponta que os estágios finais da granitogênese Parauari poderiam corresponder ao evento magmático causativo da mineralização aurífera do CMCC.

\section{MATERIAIS E MÉTODOS}

As amostras utilizadas neste estudo são provenientes de testemunhos de dois furos de sondagem rotativa cedidos pela mineradora Magellan Minerals Ltda. A identificação petrográfica dos minerais primários e secundários e das sequências paragenéticas se deu em microscópio de luz transmitida e refletida (Zeiss ${ }^{\circledast}$, modelo Axioplan 2). Para a classificação das rochas graníticas, foram realizadas análises modais em contador de pontos eletrônico ( 2 mil pontos por lâmina polida), em sete amostras. A identificação de partículas de ouro e sulfetos, além de outras fases acessórias, foi obtida por microscópio eletrônico de varredura (MEV) modelo LEO-1430, pertencente ao Laboratório de Microanálises do Instituto de Geociências da Universidade Federal do Pará (IG/UFPA). As lâminas selecionadas foram metalizadas com carbono para imageamento por elétrons retroespalhados (ERE) e análises por Energy Dispersive Spectroscopy (EDS). As condições de operação do MEV foram: corrente do feixe de elétrons $=90 \mu \mathrm{A}$, voltagem de aceleração constante $=20 \mathrm{kV}$, distância de trabalho $=$ $15 \mathrm{~mm}$, tempo de análise $=30 \mathrm{~s}$, com 4.000 a $5.000 \mathrm{c} / \mathrm{s}$ para cada análise.

O estudo das IF foi realizado em seis lâminas bipolidas de amostras de veios em zonas sericitizadas compostos de quartzo \pm pirita \pm pirrotita \pm calcopirita \pm clorita \pm sericita \pm calcita. As análises microtermométricas foram efetuadas em platina Linkam ${ }^{\circledast}$ MDSG 600 pertencente ao Laboratório de Inclusões Fluidas do IG/UFPA. A calibração foi realizada mediante padrões sintéticos com $\mathrm{H}_{2} \mathrm{O}$ e $\mathrm{CO}_{2}$ puros. A precisão das medidas é estimada $\mathrm{em} \pm 0,3^{\circ} \mathrm{C} \mathrm{e} \pm 5^{\circ} \mathrm{C}$, para temperaturas abaixo e superiores a $50^{\circ} \mathrm{C}$, respectivamente. O sequenciamento de obtenção dos dados de mudanças de fases foi: temperaturas de fusão do $\mathrm{CO}_{2}$, eutético, fusão final do gelo, fusão do clatrato, homogeneização do $\mathrm{CO}_{2}$ e homogeneização total. As salinidades dos fluidos foram calculadas com base nas temperaturas de fusão do gelo (Bodnar e Vityk, 1994) para as inclusões aquosas e temperaturas de fusão do clatrato para as inclusões aquocarbônicas (Collins, 1979). Densidades das inclusões aquosas e aquocarbônicas e isócoras das aquocarbônicas foram calculadas utilizando-se as equações de Brown e Lamb (1986) e Bowers e Helgeson (1983), com o auxílio do programa FLINCOR (Brown, 1989).

As análises químicas pontuais quantitativas por Wavelength Dispersive Spectroscopy (WDS) de filossilicatos foram obtidas por microssonda eletrônica JEOL ${ }^{\circledR}$ modelo JXA-8230 no Laboratório de Microanálises do IG/UFPA. As condições analíticas foram: voltagem de aceleração constante $=$ $15 \mathrm{kV}$, corrente do feixe de elétrons $=20 \mathrm{nA}$, diâmetro do feixe de elétrons $=10 \mu \mathrm{m}$, método de correção dos efeitos de matriz $=$ ZAF, tempo de contagem para análise de elementos maiores e menores $=20 \mathrm{~s} \mathrm{e} 40 \mathrm{~s}$, respectivamente. Os elementos analisados, padrões e cristais analisadores utilizados foram, respectivamente: F - biotita - LDE1, $\mathrm{Na}$ - sodalita - TAP, Mg - diopsídio - TAP, Al - anortita - TAP, $\mathrm{Si}$ - ortoclásio - TAP, $\mathrm{Cr}-\mathrm{Cr}_{2} \mathrm{O}_{3}-$ PETJ, $\mathrm{Ca}$ - wollastonita - PETJ, K - ortoclásio - PETJ, $\mathrm{Sr}$ celestina - PETJ, $\mathrm{Ni}-\mathrm{NiO}-\mathrm{LIF}, \mathrm{Fe}-\mathrm{Fe}_{3} \mathrm{O}_{4}-$ LIF, $\mathrm{Mn}$ - rodonita - LIF, Ba - barita - LIF, Ti - rutilo LIF, $\mathrm{Cl}$ - sodalita - PETH, V - vanadinita - PETH. $\mathrm{FeO}$ foi considerado como ferro total $(\Sigma \mathrm{Fe}=\mathrm{FeO})$ para todas as análises. Para o cálculo da fórmula estrutural, conforme 
Deer et al. (1992), foram considerados 22 átomos de oxigênio por fórmula unitária (a.p.f.u.) para biotita e mica branca e 28 átomos de oxigênio (a.p.f.u.) para clorita. A temperatura de formação da clorita foi estimada segundo a proposta de Xie et al. (1997). Para as abreviaturas dos nomes dos minerais, seguiram-se as recomendações de Whitney e Evans (2010), sendo esclarecidas caso a caso aquelas não listadas na citada proposta.

\section{ASPECTOS GEÓLOGICOS DO ALVO JERIMUM DE BAIXO}

As sondagens interceptam, fundamentalmente, monzogranitos porfiríticos (predominante) e equigranulares modificados por distintos tipos e intensidade de alteração hidrotermal, visivelmente mais bem desenvolvida em zonas fraturadas ou brechadas. Veios de quartzo são muito comuns nessas regiões. Diques andesíticos que cortam o corpo de monzogranito porfirítico são observados de maneira não incomum, embora sua amostragem restrita impossibilite maiores considerações.

O diagrama QAP (Streckeisen, 1976) mostra que as amostras dos granitos se enquadram todas no campo do monzogranito (Figura 3). O diagrama Q (A + P) M' (Figura 3) revela que tais granitos são rochas hololeucrocráticas com conteúdo modal de máficos entre 2,20 e $6,96 \%$. Assim, essas rochas apresentam composições essencialmente similares, porém texturalmente distinguidas em um biotita-monzogranito porfirítico (BMgP) e um biotita-monzogranito equigranular (BMgE). As composições

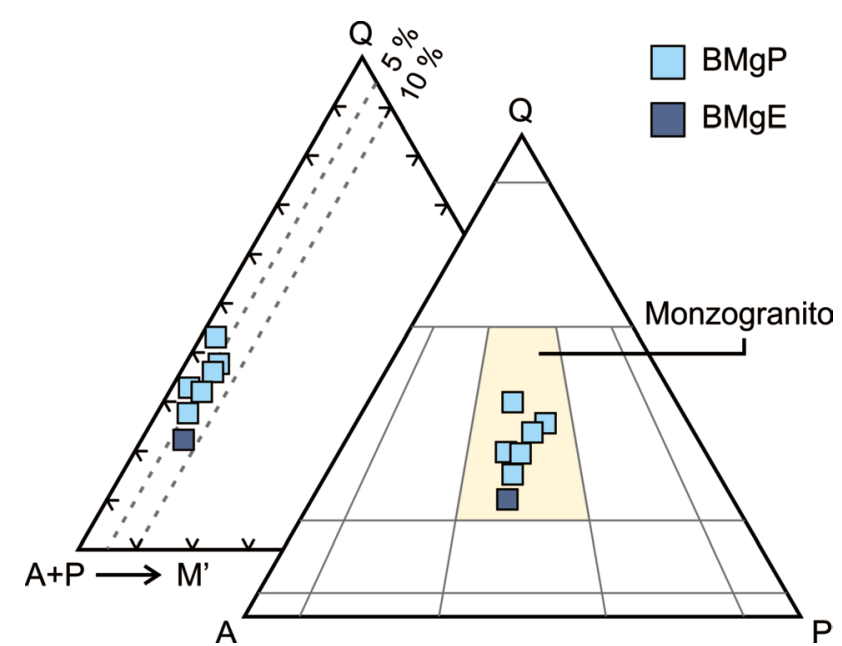

Figura 3. Diagramas $Q A P$ e $Q(A+P) M^{\prime}$, segundo Streckeisen (1976), para as amostras do biotitamonzogranito porfirítico e biotita-monzogranito equigranular, amostrados em Jerimum de Baixo. modais, em porcentagem, das amostras graníticas são fornecidas na Tabela 1.

\section{Petrografia}

\section{Biotita-monzogranito porfirítico}

A rocha exibe cor cinza rosada com porções locais levemente esverdeadas, fanerítica, hololeucocrática $\left(\mathrm{M}^{\prime}=2,0\right.$ a $\left.5,4 \%\right)$, não magnética e também sem feições de deformação dúctil aparente (Figura 4A). Exibe textura porfirítica hipidiomórfica, com fenocristais de granulação grossa imersos em matriz fina (Figura 4B). Os fenocristais sustentam o arcabouço da rocha e exibem, comumente, minerais matriciais inclusos nos seus domínios próximos às bordas, onde, por vezes, destacam feições de sobrecrescimento (Figura 4C). Sua composição mineralógica é essencialmente formada por feldspato potássico $(23,40-32,80 \%)$, quartzo $(25,98$ $40,62 \%)$ e plagioclásio $(23,78-30,95 \%)$, que ocorrem tanto como fenocristais como na matriz. A biotita desponta como o único mineral varietal $(2,00-5,45 \%)$ e na forma de lamelas finas a médias (em geral, 1,0 mm), hipidiomórficas, com cor avermelhada e pleocroísmo que varia de marrom avermelhado-claro $(\mathrm{Y}=\mathrm{Z})$ a creme pálido $(\mathrm{X})$, inclusa em fenocristais de quartzo ou dispersa na matriz. A fase acessória $(0,05-0,07 \%)$ é representada por finos cristais de zircão inclusos na biotita.

\section{Biotita-monzogranito equigranular}

Rocha com cor rosa esverdeada, fanerítica e não magnética (Figura 4D). O baixo conteúdo de máficos lhe confere características hololeucocráticas expressas por um baixo índice de cor $\left(M^{\prime}=6,7 \%\right)$. Apresenta um arranjo textural equigranular hipidiomórfico de granulação grossa. Feldspato potássico (36,12\%), plagioclásio (31,53\%) e quartzo (21,67\%) compõem essencialmente esse litotipo (Figura 4E). A biotita (6,40\%) se apresenta em lamelas hipidiomórficas $(0,1-1,0 \mathrm{~mm})$ e com pleocroísmo que varia do vermelho amarronzado $(\mathrm{Y}=\mathrm{Z})$ ao creme pálido $(\mathrm{X})$. Forma pequenos agregados ou lamelas individuais, por vezes, inclusas nas fases essenciais (Figura 4F). Apesar de a rocha não exibir trama deformacional de caráter dúctil, é observável microscopicamente a fase varietal, eventualmente, com discreta orientação. A mineralogia acessória é simples $(0,28 \%)$, representada por cristais de allanita, zircão e apatita. Os dois primeiros são observados normalmente metamictizados e o último como inclusões em plagioclásio.

\section{Granitos intensamente hidrotermalizados}

Ambas as fácies graníticas descritas anteriormente encontram-se transformadas por processos hidrotermais em 
Tabela 1. Composições modais de amostras das rochas graníticas do alvo Jerimum de Baixo.

\begin{tabular}{|c|c|c|c|c|c|c|c|}
\hline Variedade & $\mathrm{BMgE}$ & & & & & & \\
\hline Mineral Amostra & R-35 & $\mathrm{R}-19$ & $\mathrm{R}-36$ & $\mathrm{R}-37$ & $\mathrm{R}-39$ & $\mathrm{R}-42$ & $R-43$ \\
\hline Feldspato potássico & 36,12 & 32,80 & 27,00 & 31,25 & 25,25 & 30,35 & 23,40 \\
\hline Quartzo & 21,67 & 25,98 & 40,62 & 29,70 & 33,17 & 30,90 & 36,55 \\
\hline Plagioclásio & 31,53 & 29,60 & 23,78 & 26,30 & 28,55 & 29,98 & 30,95 \\
\hline Biotita & 6,40 & 4,85 & 2,00 & 5,05 & 5,03 & 2,75 & 5,45 \\
\hline Apatita & 0,07 & n.d. & n.d. & n.d. & n.d. & n.d. & n.d. \\
\hline Minerais opacos & 0,47 & 0,15 & 0,22 & n.d. & 0,20 & 0,06 & 0,10 \\
\hline Zircão & 0,07 & 0,07 & 0,06 & 0,07 & 0,05 & 0,06 & n.d. \\
\hline Allanita & 0,14 & n.d. & n.d. & n.d. & n.d. & n.d. & n.d. \\
\hline Sericita & 1,73 & 4,90 & 4,44 & 5,53 & 4,35 & 3,80 & 2,45 \\
\hline Clorita & 1,40 & 0,80 & 0,78 & 1,20 & 1,80 & 0,65 & 0,55 \\
\hline Fluorita & 0,33 & 0,15 & 0,33 & 0,60 & 1,25 & 0,35 & 0,25 \\
\hline Calcita & n.d & 0,70 & 0,78 & 0,30 & 0,35 & 1,10 & 0,30 \\
\hline Epídoto & 0,07 & n.d. & n.d. & n.d. & n.d. & n.d. & n.d. \\
\hline$Q+A+P$ & 89,32 & 88,38 & 91,40 & 87,25 & 86,97 & 91,23 & 90,90 \\
\hline$M^{\prime}$ & 6,68 & 4,92 & 2,06 & 5,12 & 5,08 & 2,81 & 5,45 \\
\hline$A+P$ & 67,65 & 62,40 & 50,78 & 57,55 & 53,80 & 60,33 & 54,35 \\
\hline$Q$ & 24,26 & 29,40 & 44,44 & 34,04 & 38,14 & 33,87 & 40,21 \\
\hline$A$ & 40,44 & 37,11 & 29,54 & 35,82 & 29,03 & 33,27 & 25,74 \\
\hline $\mathrm{P}$ & 35,30 & 33,49 & 26,02 & 30,14 & 32,83 & 32,86 & 34,05 \\
\hline Número de pontos & 2.000 & 2.000 & 2.000 & 2.000 & 2.000 & 2.000 & 2.000 \\
\hline
\end{tabular}

BMgE: biotita-monzogranito equigranular; BMgP: biotita-monzogranito porfirítico; n.d.: mineral não detectado na contagem. Valores expressos em porcentagem.
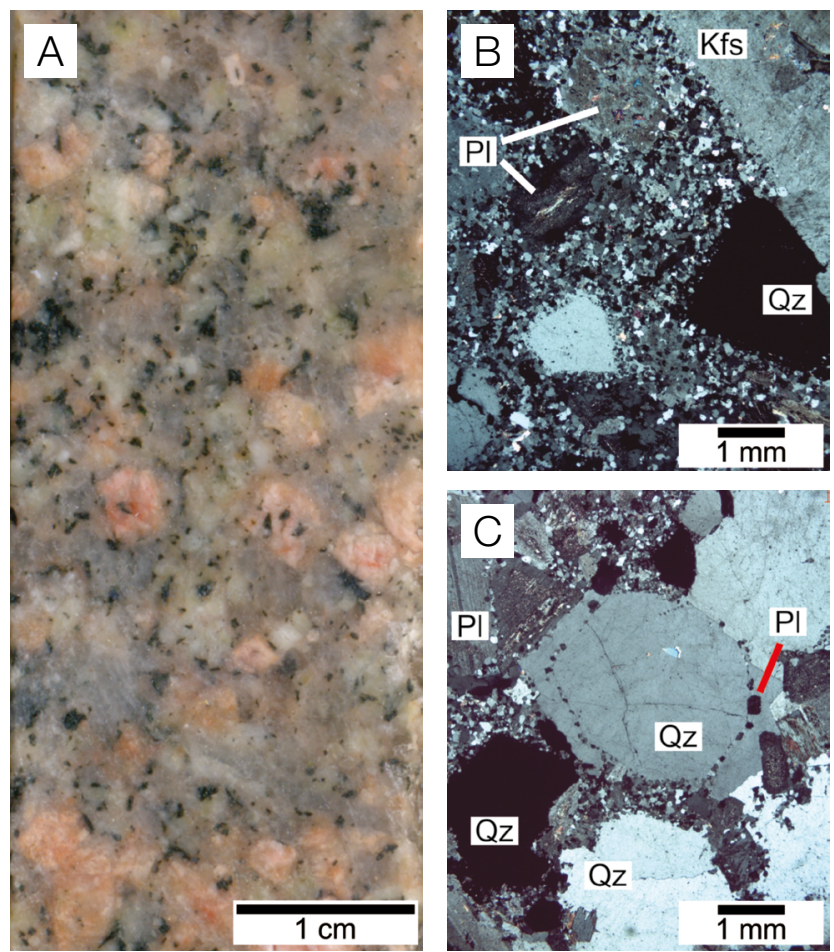

BMgP: biotita-monzogranito porfirítico; NC: nicois cruzados; BMgE: biotita-monzogranito equigranular.

Figura 4. Aspectos petrográficos macro e microscópicos das rochas graníticas do alvo Jerimum de Baixo. (A) BMgP em amostra de testemunho de sondagem; (B) aspecto textural geral microscópico do BMgP com destaque para o arranjo porfirítico da rocha, $\mathrm{NC}$; (C) fenocristais de quartzo com bordas irregulares e evidente sobrecrescimento, NC; (D) BMgE em amostra de testemunho de sondagem; (E) aspecto textural geral hipidiomórfico do BMgE, NC; (F) plagioclásio com inclusões de biotita e acículas de apatita, NC. 
diferentes intensidades, de maneira que a composição e o arranjo textural das rochas originais foram bastante comprometidos quando intensamente hidrotermalizadas. Com o aumento da participação dos minerais secundários, as rochas adquiriram cores acinzentadas a esverdeadas ou mesmo enegrecidas, em decorrência de sericitização ou cloritização, respectivamente, ou avermelhadas, quando impregnadas por óxidos de $\mathrm{Fe}$ (Figuras 5A a 5C). Tais rochas exibem, de maneira muito comum, feições de fraturamento e, ocasionalmente, brechoides. Nessas regiões, os produtos hidrotermais e feldspatos com geminações deformadas são mais evidenciados (Figuras 5D a 5F). Os minerais hidrotermais ocorrem por substituição de minerais primários e como componentes de veios/vênulas de preenchimento, cuja distribuição espacial se assemelha aos sheeted veins, e, em algumas vezes, ao estilo stockwork. Veios e vênulas de quartzo, clorita, sericita, calcita e sulfetos (pirita + pirrotita, principalmente) são comuns nessas zonas fragilizadas. Os sulfetos são encontrados em veios e vênulas de quartzo, bem como em disseminações na rocha sericitizada e em zonas brechadas associadas. As feições de brecha caracterizam-se por cristais angulosos de minerais primários (notadamente os feldspatos), que são muitas vezes margeados por lamelas de sericita \pm clorita \pm quartzo \pm sulfetos (Figuras $5 \mathrm{G}$ e $5 \mathrm{H}$ ).
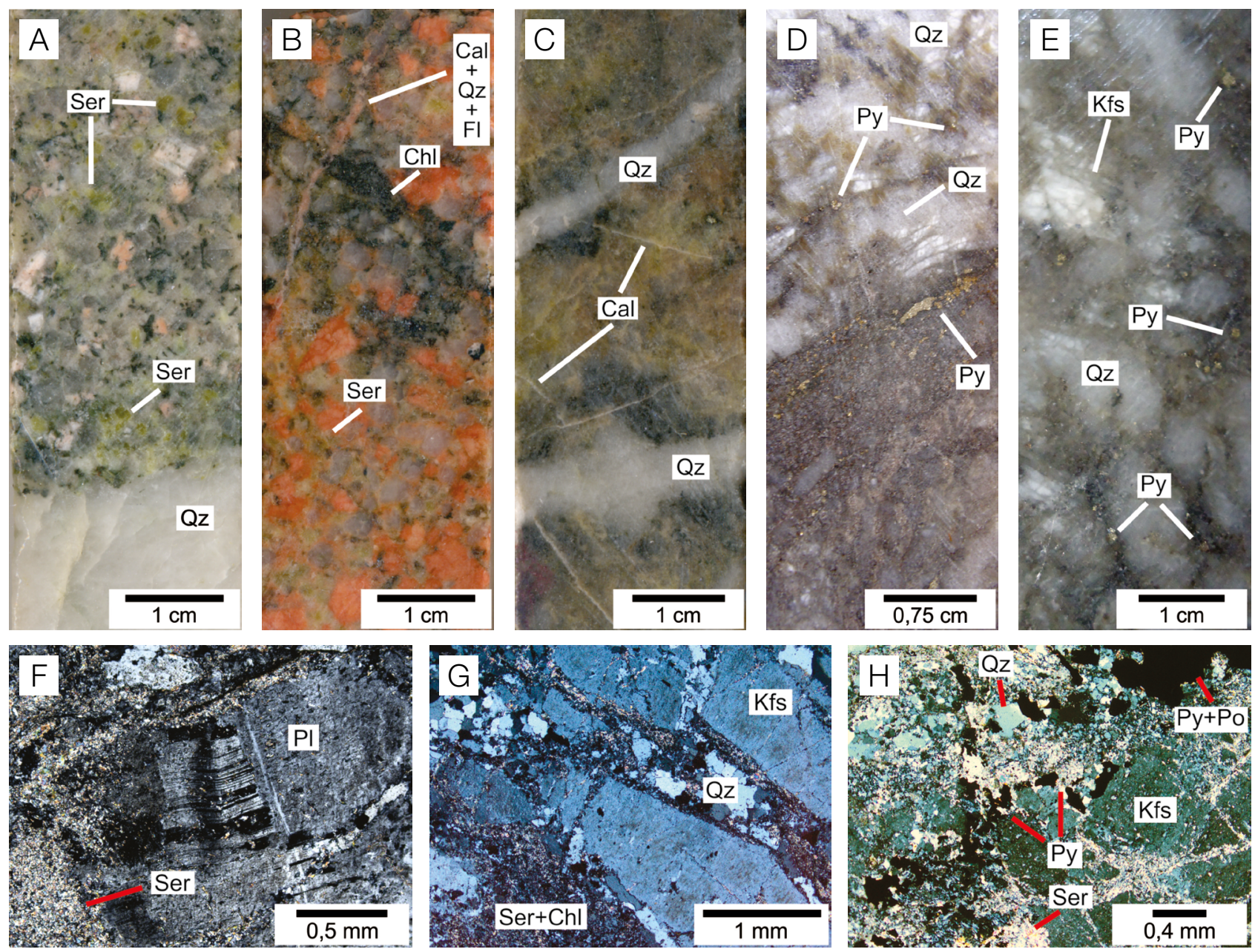

BMgP: biotita-monzogranito porfirítico; NC: nicois cruzados.

Figura 5. Aspectos petrográficos macro e microscópicos das rochas graníticas hidrotermalizadas no alvo Jerimum de Baixo. (A) BMgP com pontuações esverdeadas derivadas da substituição do plagioclásio por sericita; (B) BMgP fortemente avermelhado com região cloritizada cortada por vênula de calcita + quartzo + fluorita; (C) granito intensa e pervasivamente alterado, com veios de quartzo que truncam a rocha sericitizada e vênulas tardias de calcita, que truncam todos os estágios anteriores; (D) e (E) porções brechoides com cristais de feldspatos fraturados e de quartzo amendoados circundados por matriz de sericita + clorita + sulfetos; (F) plagioclásio com planos de geminação deformados, NC; $(G)$ rede de fraturas preenchidas por sericita, NC; $(H)$ zona brechoide rica em sulfetos densamente cortada por microvênulas de sericita, NC. 


\section{Alteração hidrotermal}

A alteração hidrotermal em Jerimum de Baixo, em linhas gerais, foi ampla e mais evidente em locais onde a deformação rúptil/cataclástica foi mais pronunciada e ao longo de alguns veios/vênulas. Os produtos hidrotermais são, geralmente, formados a partir da substituição dos minerais primários com formação de tipos de alterações hidrotermais em estilo pervasivo, quando mais intensa, porém também ocorrem como preenchimento de espaços, seja em diminutas cavidades ou como constituintes de veios monominerálicos e poliminerálicos quando em um estilo fissural. Seis tipos de alteração hidrotermal foram temporalmente identificados: cloritização, sericitização, sulfetação, silicificação, epidotização e carbonatação.

A cloritização, ainda que manifestada em outros estágios, se desenvolveu principalmente nos estágios iniciais da alteração hidrotermal e foi responsável pela coloração verde enegrecida nas regiões em que se faz presente. A clorita é observada:

(i) em paragênese com rutilo \pm quartzo pela substituição parcial ou total da biotita (Figura 6A);
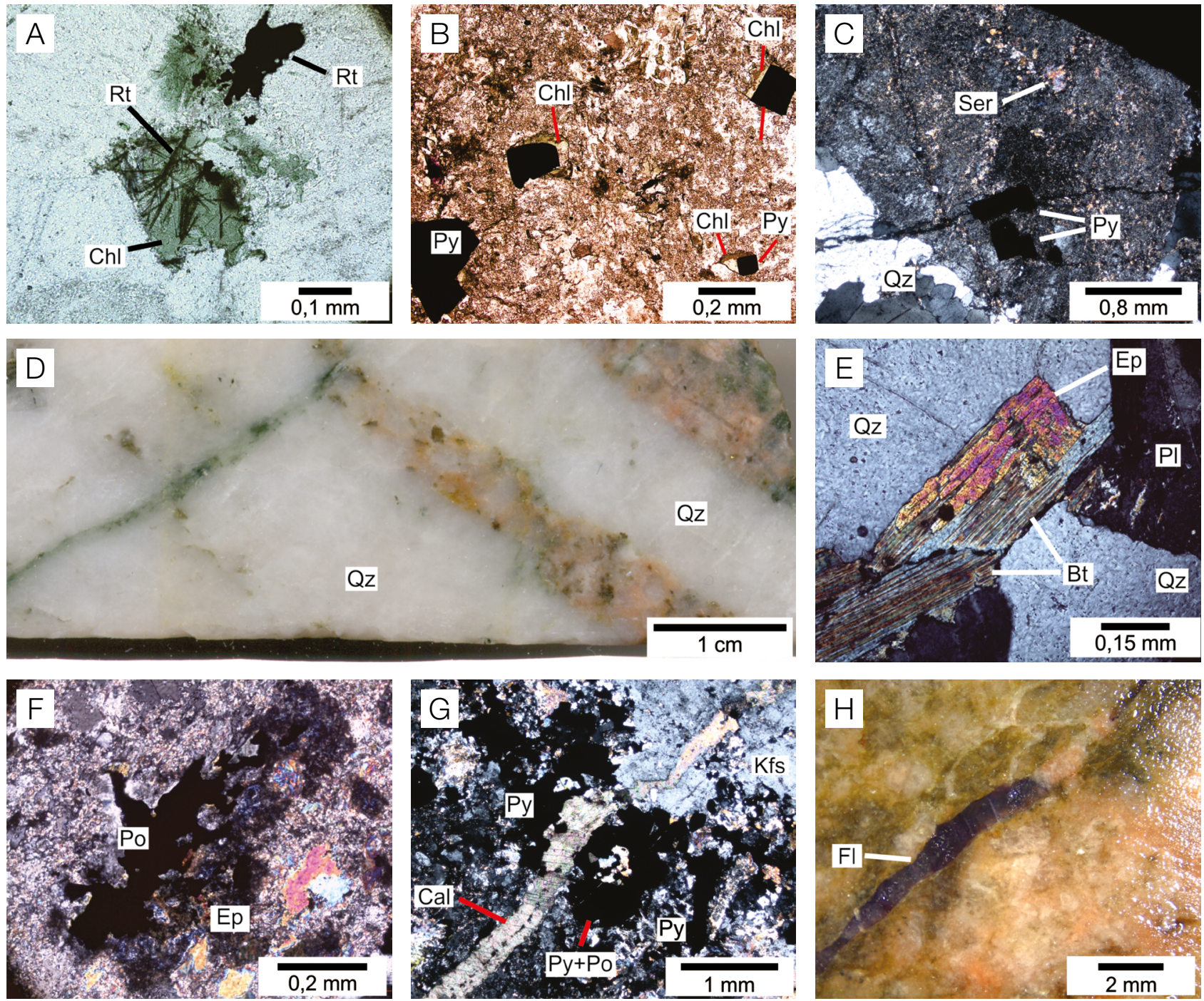

NP: nicois paralelos; BMgE: biotita-monzogranito equigranular: NC: nicois cruzados.

Figura 6. Aspectos petrográficos das alterações hidrotermais nas rochas graníticas do alvo Jerimum de Baixo. (A) Pseudomorfo de clorita + rutilo em arranjo sagenítico, NP; (B) associação clorita + pirita em BMgE alterado, NP; (C) cristal de plagioclásio substituído pela associação sericita + pirita, NC; (D) veios de quartzo laminados com fragmentos da rocha encaixante; (E) biotita cloritizada parcialmente substituída por epídoto, NC; (F) epídoto com cor de interferência anômala em contato irregular com pirrotita, NC; (G) microvênula de calcita que corta agregado de sulfetos em rocha sericitizada, NC; $(H)$ vênula de calcita + fluorita. 
(ii) associada a pirita \pm pirrotita nas rochas mais intensamente modificadas (Figura 6B);

(iii) como constituinte de vênulas poliminerálicas (quartzo \pm clorita \pm sericita) e monominerálicas.

A sericitização se apresenta bem desenvolvida e sua ocorrência mais expressiva é coincidente com o estágio de formação de sulfetos nas regiões fraturadas e brechadas. A associação sericita + quartzo + pirita \pm pirrotita \pm calcopirita substitui a biotita magmática e os feldspatos - em particular o plagioclásio (Figura $6 \mathrm{C}$ ) - , por vezes, com geração de pseudomorfos. Essa alteração é responsável pelas tonalidades verde-claro conferidas às rochas hospedeiras.

A sulfetação é representada por pirita e pirrotita, com calcopirita, galena e esfalerita em proporções muito reduzidas. Os sulfetos ocorrem principalmente como disseminações nas rochas mais severamente sericitizadas e em veios/ vênulas de quartzo.

A silicificação é reconhecida pela formação de quartzo em cristais grossos anédricos a subédricos, como componentes de veios e vênulas poliminerálicas (quartzo \pm sulfetos \pm ouro \pm sericita \pm clorita \pm fluorita \pm calcita). Esses veios configuram um estilo laminado, por vezes, com fragmentos da rocha hospedeira, nas porções mais rasas do furo (Figura 6D), ou finamente espaçados e paralelizados quando em maiores profundidades (Figura 5C). O epídoto tem pouca expressividade nas amostras estudadas e ocorre por substituição da biotita (Figura 6E) ou como pequenos agregados anédricos em que exibe, ocasionalmente, contatos irregulares com sulfetos (Figura 6F). A carbonatação é o estágio mais tardio, observadas as relações de truncamento, e é representada por vênulas de calcita \pm fluorita \pm quartzo \pm clorita \pm sericita (Figuras 6G e 6H).

McMahon (2011) e Stubens et al. (2017) mostraram que o CMCC experimentou alteração clorítica-hematítica. $\mathrm{O}$ avermelhamento dos feldspatos (sobretudo o potássico) nas rochas mais preservadas é entendido como feição ígnea original da rocha. A despeito da ausência da relação entre clorita e hematita em Jerimum de Baixo, as feições petrográficas observadas nas rochas mais fortemente avermelhadas são compatíveis com processos de oxidação descritos pelos trabalhos acima citados, mesmo que observadas localmente, em detrimento de uma alteração potássica (Boone, 1969; Juliani et al., 2005).

Um quadro paragenético esquemático é mostrado na Figura 7.

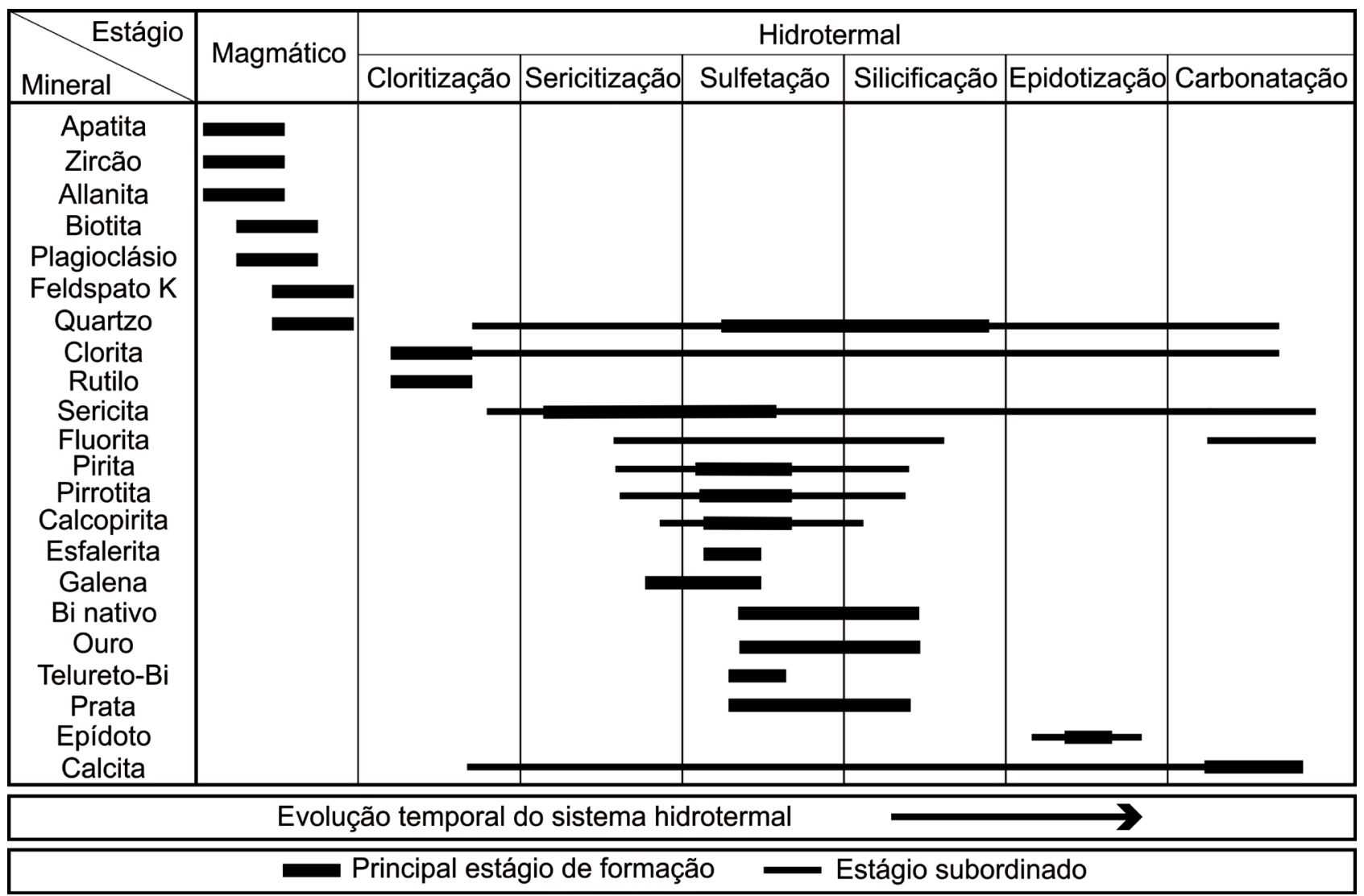

Figura 7. Sequência paragenética esquemática proposta para as rochas do alvo Jerimum de Baixo. 


\section{Mineralização}

Em Jerimum de Baixo, as hospedeiras da mineralização são rochas com moderado e, mais localmente, elevado grau de alteração hidrotermal, mas também em veios de quartzo encaixados nos corpos graníticos. A mineralização está espacial e temporalmente relacionada ao estágio de formação de sulfetos, uma vez que a região mineralizada é composta de pirita e pirrotita, principalmente, além de calcopirita, esfalerita e galena em menor importância. Os sulfetos, que não ultrapassam o valor de $2 \%$ do volume das rochas (estimativa visual), ocorrem principalmente disseminados em regiões em que a geração de mica branca hidrotermal foi mais expressiva, em particular onde o processo de brechação foi mais eficaz e também em vênulas de quartzo (Figuras 5D, 5E, 5H, $8 \mathrm{~A}$ a $8 \mathrm{E})$.

A pirita é o sulfeto predominante e ocorre como disseminações em regiões ricas em sericita + quartzo \pm clorita na rocha hospedeira, em fissuras da rocha brechoide e em veios de quartzo \pm sericita \pm clorita \pm carbonato. A pirrotita é também um sulfeto importante e normalmente compartilha com a pirita os modos de ocorrência. Calcopirita, esfalerita e galena ocorrem em menores quantidades e como inclusões ou na borda da pirita ou pirrotita. Finos cristais de bismuto nativo foram identificados por MEV-EDS associados com quartzo + sericita + galena (Figura 8F).
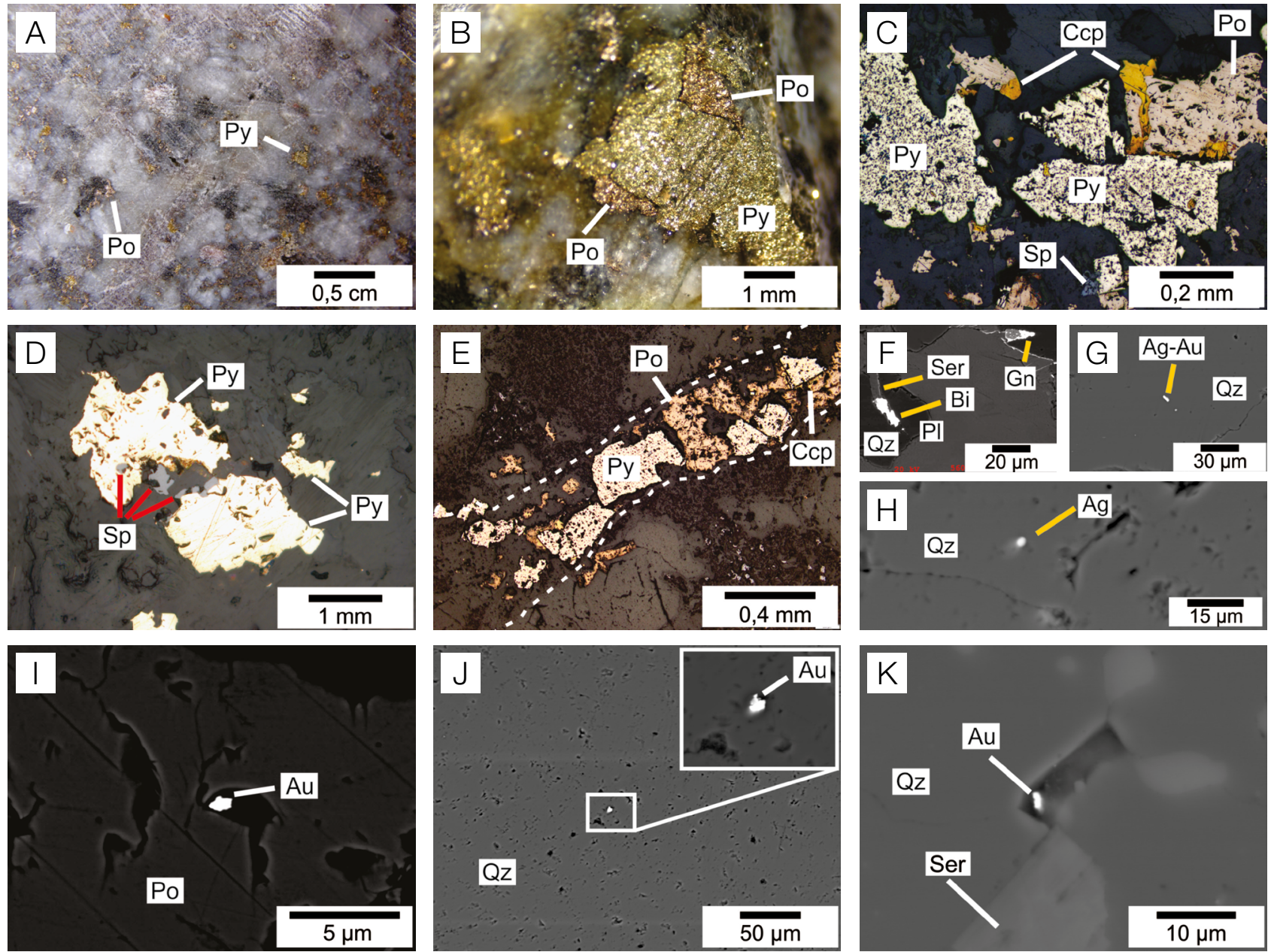

BMgE: biotita-monzogranito equigranular: LR: luz refletida; MEV-ERE: microscópio eletrônico de varredura - elétrons retroespalhados.

Figura 8. Aspectos petrográficos macro e microscópicos da mineralização no alvo Jerimum de Baixo. (A) Sulfetos (pirita + pirrotita) disseminados em BMgE alterado; (B) associação entre pirita e pirrotita em zona mineralizada; (C) associação entre os principais sulfetos no minério representada por pirita e pirrotita (principalmente), calcopirita e esfalerita, LR; (D) cristais de esfalerita nas bordas e no interior de pirita, LR; (E) pirita, pirrotita e calcopirita (no contato entre os dois primeiros) compondo microvênula de quartzo, LR; (F) bismuto nativo associado à sericita e ao quartzo, MEV-ERE; (G) partícula de liga metálica de Ag-Au em veio de quartzo, MEV-ERE; $(\mathrm{H})$ partícula de prata com teores elevados de $\mathrm{Pt}, \mathrm{Pb}, \mathrm{Bi}$, Te e $\mathrm{Au}$, MEV-ERE; (I) partícula de ouro em cavidade em cristal de pirrotita, MEV-ERE; (J) partícula de ouro livre em quartzo de veio, MEV-ERE; (K) partícula de ouro em cavidade (textura similar a boxwork) de quartzo de veio, MEV-ERE. 
Análises químicas semiquantitativas por EDS permitiram observar quantidades subordinadas de $\mathrm{Pb}, \mathrm{Bi}$ e Te na pirita, calcopirita e pirrotita com pouca variação composicional entre eles nas formas disseminada e fissural. Na esfalerita, quantidades pequenas de Bi também foram detectadas. A galena mostrou-se com quantidades significativas em As e Bi. Ligas metálicas de Ag-Au e Ag (Figuras $8 \mathrm{G}$ e 8H, respectivamente) foram observadas em veios de quartzo + sericita + clorita + sulfetos e apresentando quantidades menores de $\mathrm{Pb}, \mathrm{Pt}$, Te e $\mathrm{Bi}$ nas suas composições.

$\mathrm{O}$ ouro foi identificado como partículas anédricas nas cavidades de cristais de pirrotita disseminada em rocha sericitizada (Figura 8I) e como partículas livres inclusas em quartzo de vênulas contendo sericita + clorita + sulfetos (Figuras $8 \mathrm{~J} \mathrm{e} \mathrm{8K}$ ). Análises de MEV-EDS revelaram Te $(0,45-7,13 \%)$, Bi $(0,89-10,98 \%), \mathrm{Pb}(1,11-4,89 \%)$ e $\mathrm{Ag}(0,00-9,51 \%)$ como componentes menores na composição das partículas de ouro.

\section{ESTUDO DE INCLUSÕES FLUIDAS}

\section{Tipos e modos de ocorrência das inclusões fluidas}

As análises foram realizadas em IF aprisionadas em cristais de quartzo de veios, privilegiando aqueles cristais com menores graus de deformação. As inclusões primárias se apresentam de quatro maneiras (Figura 9A): em distribuição aleatória no interior dos cristais, em trilhas intragranulares, como IF isoladas e/ou em pequenos grupos, com o primeiro modo largamente mais comum. As inclusões secundárias se caracterizam tipicamente alojadas em microfraturas transgranulares seladas. IF em microfraturas intragranulares (pseudossecundárias) foram observadas subordinadamente. Inclusões com feições de modificações pós-aprisionamento foram evitadas. Com base nos seus aspectos petrográficos e composicionais à temperatura ambiente, foram distinguidos três tipos de IF.

O tipo C (Figura 9B) é o menos abundante; são inclusões de fluidos carbônicos monofásicos e, principalmente, bifásicos $\left(\mathrm{CO}_{\text {2liq }} \pm \mathrm{CO}_{\text {2vap }}\right)$. Apresenta-se em formas poligonais, irregulares, alongadas ou, menos comum, como cristais negativos com dimensões entre $6-12 \mu \mathrm{m}$. Ocorre em planos intragranulares (Figura 9C), raramente isolado, e de maneira mais comum distribuído em arranjos aleatórios associados espacialmente com o tipo AC.

$\mathrm{O}$ tipo $\mathrm{AC}$ refere-se a fluidos aquocarbônicos bifásicos $\left(\mathrm{H}_{2} \mathrm{O}_{\text {liq }}+\mathrm{CO}_{2 \text { vap }}\right.$, rara $)$ e trifásicos $\left(\mathrm{H}_{2} \mathrm{O}_{\text {liq }}+\mathrm{CO}_{2 \text { liq }}+\mathrm{CO}_{\text {2vap }}\right)$ com dimensões entre $5-20 \mu \mathrm{m}$. Morfologicamente, as cavidades se apresentam arredondadas, irregulares, levemente alongadas ou poligonalizadas. Esse tipo de inclusão mostra ampla variação nas proporções volumétricas de $\mathrm{CO}_{2}\left(\mathrm{CO}_{2}=0,20-0,85\right.$, com moda em 0,70 nas enriquecidas em $\mathrm{CO}_{2}$ e 0,30 nas enriquecidas em $\mathrm{H}_{2} \mathrm{O}$ ). Ele ocorre de maneira mais comum em arranjos aleatórios tridimensionais e como pequenos agrupamentos, nos quais se observam IF com razões $\mathrm{H}_{2} \mathrm{O} / \mathrm{CO}_{2}$ contrastantes associadas espacialmente (Figuras 9D a 9H) - ocorrências isoladas ou em trilhas intragranulares são menos expressivas (Figura 9I); e corresponde ao tipo de IF que ocorre com mais frequência nos cristais de quartzo associados a sulfetos (Figura 9J).

O tipo AQ são IF aquosas que, quando monofásicas, manifestam-se em cavidades preenchidas pela fase líquida, com as menores dimensões $(1-4 \mu \mathrm{m})$, em formas arredondadas e exclusivamente em planos transgranulares. Quando bifásicas (Figura $9 \mathrm{~K}$ ), são dominadas por líquido $(\mathrm{F}=0,70$ a 0,90 ), sem a presença de fase carbônica detectável microtermometricamente, em cavidades arredondadas, poligonalizadas ou levemente alongadas. Apresentam maiores dimensões $(5-15 \mu \mathrm{m})$, ocorrem principalmente em arranjos aleatórios algo orientados e mais subordinadamente em pequenos conjuntos de inclusões ou isoladas e em trilhas transgranulares (Figuras 9L e 9M).

\section{Resultados microtermométricos}

Uma síntese dos dados microtermométricos obtidos nos vários tipos de IF no alvo Jerimum de Baixo é disponibilizada na Tabela 2.

As IF do tipo $\mathrm{C}$ têm temperatura final de fusão do $\mathrm{CO}_{2}$ $\left(\mathrm{TfCO}_{2}\right)$ no intervalo de $-58,6$ a $-56,6^{\circ} \mathrm{C}$, com um único caso em $-61,3^{\circ} \mathrm{C}$ (Figura 10A), estendendo-se ligeiramente abaixo do ponto tríplice de $\mathrm{CO}_{2}$, o que indica a presença de outros voláteis na fase carbônica (por exemplo, $\mathrm{N}_{2}, \mathrm{H}_{2} \mathrm{~S}$, $\left.\mathrm{CH}_{4}\right)$. As temperaturas de homogeneização do $\mathrm{CO}_{2}\left(\mathrm{ThCO}_{2}\right)$ ocorrem entre 12,5 e $31,1^{\circ} \mathrm{C}$, principalmente para o estado líquido (Figura 10B).

As IF do tipo AC mostram $T \mathrm{fCO}_{2}$ bastante similares independentemente da proporção de $\mathrm{CO}_{2} / \mathrm{H}_{2} \mathrm{O}$, entre $-58,2 \mathrm{e}$ $-56,6^{\circ} \mathrm{C}$, o que sugere o $\mathrm{CO}_{2}$ como o principal componente volátil na fase carbônica (Figura 10A). As Tfclat foram registradas entre 6,1 e $8,9^{\circ} \mathrm{C}$ (tipo $\mathrm{AC}$ rica em $\mathrm{CO}_{2}=6,6 \mathrm{a}$ $8,5^{\circ} \mathrm{C}$ e tipo $\mathrm{AC}$ pobre em $\mathrm{CO}_{2}=4,8$ a $8,9^{\circ} \mathrm{C}$ ) (Figura $10 \mathrm{C}$ ). Nas IF ricas em $\mathrm{CO}_{2}$, as $\mathrm{ThCO}_{2}$ variaram de 22,7 a $31,1^{\circ} \mathrm{C}$, enquanto naquelas ricas na fase aquosa ocorreram entre 26,2 e $30,9^{\circ} \mathrm{C}$, em ambos os casos majoritariamente para a fase líquida (Figura 10B). Apenas duas temperaturas de eutético (Teu) foram observadas em $-36,8$ e $-33,6^{\circ} \mathrm{C}$, o que sinaliza a participação de $\mathrm{MgCl}_{2} \mathrm{e} / \mathrm{ou} \mathrm{FeCl}_{2}$. As temperaturas de homogeneização total $(\mathrm{Tht})$ cobrem o intervalo de 237,0 a $405,0^{\circ} \mathrm{C}$, com valores concentrados entre 280,0 e $340,0^{\circ} \mathrm{C}$ e principalmente pela contração da fase $\mathrm{CO}_{2}$. As IF do tipo AC ricas em $\mathrm{CO}_{2}$ apresentaram $T$ ht entre 255,1 e $405,0^{\circ} \mathrm{C}$, ao passo que aquelas com menores quantidades de $\mathrm{CO}_{2}$ homogeneizaram completamente 

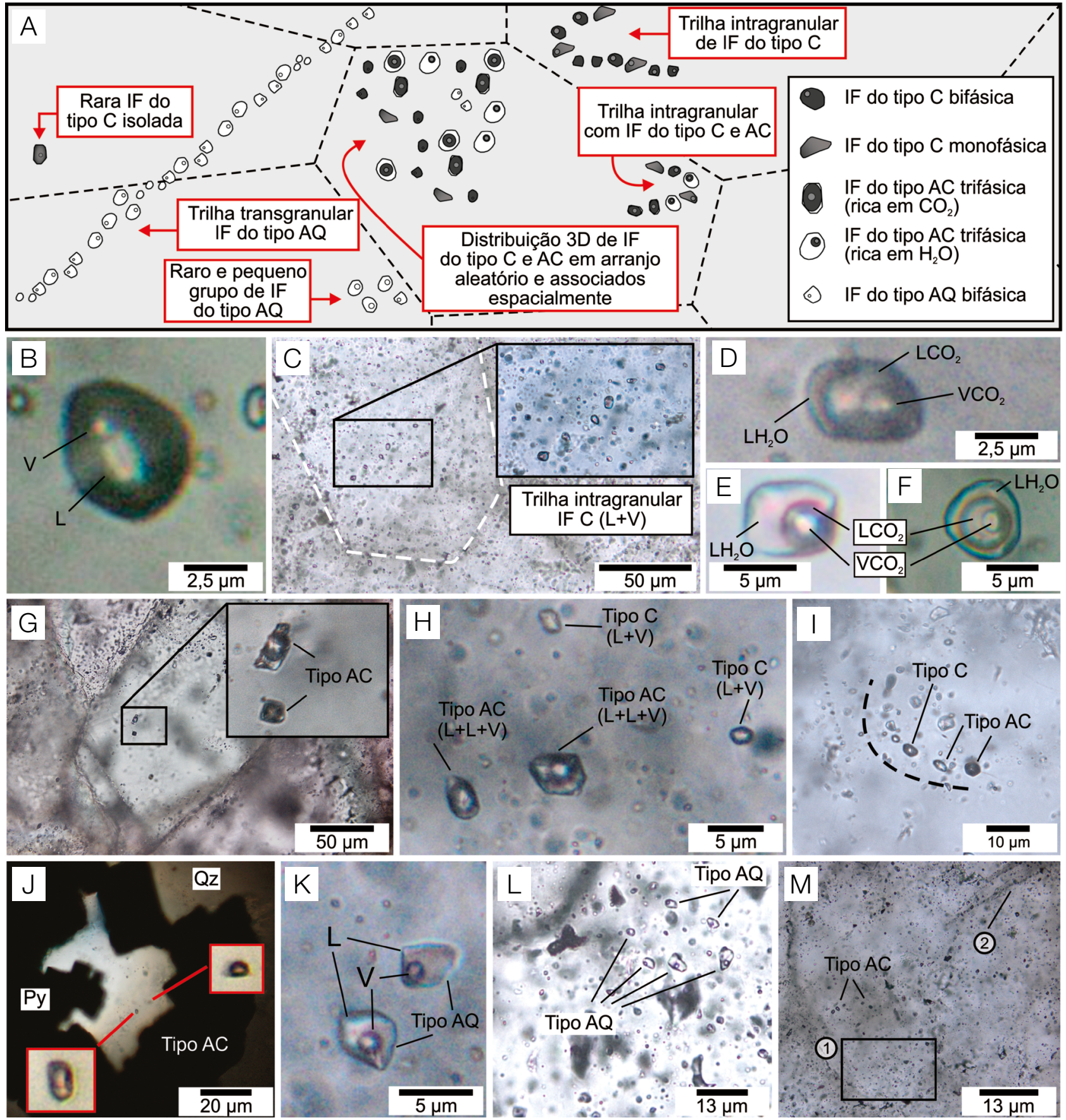

IF: inclusões fluidas.

Figura 9. Inclusões fluidas observadas em cristais de quartzo de veios do alvo Jerimum de Baixo. (A) Desenho esquemático que mostra os diferentes tipos e modos de ocorrência das IF observadas nos cristais de quartzo de veios mineralizados no alvo Jerimum de Baixo; (B) IF do tipo $\mathrm{C}\left(\mathrm{CO}_{2}\right)$; (C) cristal de quartzo (linha branca tracejada) com grande densidade de IF. Destaque para a trilha intragranular de IF do tipo C; (D) IF do tipo AC trifásica enriquecida na fase $\mathrm{CO}_{2}$; (E) IF do tipo AC trifásica enriquecida na fase $\mathrm{H}_{2} \mathrm{O}$; (F) IF menos recorrente do tipo $\mathrm{AC}$ com razão $\mathrm{H}_{2} \mathrm{O} / \mathrm{CO}_{2}$ intermediária; (G) IF do tipo AC com diferentes razões $\mathrm{H}_{2} \mathrm{O} / \mathrm{CO}_{2}$ associadas; (H) grupo formado por IF coexistentes dos tipos $\mathrm{C}$ e AC; (I) trilha composta de IF pseudossecundárias dos tipos $\mathrm{C}$ e AC; (J) IF do tipo AC em cristal de quartzo em equilíbrio com cristais de pirita; (K) IF do tipo $A Q$ bifásica; (L) grupo de inclusões do tipo $A Q$; (M) cristais de quartzo com IF do tipo $A C$ dispostas em pequenas trilhas intragranulares e (i) distribuídas aleatoriamente e (ii) IF do tipo $A Q$ em trilhas secundárias aprisionadas em microfraturas. 
entre 237,0 e $361,2^{\circ} \mathrm{C}$ (Figura 10D). Algumas inclusões homogeneizaram para o estado vapor pela expansão da fase $\mathrm{CO}_{2}$, no intervalo de 292,5 a $363,0^{\circ} \mathrm{C}$, a despeito da proporção $\mathrm{CO}_{2} / \mathrm{H}_{2} \mathrm{O}$ aprisionada $\left(\mathrm{CO}_{2}=0,25\right.$ a 0,70$) \mathrm{e}$, por vezes, em associação espacial com aquelas que homogeneizaram para o estado líquido.

As IF do tipo AQ apresentam temperaturas de fusão final do gelo ( $\mathrm{Tfg}$ ) dentro do intervalo de $-13,2$ e $-2,6^{\circ} \mathrm{C}$ para as consideradas primárias (Figura 10E). As IF aprisionadas secundariamente apresentaram um amplo intervalo de $T$ fg, com variação entre $-18,0$ e $-0,1^{\circ} \mathrm{C}$. As $T$ eu foram observadas em poucas das inclusões primárias e dentro do intervalo de $-37,2$ a $-20,1^{\circ} \mathrm{C}$, o que aponta a presença de solutos como $\mathrm{KCl}, \mathrm{MgCl}_{2}$ e $\mathrm{FeCl}_{2}$ (sistema $\mathrm{H}_{2} \mathrm{O}-\mathrm{NaCl} \pm \mathrm{KCl} \pm \mathrm{MgCl}_{2} \pm \mathrm{FeCl}_{2} \rightarrow \mathrm{AQ}_{1}$ ). Nas secundárias, as Teu cobrem dois intervalos bem distintos: entre $-23,0$ e $-21,2^{\circ} \mathrm{C}$, compatíveis com o sistema $\mathrm{H}_{2} \mathrm{O}$ $\mathrm{NaCl}\left(\mathrm{AQ}_{2}\right)\left(\right.$ Borisenko, 1977), e entre $-62,5$ e $-74,2^{\circ} \mathrm{C}$, atribuíveis ao sistema $\mathrm{H}_{2} \mathrm{O}-\mathrm{NaCl}-\mathrm{CaCl}_{2}\left(\mathrm{AQ}_{3}\right)$ (Davis et al., 1990). Valores inferiores $\mathrm{a} \approx-52^{\circ} \mathrm{C}$ foram considerados como resultantes da metaestabilidade do sistema $\mathrm{H}_{2} \mathrm{O}-\mathrm{NaCl}-\mathrm{CaCl}_{2}$, presença de cátions incomuns (por exemplo, Li e Sr) ou transições de fase de gelo hexagonal em fluidos de composição idêntica (Davis et al., 1990; Walker e Samson, 1998). Para as IF primárias, não se notou relação clara entre $T$ eu e $T$ fg, em detrimento das IF secundárias, nas quais se observa que os menores valores de $T$ eu são registrados naquelas com as menores $T$ fg (maior salinidade) (Figura $10 \mathrm{~F}$ ). A Tht ocorreu sempre para o estado líquido e dentro do intervalo total de 80,0 a $249,0^{\circ} \mathrm{C}$ (Figura $\left.10 \mathrm{D}\right)\left(\mathrm{IF}_{\mathrm{AQ}}=118,0-\right.$ $249,0^{\circ} \mathrm{C} ; \mathrm{IF}_{\mathrm{AQ}_{2}}=85,5-155,0^{\circ} \mathrm{C}$; e IF $\mathrm{AQ}_{3}=80,0-$ $116,2^{\circ} \mathrm{C}$ ) (Figura 10E).

\section{Densidade e composição}

Os dados microtermométricos obtidos nas inclusões $\mathrm{C}$ e AC sugerem que a presença de outros voláteis na fase carbônica pouco afetou as suas propriedades microtermométricas. Com base nisso, a composição das inclusões do tipo $\mathrm{AC}$ ricas $\mathrm{em} \mathrm{CO}_{2}$ é dada por: $X_{\mathrm{CO} 2}=0,22-0,63 \mathrm{~mol} \%, X_{\mathrm{H} 2 \mathrm{O}}=0,36-0,76 \mathrm{~mol} \%$, $X_{\mathrm{NaCl}}=0,00-0,01 \mathrm{~mol} \% \mathrm{e}$, em função dos valores de $T$ fclat, a salinidade estimada situa-se entre 3,0 e $6,5 \%$ em peso equivalente a $\mathrm{NaCl}$. A densidade da fase carbônica $\left(\mathrm{\rho CO}_{2}\right)$ varia entre $0,42 \mathrm{e} 0,74 \mathrm{~g} / \mathrm{cm}^{3}$, enquanto a densidade global ( $\rho$ global) oscila de 0,58 a $0,82 \mathrm{~g} / \mathrm{cm}^{3}$. Para as IF AC enriquecidas na fase $\mathrm{H}_{2} \mathrm{O}$, têm-se: $X_{\mathrm{CO} 2}=0,06-0,17 \mathrm{~mol} \%, X_{\mathrm{H} 2 \mathrm{O}}=0,82-0,92 \mathrm{~mol} \%$, $X_{\mathrm{NaCl}}=0,01-0,03 \mathrm{~mol} \%$ e salinidade entre $2,2 \mathrm{e} 9,4 \%$ em peso equivalente de $\mathrm{NaCl}$. A $\rho \mathrm{CO}_{2}$ abrange o intervalo de 0,39 a $0,69 \mathrm{~g} / \mathrm{cm}^{3}$ e a $\rho g l o b a l$ varia de $0,80 \mathrm{a} 0,97 \mathrm{~g} / \mathrm{cm}^{3}$. Para o tipo $\mathrm{C}$, a densidade circunscreve o intervalo de 0,35 a $0,85 \mathrm{~g} / \mathrm{cm}^{3}$. Para esses tipos, esses valores caracterizam fluidos de baixa a moderada densidade e salinidade.

Nas inclusões do tipo AQ, a salinidade abrange os intervalos de 4,3 a 17,1\% $\left(\mathrm{H}_{2} \mathrm{O}-\mathrm{NaCl} \pm \mathrm{KCl} \pm \mathrm{MgCl}_{2} \pm \mathrm{FeCl}_{2}\right.$ : $\left.\mathrm{AQ}_{1}\right)$, de 0,9 a $10,4 \%\left(\mathrm{H}_{2} \mathrm{O}-\mathrm{NaCl}: \mathrm{AQ}_{2}\right)$ e de 16,8 a $21,0 \%$ $\left(\mathrm{H}_{2} \mathrm{O}-\mathrm{NaCl}-\mathrm{CaCl}_{2}: \mathrm{AQ}_{3}\right)$ em peso equivalente de $\mathrm{NaCl}$. A densidade compreende valores entre 0,90 e $1,03 \mathrm{~g} / \mathrm{cm}^{3}$ para $\mathrm{AQ}_{1}, 0,93$ e $1,03 \mathrm{~g} / \mathrm{cm}^{3}$ para $\mathrm{AQ}_{2}$ e 1,10 e $1,11 \mathrm{~g} / \mathrm{cm}^{3}$ para $\mathrm{AQ}_{3}$.

\section{QUÍMICA MINERAL}

\section{Biotita}

A biotita analisada é de origem ígnea e ocorre intersticialmente associada ao quartzo e feldspato ou como inclusão em

Tabela 2. Síntese dos dados microtermométricos para os diferentes tipos de inclusões fluidas aprisionadas em cristais de quartzo dos veios do alvo Jerimum de Baixo.

\begin{tabular}{|c|c|c|c|c|c|c|c|c|}
\hline Tipo $^{1}$ & Origem $^{2}$ & $\mathrm{TfCO}_{2}$ & Tfclat & $\mathrm{ThCO}_{2}$ & Teut & Tfg & Tht & Salinidade \\
\hline Tipo C & $P$ e Ps & $\begin{array}{c}-61,3 a \\
-56,6\end{array}$ & - & $\begin{array}{c}12,5 \mathrm{a} \\
31,1\end{array}$ & - & - & - & - \\
\hline $\begin{array}{l}\text { Tipo AC } \\
\left(\mathrm{CO}_{2}>0,5\right)\end{array}$ & $\mathrm{P}$ e Ps & $\begin{array}{l}-58,2 a \\
-56,6\end{array}$ & 6,6 a 8,5 & $\begin{array}{c}22,7 \text { a } \\
31,1\end{array}$ & - & - & $\begin{array}{l}255,1 \mathrm{a} \\
405,0\end{array}$ & 3,0 a 6,5 \\
\hline $\begin{array}{l}\text { Tipo AC } \\
\left(\mathrm{CO}_{2}<0,5\right)\end{array}$ & $\mathrm{P}$ e Ps & $\begin{array}{c}-58,1 a \\
-56,6\end{array}$ & 4,8 a 8,9 & $\begin{array}{c}26,2 \text { e } \\
30,9\end{array}$ & $\begin{array}{l}-36,8 \text { e } \\
-33,6\end{array}$ & - & $\begin{array}{c}237,0 \mathrm{a} \\
361,2\end{array}$ & 2,2 e 9,4 \\
\hline $\begin{array}{l}\text { Tipo } \mathrm{AQ}_{1} \\
\left(\mathrm{H}_{2} \mathrm{O}-\mathrm{NaCl} \pm \mathrm{KCl} \pm\right. \\
\left.\mathrm{MgCl}_{2} \pm \mathrm{FeCl}_{2}\right)\end{array}$ & $P$ & - & - & - & $\begin{array}{l}-37,2 \mathrm{a} \\
-20,1\end{array}$ & $\begin{array}{c}-13,2 \mathrm{a} \\
-2,6\end{array}$ & $\begin{array}{c}118,0 \mathrm{a} \\
249,0\end{array}$ & 4,3 a 17,1 \\
\hline $\begin{array}{l}\text { Tipo } A Q_{2} \\
\left(\mathrm{H}_{2} \mathrm{O}-\mathrm{NaCl}\right)\end{array}$ & $S$ & - & - & - & $\begin{array}{l}-23,0 \mathrm{a} \\
-21,2\end{array}$ & $-6,9 a-0,1$ & $\begin{array}{l}85,5 \mathrm{a} \\
155,0\end{array}$ & 0,9 a 10,4 \\
\hline $\begin{array}{l}\text { Tipo } \mathrm{AQ}_{3} \\
\left(\mathrm{H}_{2} \mathrm{O}-\mathrm{NaCl}-\mathrm{CaCl}_{2}\right)\end{array}$ & $S$ & - & - & - & $\begin{array}{l}-62,5 a \\
-74,2 \\
\end{array}$ & $\begin{array}{c}-12,9 a \\
-18,0 \\
\end{array}$ & $\begin{array}{l}80,0 \text { a } \\
116,2\end{array}$ & $\begin{array}{c}16,8 \mathrm{a} \\
21,0\end{array}$ \\
\hline
\end{tabular}

${ }^{1}$ Tipos de inclusões fluidas: C: carbônica; AC: aquocarbônica; AQ: aquosa; ${ }^{2}$ Origem das inclusões fluidas: P: primária; Ps: pseudossecundária; S: secundária; $\mathrm{TfCO}_{2}$ : temperatura de fusão do $\mathrm{CO}_{2}$ sólido; Tfclat: temperatura de fusão do clatrato; ThCO $\mathrm{CO}_{2}$ temperatura de homogeneização do $\mathrm{CO}_{2}$; Teut: temperatura do ponto eutético; Tfg: temperatura de fusão final do gelo; Tht: temperatura de homogeneização total. Valores de temperaturas dados em ${ }^{\circ} \mathrm{C}$ e salinidades em \% em peso equivalente de $\mathrm{NaCl}$. 
plagioclásio do $\mathrm{BMgE}$ e fenocristais de quartzo do $\mathrm{BMgP}$. Os cristais mais preservados dos processos hidrotermais (cloritização, sericitização e epidotização) foram priorizados neste estudo.

A biotita de ambas as fácies graníticas corresponde a uma mica extremamente rica em ferro, cujos pontos plotam próximo ao polo da annita, segundo o diagrama $\mathrm{Fe} /(\mathrm{Fe}+$ $\mathrm{Mg}$ ) vs. Al ${ }^{\mathrm{IV}}$ (Figura 11A; Deer et al., 1992). Os valores para $X_{\mathrm{Fe}}\left[X_{\mathrm{Fe}}=\mathrm{Fe} /(\mathrm{Fe}+\mathrm{Mg})\right]$ são similares comparativamente, variando entre $0,83-0,88$ e com moda 0,87 para a biotita do $\mathrm{BMgE}$ e entre $0,84-0,85$ e com moda 0,85 para a do $\mathrm{BMgP}$. $\mathrm{O}$ teor de $\mathrm{FeO}$ varia entre 23,52 - 32,29 \% (moda 29,64\%) para a que compõe o BMgE e $31,49-32,24 \%$ para a do BMgP. No diagrama Al total vs. Mg (Figura 11B; Nachit et al.,
1985), a mica estudada plota nos campos da biotita de rochas com assinatura geoquímica cálcico-alcalina a subalcalina. Dados analíticos estão disponibilizados na Tabela 3.

\section{Mica branca}

A mica branca analisada representa as seguintes variedades texturais:

(i) advindas de processos de substituição da biotita e plagioclásio tanto nas regiões menos modificadas quanto naquelas mais hidrotermalizadas;

(ii) relacionadas a sulfetos disseminados;

(iii) compondo vênulas;

(iv)associadas a corpos brechoides.
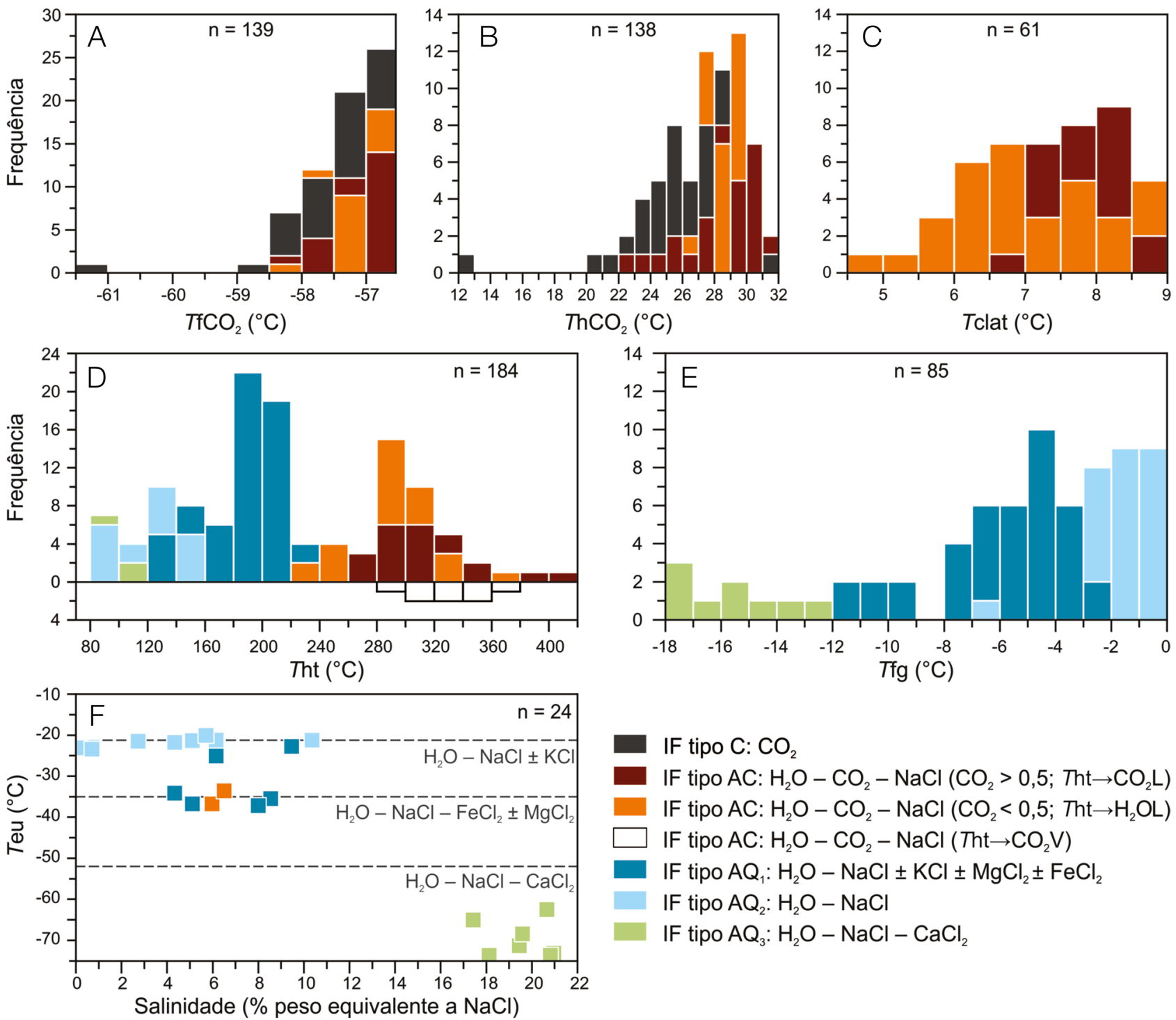

IF: inclusões fluidas.

Figura 10. Histogramas de frequência (A-E) e diagrama Teu vs. salinidade (F) para os dados microtermométricos das IF em Jerimum de Baixo. 
De maneira geral, a mica branca apresenta excesso de cátions no sítio octaédrico e carência na posição intercamada - embora ainda não compreendidas como micas com deficiência intercamada, consoante aos critérios de Rieder et al. (1998). Apesar das variedades texturais, não se observaram diferenças composicionais significativas entre elas. Com base na relação $\mathrm{Al}$ total $-\mathrm{M}^{+2}-\mathrm{Si}$ (Monier e Robert, 1986), nota-se a concentração dos pontos na metade superior da linha muscovita-celadonita (segmento muscovita-fengita) (Figura 12A). O diagrama $\mathrm{Al}^{\mathrm{VI}} v s . \mathrm{M}^{+2}$ evidencia uma ótima correlação negativa entre as análises plotadas $\left(R^{2}=\right.$ 0,91 ) na proporção 1:1 (Figura 12B). Tal correlação indica a existência de substituição isomórfica entre $\mathrm{Al}$ e os cátions divalentes no sítio octaédrico, o que dá origem à série fengítica com a manutenção do caráter dioctaédrico na mica analisada. Nesse cenário, a relação que melhor representa essa substituição é $\left(\mathrm{Si}_{+1} \mathrm{Al}_{-1}\right)^{\mathrm{IV}}\left(\mathrm{M}^{+2}{ }_{+1} \mathrm{Al}_{-1}\right)^{\mathrm{VI}}$. Os dados analíticos estão disponibilizados na Tabela 4.

\section{Clorita}

As análises foram realizadas em cristais de clorita:

(i) de preenchimento (vênulas);

(ii) de substituição (biotita $\rightarrow$ clorita);

(iii) diretamente associados a sulfetos disseminados em rocha profundamente alterada;

(iv) de corpos brechoides.

As cloritas analisadas são ricas em ferro $(\mathrm{FeO}=$ $35,96-41,28 \%$ ), sendo classificadas como chamosita (Figura 13A; Bailey, 1988). Composicionalmente, foi constatado que a clorita resultante da substituição da biotita nas regiões mais preservadas associada aos sulfetos disseminados e zonas brechoides são as variedades chamosíticas mais ricas em ferro. Os valores para $X_{\mathrm{Fe}}$ são mais elevados na chamosita de substituição nos granitos e menos expressivos na equivalente venular, com valores relativamente intermediários para aqueles presentes nas zonas mais intensamente alteradas. A observação do comportamento catiônico nos sítios de acomodação mostra, em geral, uma forte correlação negativa entre os cátions tetraédricos e os cátions octaédricos (Figura 13B). Dessa forma, admite-se que o mecanismo de substituição mais importante pode ser descrito pela equação $\left(\mathrm{Si}_{+1} \mathrm{Al}_{-1}\right)^{\mathrm{IV}}$ $\left(\mathrm{Al}_{-1} \mathrm{R}_{+1}^{+2}\right)^{\mathrm{VI}}$ (Cathelineau, 1988). A Tabela 5 disponibiliza os dados analíticos.

\section{DISCUSSÃO}

\section{Interpretação dos dados de inclusões fluidas}

O modo de ocorrência e distribuição das IF aquocarbônicas observados em cristais de quartzo de veios em Jerimum de Baixo poderiam ser explicados por um dos seguintes mecanismos (ou uma combinação destes):

(i) modificações pós-aprisionamento de um fluido $\mathrm{H}_{2} \mathrm{O}$ $\mathrm{CO}_{2}-\mathrm{NaCl}$;

(ii) mistura parcial e aprisionamento heterogêneo de dois fluidos hidrotermais originalmente não relacionados;

(iii) separação de fases em um fluido $\mathrm{H}_{2} \mathrm{O}-\mathrm{CO}_{2}-\mathrm{NaCl}$ homogêneo;
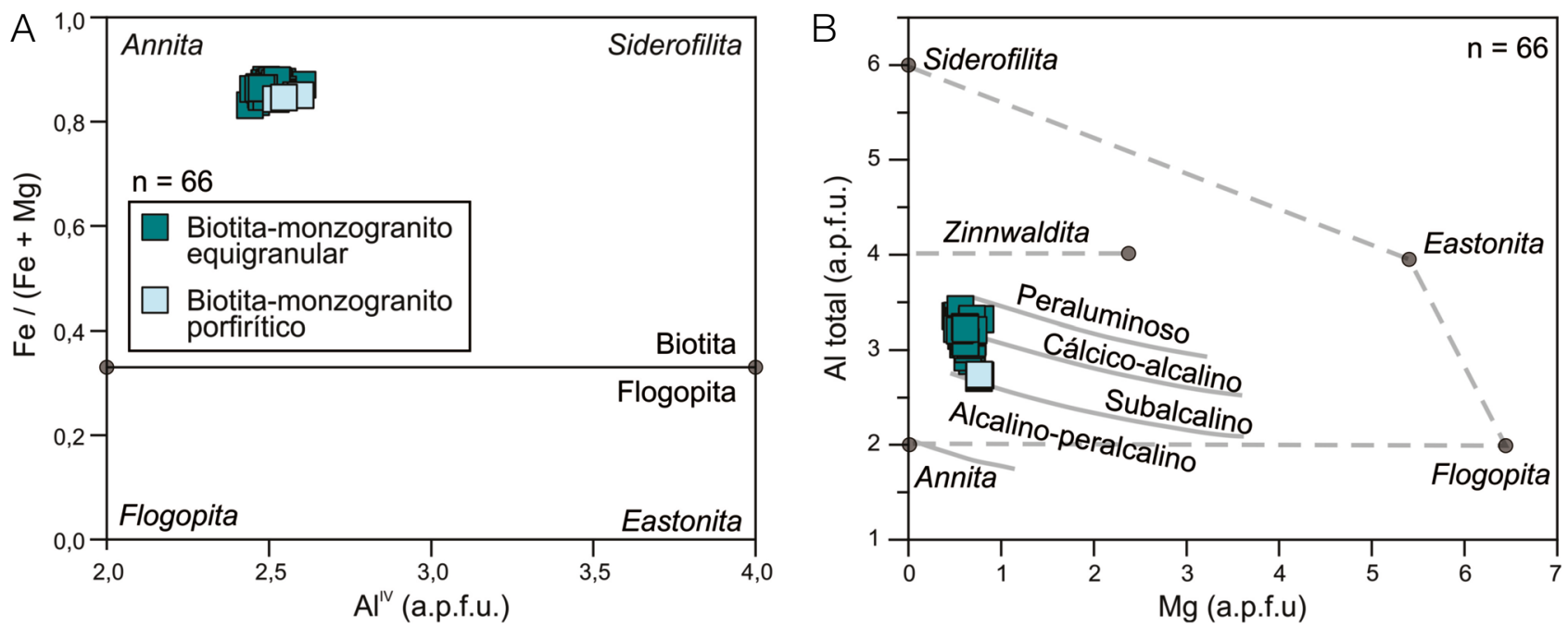

a.p.f.u: átomos de oxigênio por fórmula unitária.

Figura 11. Diagramas binários com as variações composicionais da biotita nos plútons do alvo Jerimum de Baixo. (A) Diagrama Fe / (Fe + Mg) vs. Alv com composições dos membros finais ideais (Deer et al., 1992); (B) diagrama Al total vs. Mg (campos segundo Nachit et al., 1985). 
Embora os veios mostrem cristais de quartzo com sinais de deformação e recristalizações localizadas, as inclusões analisadas se apresentam em formas regulares e sem evidências de vazamentos/estrangulamentos, além de hospedadas em cristais pouco a não deformados.

Inclusões dos tipos C, AC e AQ (em especial, as primárias) poderiam ser produzidas por mistura em variadas proporções entre fluidos semelhantes aos tipos $\mathrm{C}$ e AQ. Todavia, aspectos petrográficos (relações texturais e de truncamento), somados aos dados microtermométricos das populações de IF, indicam que aquelas dos tipos $\mathrm{C}$ e $\mathrm{AC}$ são as mais precoces e cogenéticas, ao mesmo tempo que as do tipo AQ são mais tardias. Além disso, não se observam trends em um diagrama Tht $v s$. salinidade (Figura 14) entre os tipos de inclusões com $\mathrm{CO}_{2}$ e as aquosas, comuns em eventos de mistura (Cathelineau e Marignac, 1994).

A coexistência dos tipos C e AC (e seus subtipos) em um mesmo domínio microscópico em grupos de inclusões relacionadas espacialmente e apresentando valores relativamente similares para $T \mathrm{fCO}_{2}$ e $\mathrm{ThCO}_{2}$ podem ser indicativos de que as inclusões foram aprisionadas a partir de um mesmo fluido durante a evolução do sistema hidrotermal. As variações das razões $\mathrm{CO}_{2} / \mathrm{H}_{2} \mathrm{O}$ e dos dados microtermométricos, tais como variações na $T_{\mathrm{h}} \mathrm{CO}_{2}$ (variação de densidade) e na $T h t$, indicam que o fluido foi aprisionado em estado heterogêneo.

Tabela 3. Análises de microssonda eletrônica representativas da biotita dos granitos do alvo Jerimum de Baixo, Campo Mineralizado do Cuiú-Cuiú.

\begin{tabular}{|c|c|c|c|c|c|c|c|c|c|c|c|c|c|}
\hline \multirow{3}{*}{$\begin{array}{l}\text { Fácies } \\
\text { Amostra } \\
\text { Análises }\end{array}$} & \multicolumn{9}{|c|}{$\mathrm{BMgE}$} & \multicolumn{4}{|c|}{ BMgP } \\
\hline & \multicolumn{9}{|c|}{ EK-R-35 } & \multicolumn{4}{|c|}{ EK-R-36 } \\
\hline & bC1_2 & bC2_4 & bC2_5 & bC3_1 & bC3_9 & bC4_11 & bC4_14 & bC5_1 & bC5_2 & bC6_1 & bC6_2 & bC6_3 & bC6_4 \\
\hline $\mathrm{SiO}_{2}$ & 34,37 & 34,81 & 34,52 & 34,38 & 35,07 & 34,37 & 34,49 & 34,54 & 34,19 & 33,46 & 33,66 & 34,51 & 34,14 \\
\hline $\mathrm{TiO}_{2}$ & 2,84 & 2,79 & 2,52 & 3,38 & 0,80 & 3,26 & 2,63 & 3,21 & 3,17 & 2,50 & 2,59 & 2,51 & 2,55 \\
\hline $\mathrm{Al}_{2} \mathrm{O}_{3}$ & 17,09 & 17,99 & 17,97 & 16,25 & 17,78 & 16,14 & 16,59 & 16,71 & 16,32 & 14,16 & 14,36 & 14,59 & 14,54 \\
\hline $\mathrm{FeO}$ & 28,61 & 28,11 & 28,82 & 29,29 & 28,97 & 29,14 & 29,35 & 29,50 & 29,82 & 32,10 & 32,24 & 31,49 & 31,60 \\
\hline $\mathrm{MnO}$ & 0,72 & 0,69 & 0,70 & 0,82 & 1,04 & 0,84 & 0,92 & 0,72 & 0,73 & 0,44 & 0,47 & 0,46 & 0,43 \\
\hline $\mathrm{MgO}$ & 2,48 & 2,15 & 2,25 & 2,81 & 3,29 & 2,80 & 2,62 & 2,52 & 2,60 & 3,16 & 3,18 & 3,29 & 3,23 \\
\hline $\mathrm{CaO}$ & 0,02 & 0,02 & 0,01 & 0,03 & 0,02 & 0,00 & 0,04 & 0,03 & 0,02 & 0,03 & 0,04 & 0,04 & 0,04 \\
\hline $\mathrm{Na}_{2} \mathrm{O}$ & 0,06 & 0,08 & 0,09 & 0,13 & 0,09 & 0,10 & 0,14 & 0,22 & 0,16 & 0,15 & 0,12 & 0,15 & 0,13 \\
\hline $\mathrm{K}_{2} \mathrm{O}$ & 8,82 & 9,18 & 9,28 & 8,71 & 8,95 & 8,80 & 8,72 & 8,94 & 8,60 & 8,77 & 8,80 & 8,77 & 8,80 \\
\hline $\mathrm{F}$ & 0,05 & 0,06 & 0,06 & 0,12 & 0,10 & 0,11 & 0,03 & 0,00 & 0,06 & 1,53 & 1,60 & 1,60 & 1,55 \\
\hline $\mathrm{Cl}$ & 0,08 & 0,09 & 0,07 & 0,08 & 0,08 & 0,09 & 0,09 & 0,09 & 0,09 & 0,09 & 0,08 & 0,08 & 0,09 \\
\hline Subtotal & 95,12 & 95,96 & 96,29 & 95,99 & 96,19 & 95,65 & 95,60 & 96,48 & 95,75 & 96,39 & 97,13 & 97,48 & 97,11 \\
\hline $\mathrm{O}=\mathrm{F}, \mathrm{Cl}$ & 0,04 & 0,05 & 0,04 & 0,07 & 0,06 & 0,06 & 0,03 & 0,02 & 0,04 & 0,67 & 0,69 & 0,69 & 0,67 \\
\hline Total & 95,08 & 95,92 & 96,25 & 95,92 & 96,13 & 95,59 & 95,57 & 96,45 & 95,70 & 95,72 & 96,44 & 96,79 & 96,44 \\
\hline \multicolumn{14}{|c|}{ Fórmula estrutural calculada na base de 22 átomos de oxigênio } \\
\hline $\mathrm{Si}$ & 5,51 & 5,51 & 5,47 & 5,49 & 5,56 & 5,50 & 5,53 & 5,49 & 5,48 & 5,42 & 5,40 & 5,48 & 5,45 \\
\hline Alv & 2,49 & 2,49 & 2,53 & 2,51 & 2,44 & 2,50 & 2,47 & 2,51 & 2,52 & 2,58 & 2,60 & 2,52 & 2,55 \\
\hline Sítio Z & 8,00 & 8,00 & 8,00 & 8,00 & & 8,00 & & 8,00 & & 8,00 & 8,00 & 8,00 & 8,00 \\
\hline$A l^{v 1}$ & 0,73 & 0,86 & 0,83 & 0,54 & 0,88 & 5 & 0,66 & 0,61 & 0,56 & 0,12 & 0,12 & 0,21 & 0,19 \\
\hline $\mathrm{Ti}$ & 0,34 & 0,33 & 0,30 & 0,41 & 0,09 & 0,39 & 0,32 & 0,38 & 0,38 & 0,30 & 0,31 & 0,30 & 0,31 \\
\hline $\mathrm{Fe}$ & 3,83 & 3,72 & 3,82 & 3,91 & 3,84 & 3,90 & 3,93 & 3,92 & 4,00 & 4,35 & 4,33 & 4,18 & 4,22 \\
\hline $\mathrm{Mn}$ & 0,10 & 0,09 & 0,09 & 0,11 & 0,14 & 0,11 & 0,13 & 0,10 & 0,10 & 0,06 & 0,06 & 0,06 & 0,06 \\
\hline $\mathrm{Mg}$ & 0,59 & 0,51 & 0,53 & 0,67 & 0,78 & 0,67 & 0,63 & 0,60 & 0,62 & 0,76 & 0,76 & 0,78 & 0,77 \\
\hline Sítio Y & 5,60 & 5,51 & 5,57 & 5,63 & 5,73 & 5,63 & 5,66 & 5,61 & 5,66 & 5,59 & 5,58 & 5,53 & 5,54 \\
\hline $\mathrm{Ca}$ & 0,00 & 0,00 & 0,00 & 0,00 & 0,00 & 0,00 & 0,01 & 0,01 & 0,00 & 0,01 & 0,01 & 0,01 & 0,01 \\
\hline $\mathrm{Na}$ & 0,02 & 0,02 & 0,03 & 0,04 & 0,03 & 0,03 & 0,04 & 0,07 & 0,05 & 0,05 & 0,04 & 0,04 & 0,04 \\
\hline K & 1,80 & 1,85 & 1,88 & 1,77 & 1,81 & 1,80 & 1,78 & 1,81 & 1,76 & 1,81 & 1,80 & 1,78 & 1,79 \\
\hline Sítio X & 1,82 & 1,88 & 1,90 & 1,82 & 1,84 & 1,83 & 1,83 & 1,89 & 1,81 & 1,86 & 1,85 & 1,83 & 1,84 \\
\hline $\mathrm{F}$ & 0,02 & 0,03 & 0,03 & 0,06 & 0,05 & 0,05 & 0,01 & 0,00 & 0,03 & 0,79 & 0,81 & 0,80 & 0,78 \\
\hline $\mathrm{Cl}$ & 0,02 & 0,02 & 0,02 & 0,02 & 0,02 & 0,02 & 0,02 & 0,02 & 0,03 & 0,02 & 0,02 & 0,02 & 0,03 \\
\hline Cátions & 19,42 & 19,39 & 19,48 & 19,45 & 19,57 & 19,46 & 19,49 & 19,49 & 19,47 & 19,45 & 19,43 & 19,35 & 19,39 \\
\hline $\begin{array}{l}\mathrm{Fe} /(\mathrm{Fe} \\
+\mathrm{Mg})\end{array}$ & 0,866 & 0,880 & 0,878 & 0,854 & 0,831 & 0,854 & 0,863 & 0,868 & 0,866 & 0,851 & 0,850 & 0,843 & 0,846 \\
\hline
\end{tabular}


Evidências que testemunham a favor de imiscibilidade de fluidos em Jerimum de Baixo, segundo Ramboz et al. (1982), são:

(i) IF aquocarbônicas com razões $\mathrm{H}_{2} \mathrm{O} / \mathrm{CO}_{2}$ contrastantes e possivelmente coevas (representantes dos extremos imiscíveis);

(ii) que apresentam intervalos de $T \mathrm{ht}$ similares;

(iii) que em alguns agrupamentos homogeneízam para o estado líquido e outras para o vapor em temperaturas similares.

O fenômeno do particionamento preferencial dos sais para a fase aquosa em processos de separação de fases, que resultaria em IF do tipo $\mathrm{AC}$ ricas $\mathrm{em}_{2} \mathrm{O}$ mais salinas, não foi estatisticamente estabelecido. A ausência de $\mathrm{H}_{2} \mathrm{O}$ em inclusões carbônicas pode ser inconsistente com a hipótese de separação de fases a partir de um fluido $\mathrm{H}_{2} \mathrm{O}-\mathrm{CO}_{2}$ $-\mathrm{NaCl}$. No entanto, a presença de uma fase aquosa microscopicamente indetectável (até 15\% em volume) ao longo das paredes internas da cavidade pode ser esperada considerando as dimensões diminutas de várias dessas inclusões (Hollister, 1990).

As inclusões aquosas interpretadas como representativas do sistema $\mathrm{H}_{2} \mathrm{O}-\mathrm{NaCl} \pm \mathrm{KCl} \pm \mathrm{MgCl}_{2} \pm \mathrm{FeCl}_{2}$, mesmo que primárias e em um mesmo campo microscópico com as do tipo $\mathrm{C}$ e/ou $\mathrm{AC}$, não se mostram petrograficamente contemporâneas a essas últimas, o que é consistente com os dados de Tht. Ainda que em sistemas aquocarbônicos imiscíveis normalmente se produzam extremos ricos $\mathrm{em}_{2} \mathrm{O}$ e
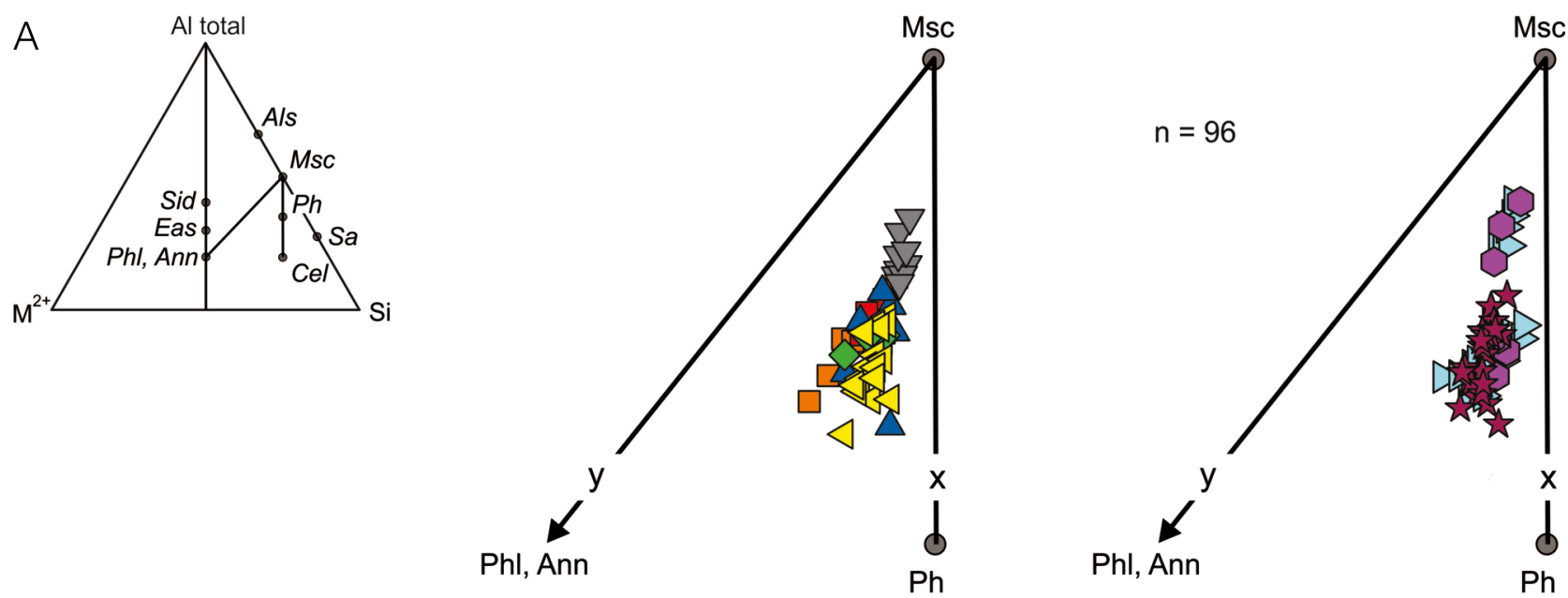

\section{$\triangleright$ Associada a sulfetos \\ Z Zona brechoide \\ ฟ Vênulas}

Substituindo biotita

$\mathrm{BMgP}$

$\triangle \mathrm{BMgE}$

$\diamond$ Rocha intensamente alterada

Substituindo plagioclásio

$\begin{array}{ll}\square & \text { BMgP } \\ \nabla & \text { BMgE } \\ \triangleleft & \text { Rocha intensamente alterada }\end{array}$

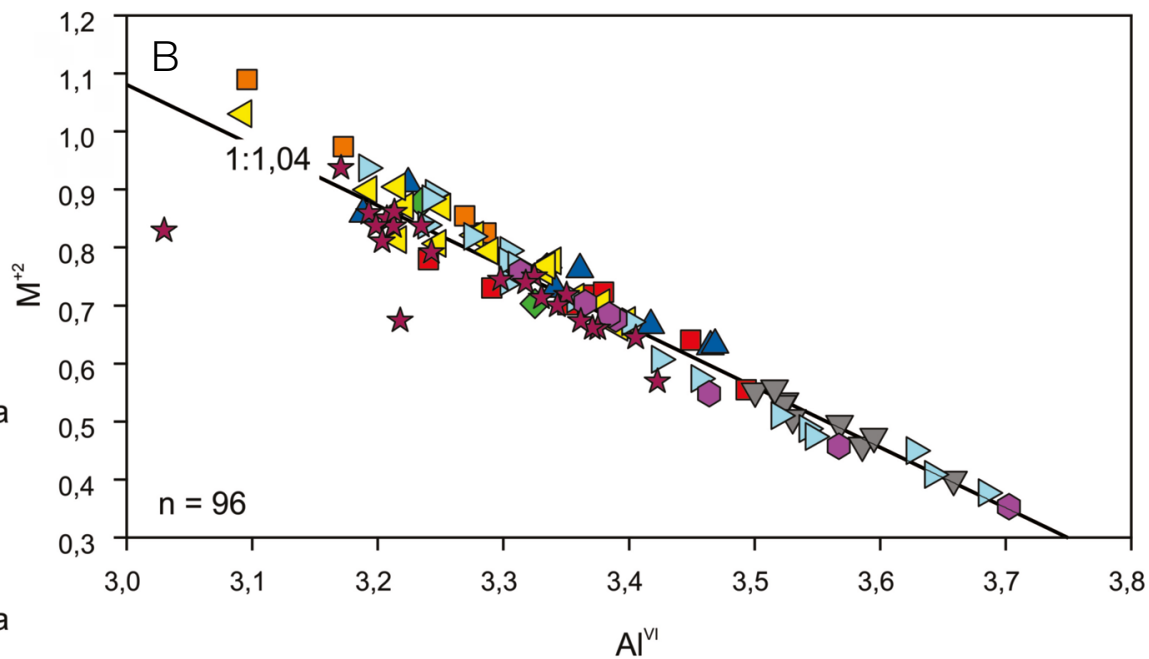

BMgP: biotita-monzogranito porfirítico; BMgE: biotita-monzogranito equigranular; Ph: fengita; Als: aluminossilicato; Sid: siderofilita

Figura 12. Diagrama químico para a mica branca estudada em Jerimum de Baixo. (A) Variação composicional segundo o diagrama Al total $-\mathrm{M}^{+2}-\mathrm{Si}$ (Monier e Robert, 1986); (B) diagrama binário catiônico que evidencia a forte correlação negativa entre $\mathrm{Al}^{\mathrm{VI}}$ e $\mathrm{M}^{+2}$. 
pobres em $\mathrm{H}_{2} \mathrm{O}$ (que aqui poderiam ser representados pelos tipo $\mathrm{C}$ e parte das do tipo $\mathrm{AQ}$ ), cenários de efervescência gerando membros finais com a fase $\mathrm{CO}_{2}$ perceptível têm sido registrados por diversos trabalhos (Chi et al., 2009; Klein et al., 2006; Klein e Fuzikawa, 2010; Schmidt-Mumm et al., 1997), inclusive no próprio Campo Mineralizado do

Tabela 4. Análises de microssonda eletrônica representativas da mica branca do alvo Jerimum de Baixo, Campo Mineralizado do Cuiú-Cuiú.

\begin{tabular}{|c|c|c|c|c|c|c|c|c|c|c|c|c|}
\hline \multirow{4}{*}{$\begin{array}{l}\text { Ocorrência } \\
\text { Amostra } \\
\text { Análises }\end{array}$} & \multicolumn{6}{|c|}{ Substituindo plagioclásio } & \multicolumn{6}{|c|}{ Substituindo biotita } \\
\hline & \multicolumn{2}{|c|}{$\mathrm{BMgE}$} & \multicolumn{2}{|c|}{$\mathrm{BMgP}$} & \multicolumn{2}{|c|}{$\begin{array}{l}\text { Granito } \\
\text { alterado }\end{array}$} & \multicolumn{2}{|c|}{$\mathrm{BMgE}$} & \multicolumn{2}{|c|}{$\mathrm{BMgP}$} & \multicolumn{2}{|c|}{$\begin{array}{l}\text { Granito } \\
\text { alterado }\end{array}$} \\
\hline & \multicolumn{2}{|c|}{ EK-R-35 } & \multicolumn{2}{|c|}{ EK-R-40 } & \multicolumn{2}{|c|}{ EK-R-28 } & \multicolumn{2}{|c|}{ EK-R-35 } & \multicolumn{2}{|c|}{ EK-R-40 } & \multicolumn{2}{|c|}{ EK-R-28 } \\
\hline & SC8_1 & SC8_5 & SC2_3 & SC2_4 & SC6_1 & SC6_6 & SC6_1 & SC6_4 & SC1_4 & SC1_6 & SC4_7 & SC4_9 \\
\hline $\mathrm{SiO}_{2}$ & 46,68 & 46,64 & 47,11 & 46,87 & 47,85 & 46,67 & 48,81 & 46,36 & 45,85 & 46,52 & 46,12 & 46,50 \\
\hline $\mathrm{TiO}_{2}$ & 0,34 & 0,08 & 0,07 & 0,10 & 0,53 & 0,37 & 0,34 & 0,28 & 0,41 & 0,29 & 0,31 & 0,19 \\
\hline $\mathrm{Al}_{2} \mathrm{O}_{3}$ & 33,05 & 33,70 & 31,63 & 33,12 & 29,38 & 30,08 & 29,54 & 30,42 & 29,72 & 31,47 & 30,87 & 31,37 \\
\hline $\mathrm{FeO}$ & 4,03 & 3,88 & 4,68 & 4,27 & 3,75 & 5,91 & 4,75 & 6,23 & 6,70 & 4,82 & 6,09 & 4,88 \\
\hline $\mathrm{MnO}$ & 0,14 & 0,12 & 0,12 & 0,11 & 0,06 & 0,17 & 0,03 & 0,16 & 0,05 & 0,06 & 0,15 & 0,04 \\
\hline $\mathrm{MgO}$ & 0,42 & 0,13 & 0,81 & 0,32 & 3,01 & 1,02 & 1,62 & 0,88 & 1,54 & 1,36 & 0,82 & 1,02 \\
\hline $\mathrm{CaO}$ & 0,00 & 0,01 & 0,00 & 0,01 & 0,03 & 0,00 & 0,01 & 0,02 & 0,00 & 0,01 & 0,00 & 0,01 \\
\hline $\mathrm{Na}_{2} \mathrm{O}$ & 0,50 & 0,49 & 0,44 & 0,46 & 0,15 & 0,44 & 0,13 & 0,44 & 0,15 & 0,20 & 0,46 & 0,36 \\
\hline $\mathrm{K}_{2} \mathrm{O}$ & 10,34 & 10,27 & 10,14 & 10,31 & 10,24 & 10,15 & 10,43 & 9,97 & 10,39 & 10,51 & 10,20 & 10,50 \\
\hline $\mathrm{F}$ & 0,21 & 0,20 & 0,76 & 0,52 & 0,48 & 0,53 & 0,56 & 0,47 & 0,49 & 0,53 & 0,56 & 0,35 \\
\hline $\mathrm{Cl}$ & 0,00 & 0,00 & 0,01 & 0,00 & 0,01 & 0,00 & 0,00 & 0,01 & 0,00 & 0,00 & 0,01 & 0,02 \\
\hline Subtotal & 95,70 & 95,52 & 95,75 & 96,08 & 95,47 & 95,34 & 96,22 & 95,25 & 95,31 & 95,78 & 95,59 & 95,24 \\
\hline $\mathrm{O}=\mathrm{F}, \mathrm{Cl}$ & 0,09 & 0,08 & 0,32 & 0,22 & 0,20 & 0,22 & 0,23 & 0,20 & 0,21 & 0,22 & 0,24 & 0,15 \\
\hline Total & 95,61 & 95,43 & 95,43 & 95,87 & 95,27 & 95,12 & 95,98 & 95,05 & 95,10 & 95,55 & 95,35 & 95,09 \\
\hline \multicolumn{13}{|c|}{ Fórmula estrutural calculada na base de 22 átomos de oxigênio } \\
\hline $\mathrm{Si}$ & 6,27 & 6,26 & 6,34 & 6,27 & 6,44 & 6,36 & 6,53 & 6,33 & 6,29 & 6,28 & 6,28 & 6,31 \\
\hline Alv & 1,73 & 1,74 & 1,66 & 1,73 & 1,56 & 1,64 & 1,47 & 1,67 & 1,71 & 1,72 & 1,72 & 1,69 \\
\hline Sítio Z & 8,00 & 8,00 & 8,00 & 8,00 & 8,00 & 8,00 & 8,00 & 8,00 & 8,00 & 8,00 & 8,00 & 8,00 \\
\hline $\mathrm{Al}^{\mathrm{M}}$ & 3,50 & 3,59 & 3,35 & 3,49 & 3,09 & 3,19 & 3,19 & 3,22 & 3,10 & 3,29 & 3,23 & 3,33 \\
\hline $\mathrm{Ti}$ & 0,03 & 0,01 & 0,01 & 0,01 & 0,05 & 0,04 & 0,03 & 0,03 & 0,04 & 0,03 & 0,03 & 0,02 \\
\hline $\mathrm{Fe}$ & 0,45 & 0,44 & 0,53 & 0,48 & 0,42 & 0,67 & 0,53 & 0,71 & 0,77 & 0,54 & 0,69 & 0,55 \\
\hline $\mathrm{Mn}$ & 0,02 & 0,01 & 0,01 & 0,01 & 0,01 & 0,02 & 0,00 & 0,02 & 0,01 & 0,01 & 0,02 & 0,00 \\
\hline $\mathrm{Mg}$ & 0,08 & 0,03 & 0,16 & 0,06 & 0,60 & 0,21 & 0,32 & 0,18 & 0,31 & 0,27 & 0,17 & 0,21 \\
\hline Sítio Y & 4,09 & 4,08 & 4,06 & 4,06 & 4,18 & 4,13 & 4,08 & 4,16 & 4,23 & 4,14 & 4,14 & 4,12 \\
\hline $\mathrm{Ca}$ & 0,00 & 0,00 & 0,00 & 0,00 & 0,00 & 0,00 & 0,00 & 0,00 & 0,00 & 0,00 & 0,00 & 0,00 \\
\hline $\mathrm{Na}$ & 0,13 & 0,13 & 0,11 & 0,12 & 0,04 & 0,12 & 0,03 & 0,12 & 0,04 & 0,05 & 0,12 & 0,09 \\
\hline K & 1,77 & 1,76 & 1,74 & 1,76 & 1,76 & 1,76 & 1,78 & 1,74 & 1,82 & 1,81 & 1,77 & 1,82 \\
\hline Intercamada & 1,90 & 1,89 & 1,86 & 1,88 & 1,80 & 1,88 & 1,82 & 1,86 & 1,86 & 1,86 & 1,89 & 1,91 \\
\hline $\mathrm{F}$ & 0,09 & 0,08 & 0,32 & 0,22 & 0,20 & 0,23 & 0,24 & 0,20 & 0,21 & 0,23 & 0,24 & 0,15 \\
\hline $\mathrm{Cl}$ & 0,00 & 0,00 & 0,00 & 0,00 & 0,00 & 0,00 & 0,00 & 0,00 & 0,00 & 0,00 & 0,00 & 0,01 \\
\hline Cátions & 17,99 & 17,97 & 17,91 & 17,94 & 17,98 & 18,01 & 17,90 & 18,02 & 18,09 & 18,00 & 18,04 & 18,03 \\
\hline $\begin{array}{l}\mathrm{Fe} /(\mathrm{Fe}+ \\
\mathrm{Mg})\end{array}$ & 0,844 & 0,945 & 0,765 & 0,883 & 0,411 & 0,765 & 0,621 & 0,798 & 0,710 & 0,666 & 0,806 & 0,728 \\
\hline
\end{tabular}


Cuiú-Cúiu (Assunção e Klein, 2014; Klein et al., 2001). Com base no exposto, entende-se que as IF desse sistema salino representam um episódio de aprisionamento independente e distinto do fluido $\mathrm{H}_{2} \mathrm{O}-\mathrm{CO}_{2}-\mathrm{NaCl}$, cujo mecanismo de separação de fases - efervescência - é o processo que desencadeia o estágio mineralizante. É importante notar que o principal intervalo de $T$ ht observado é amplo $\left(280-340^{\circ} \mathrm{C}\right)$, com extremos imiscíveis das IF do tipo AC que homogeneizaram ao longo e, subordinadamente, acima dele (amostra DDZ778). Esse comportamento indicaria um processo contínuo para a separação de fases.

A ocorrência de IF com salinidades contrastantes, aprisionadas em um mesmo arranjo espacial e a observação da correlação positiva entre as suas Tht e salinidade (Figura 14) pode ser interpretada como resultado da mistura do fluido $\mathrm{H}_{2} \mathrm{O}-\mathrm{NaCl} \pm \mathrm{KCl} \pm \mathrm{MgCl}_{2} \pm \mathrm{FeCl}_{2}\left(\mathrm{AQ}_{1}\right)$ com um fluido mais tardio, representado pelo fluido do sistema $\mathrm{H}_{2} \mathrm{O}-\mathrm{NaCl}$ $\left(\mathrm{AQ}_{2}\right)$, gerando o trend de diluição observado na Figura 14.

Os fluidos atribuídos ao sistema $\mathrm{H}_{2} \mathrm{O}-\mathrm{NaCl}-\mathrm{CaCl}_{2}$ $\left(\mathrm{AQ}_{3}\right)$ mostram os mais elevados valores de salinidade $\mathrm{e}$ baixas temperaturas de aprisionamento. Tendo em vista que a história hidrotermal observada em Jerimum de Baixo adquire um caráter mais cálcico nos seus momentos finais, é plausível que esse tipo de fluido esteja relacionado com a formação do epídoto, da calcita e da fluorita.

\section{Geotermômetro da clorita}

Diversos estudos têm utilizado a composição química da clorita para estimar as suas temperaturas de formação. Apesar das limitações observadas nas abordagens empíricas (De Caritat et al., 1993; Kranidiotis e MacLean, 1987; Xie et al., 1997), a técnica comumente rende resultados

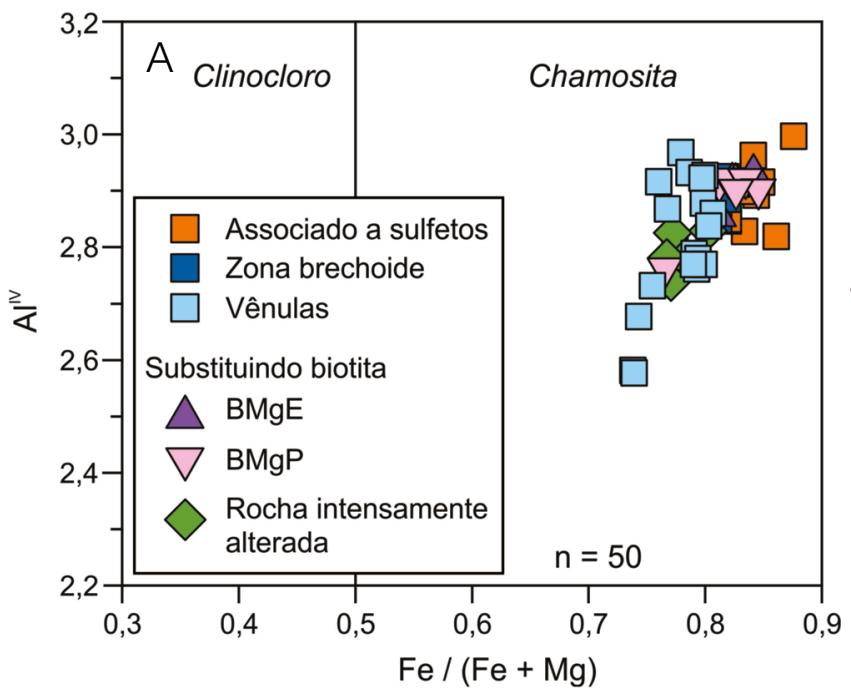

razoáveis quando alguns requisitos são observados ( $c f$., Klein et al., 2007):

(i) correlação linear entre $X_{\mathrm{Fe}}$ e $\mathrm{Al}^{\mathrm{IV}}$;

(ii) consistência entre os dados químicos das cloritas estudadas e aqueles utilizados na calibração dos geotermômetros;

(iii) comparação dos resultados com estimativas de temperatura independentes.

Em Jerimum de Baixo, a clorita analisada mostra uma correlação linear positiva (coeficiente de correlação $=0,7$ ) entre $X_{\mathrm{Fe}}$ e $\mathrm{Al}^{\mathrm{IV}}$, que, apesar de não ser perfeita, é assumida como existente. A composição química dessa clorita se situa dentro do intervalo composicional daquelas usadas por Zang e Fyfe (1995) e Xie et al. (1997) para calibrarem seus geotermômetros. No primeiro, algumas ressalvas na calibração são importantes: 0 desconhecimento da interferência das condições de pressão nos resultados obtidos e a retirada em excesso de $\mathrm{Al}^{\mathrm{IV}}$ pelo fator de correção aplicado na equação utilizada, o que rebaixa os resultados geotermométricos. No segundo, pesa a favor a apreciação da influência da composição da rocha hospedeira na composição da clorita e a melhor concordância com os dados termométricos independentes aqui apresentados (IF), o que rende temperaturas mais consistentes. Dessa forma, o intervalo total de temperaturas de formação da chamosita é de $261-315^{\circ} \mathrm{C}$, com os valores amplamente concentrados entre $280-305^{\circ} \mathrm{C}$.

\section{Estimativas das condições de pressão e profundidade}

Fluidos aprisionados em condições de efervescência/boiling são especialmente interessantes para estimativas de pressão no momento do aprisionamento, pois registram tais condições sem a necessidade de correção de pressão. Assumindo-se que

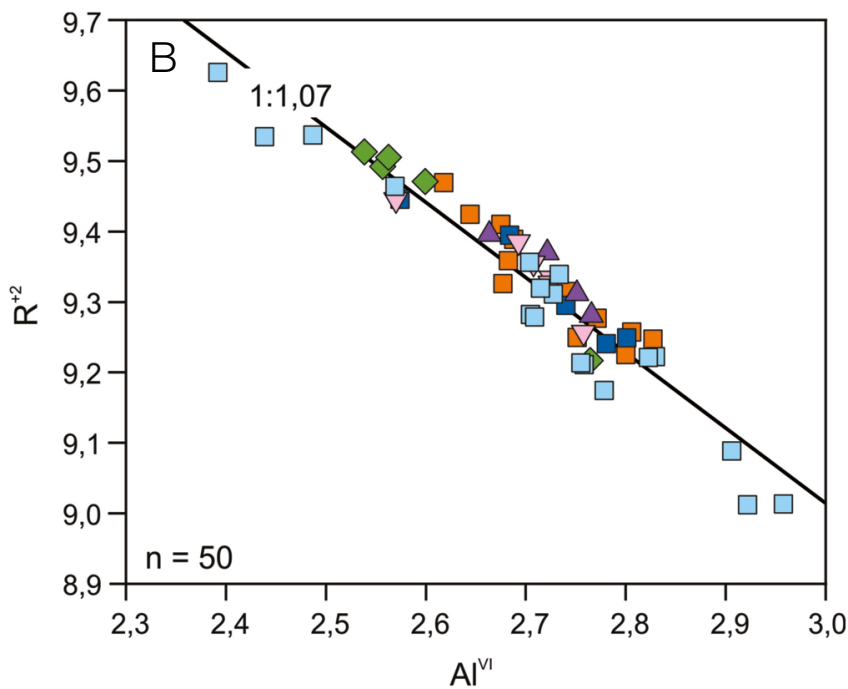

BMgE: biotita-monzogranito equigranular; BMgP: biotita-monzogranito porfirítico.

Figura 13. Diagramas composicionais e catiônicos para a clorita do alvo Jerimum de Baixo. (A) Diagrama binário Fe / (Fe + Mg) vs. $\mathrm{Al}^{\mathrm{IV}}$ (Bailey, 1988) com o coeficiente de correlação (R) é 0,7; (B) diagrama catiônico $\mathrm{Al}^{\mathrm{Vl}} \mathrm{vs} \mathrm{R}^{+2}$, que evidencia forte correlação negativa. 
as IF aquocarbônicas foram aprisionadas durante o estágio mineralizante e que satisfazem os critérios para condições de imiscibilidade, isócoras construídas a partir das suas densidades globais mínima e máxima dentro do intervalo térmico estimado para o estágio mineralizante foram cruzadas com as temperaturas de formação da clorita. Dessa forma, a estimativa para as condições de pressão mais provável para o aprisionamento desses fluidos corresponde a uma faixa de 0,7 a 2,1 kbar, que, admitindo-se condições litostáticas, equivale a profundidades entre 1,9 e 5,8 km (Figura 15). Essa estimativa é compatível com regime rúptil a rúptil-dúctil da crosta e é corroborada pelos dados petrográficos e estruturais (rochas hospedeiras com aspectos texturais originais localmente preservados, cristais de plagioclásio com planos

Tabela 5. Análises de microssonda eletrônica representativas da clorita do alvo Jerimum de Baixo, Campo Mineralizado do Cuiú-Cuiú.

\begin{tabular}{|c|c|c|c|c|c|c|c|c|}
\hline \multirow[t]{2}{*}{ Ocorrência } & \multicolumn{6}{|c|}{ Substituindo biotita } & \multicolumn{2}{|c|}{ Associada a sulfetos } \\
\hline & \multicolumn{2}{|c|}{ BMgE } & \multirow{2}{*}{\multicolumn{2}{|c|}{$\begin{array}{c}\text { BMgP } \\
\text { EK-R-36 }\end{array}$}} & \multirow{2}{*}{\multicolumn{2}{|c|}{ Granito alterado }} & \multirow{2}{*}{\multicolumn{2}{|c|}{ EK-R-28 }} \\
\hline Amostra & EK- & -35 & & & & & & \\
\hline Análises & C-C5_12 & C-C5_14 & C-C2_1 & C-C2_6 & C-C4_2 & C-C4_3 & C-C1_9 & C-C3_1 \\
\hline $\mathrm{SiO}_{2}$ & 21,95 & 22,57 & 22,31 & 23,43 & 23,03 & 23,02 & 22,67 & 22,34 \\
\hline $\mathrm{TiO}_{2}$ & 0,02 & 0,03 & 0,05 & 0,18 & 0,09 & 0,09 & 0,02 & 0,03 \\
\hline $\mathrm{Al}_{2} \mathrm{O}_{3}$ & 20,74 & 20,54 & 20,88 & 20,25 & 21,14 & 20,48 & 20,75 & 21,71 \\
\hline $\mathrm{FeO}$ & 38,61 & 39,30 & 39,80 & 38,06 & 38,42 & 38,25 & 39,43 & 40,44 \\
\hline $\mathrm{MnO}$ & 1,29 & 0,85 & 0,24 & 0,82 & 1,19 & 0,83 & 1,17 & 1,00 \\
\hline $\mathrm{MgO}$ & 4,56 & 5,12 & 5,16 & 6,53 & 5,30 & 6,34 & 4,41 & 4,28 \\
\hline $\mathrm{CaO}$ & 0,01 & 0,04 & 0,04 & 0,02 & 0,02 & 0,03 & 0,09 & 0,01 \\
\hline $\mathrm{Na}_{2} \mathrm{O}$ & 0,02 & 0,04 & 0,00 & 0,05 & 0,05 & 0,02 & 0,02 & 0,01 \\
\hline $\mathrm{K}_{2} \mathrm{O}$ & 0,02 & 0,03 & 0,01 & 0,02 & 0,03 & 0,02 & 0,04 & 0,00 \\
\hline $\mathrm{F}$ & 0,00 & 0,00 & 0,00 & 0,00 & 0,00 & 0,00 & 0,00 & 0,00 \\
\hline $\mathrm{Cl}$ & 0,00 & 0,01 & 0,01 & 0,00 & 0,00 & 0,01 & 0,00 & 0,00 \\
\hline Subtotal & 87,22 & 88,52 & 88,52 & 89,37 & 89,27 & 89,07 & 88,59 & 89,82 \\
\hline $\mathrm{O}=\mathrm{F}, \mathrm{Cl}$ & 0,00 & 0,00 & 0,00 & 0,00 & 0,00 & 0,00 & 0,00 & 0,00 \\
\hline Total & 87,22 & 88,52 & 88,52 & 89,37 & 89,27 & 89,07 & 88,58 & 89,82 \\
\hline \multicolumn{9}{|c|}{ Fórmula estrutural calculada na base de 28 átomos de oxigênio } \\
\hline $\mathrm{Si}$ & 5,09 & 5,14 & 5,08 & 5,24 & 5,17 & 5,17 & 5,17 & 5,04 \\
\hline Alv & 2,91 & 2,86 & 2,92 & 2,76 & 2,83 & 2,83 & 2,83 & 2,96 \\
\hline Sítio Z & 8,00 & 8,00 & 8,00 & 8,00 & 8,00 & 8,00 & 8,00 & 8,00 \\
\hline $\mathrm{All}^{\mathrm{M}}$ & 2,75 & 2,66 & 2,69 & 2,57 & 2,76 & 2,60 & 2,75 & 2,81 \\
\hline $\mathrm{Ti}$ & 0,00 & 0,01 & 0,01 & 0,03 & 0,02 & 0,01 & 0,00 & 0,01 \\
\hline $\mathrm{Fe}$ & 7,48 & 7,49 & 7,58 & 7,11 & 7,21 & 7,19 & 7,53 & 7,63 \\
\hline $\mathrm{Mn}$ & 0,25 & 0,16 & 0,05 & 0,16 & 0,23 & 0,16 & 0,23 & 0,19 \\
\hline $\mathrm{Mg}$ & 1,57 & 1,74 & 1,75 & 2,18 & 1,78 & 2,12 & 1,50 & 1,44 \\
\hline $\mathrm{Ca}$ & 0,00 & 0,01 & 0,01 & 0,00 & 0,00 & 0,01 & 0,02 & 0,00 \\
\hline $\mathrm{Na}$ & 0,01 & 0,02 & 0,00 & 0,02 & 0,02 & 0,01 & 0,01 & 0,00 \\
\hline $\mathrm{K}$ & 0,00 & 0,01 & 0,00 & 0,01 & 0,01 & 0,00 & 0,01 & 0,00 \\
\hline Sítio Y & 12,08 & 12,10 & 12,10 & 12,08 & 12,03 & 12,10 & 12,05 & 12,07 \\
\hline $\mathrm{F}$ & 0,00 & 0,00 & 0,00 & 0,00 & 0,00 & 0,00 & 0,00 & 0,00 \\
\hline $\mathrm{Cl}$ & 0,00 & 0,00 & 0,00 & 0,00 & 0,00 & 0,00 & 0,00 & 0,00 \\
\hline Cátions & 20,08 & 20,10 & 20,10 & 20,08 & 20,03 & 20,10 & 20,05 & 20,07 \\
\hline $\begin{array}{l}\mathrm{Fe} /(\mathrm{Fe}+ \\
\mathrm{Mg})\end{array}$ & 0,826 & 0,812 & 0,812 & 0,766 & 0,803 & 0,772 & 0,834 & 0,841 \\
\hline $\mathrm{Ca}+\mathrm{Na}+\mathrm{K}$ & 0,02 & 0,04 & 0,01 & 0,03 & 0,04 & 0,02 & 0,04 & 0,01 \\
\hline Cath $\left({ }^{\circ} \mathrm{C}\right)$ & 407 & 398 & 407 & 383 & 394 & 393 & 393 & 415 \\
\hline $\mathrm{KM}\left({ }^{\circ} \mathrm{C}\right)$ & 388 & 381 & 387 & 368 & 377 & 375 & 380 & 394 \\
\hline $\mathrm{ZF}\left({ }^{\circ} \mathrm{C}\right)$ & 281 & 277 & 283 & 271 & 275 & 277 & 272 & 285 \\
\hline $\mathrm{X}\left({ }^{\circ} \mathrm{C}\right)$ & 297 & 290 & 300 & 285 & 288 & 294 & 281 & 301 \\
\hline
\end{tabular}

Cath: Cathelineau (1988); KM: Kranidiotis e MacLean (1987); ZF: Zang e Fyfe (1995); X: Xie et al (1997). 
de macla encurvados, cristais de quartzo com extinção ondulante, veios de quartzo paralelizados localmente cisalhados, preenchimento de espaços abertos por clorita \pm sericita e o estilo fissural de alguns estágios da alteração hidrotermal).

\section{Transporte e mecanismos de precipitação}

Em soluções hidrotermais, o transporte do ouro é mais eficientemente realizado sob a forma de complexos de bissulfeto

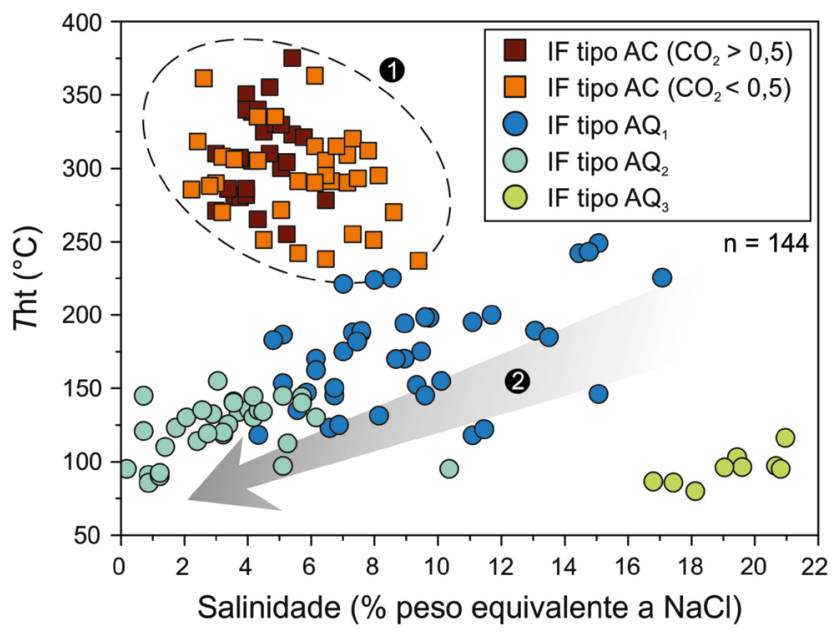

IF: inclusões fluidas.

Figura 14. Diagrama Tht vs. salinidade com a variação composicional dos tipos de inclusões fluidas aprisionadas em cristais de quartzo em veios do alvo Jerimum de Baixo. O campo (1) destaca as inclusões aquocarbônicas aprisionadas durante o processo de efervescência, enquanto o vetor (2) marca o trend de mistura e diluição do fluido aquoso primário $\left(A Q_{1}\right)$ por um fluido mais tardio $\left(A Q_{2}\right)$.

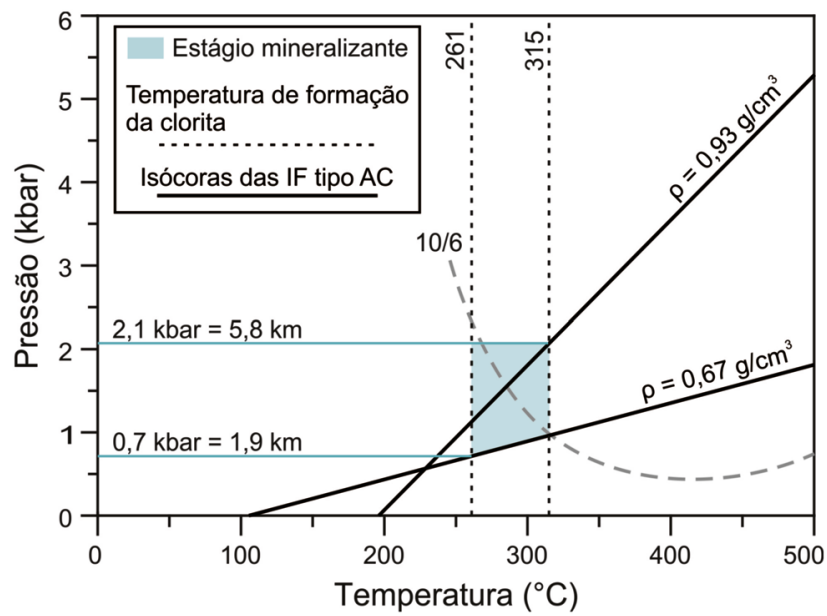

Figura 15. Diagrama Pressão-Temperatura que mostra as condições de pressão e temperatura estimadas (área azul) para o aprisionamento das IF aquocarbônicas do alvo Jerimum de Baixo. A curva tracejada representa o solvus para o sistema $\mathrm{H}_{2} \mathrm{O}-\mathrm{CO}_{2}-\mathrm{NaCl} \operatorname{com} X_{\mathrm{cO} 2}=10$ e $6 \%$ em peso equivalente de $\mathrm{NaCl}$ (Bowers e Helgeson, 1983). de ouro $\left[\mathrm{Au}(\mathrm{HS})_{2}{ }_{2}^{-}, \mathrm{Au}(\mathrm{HS})^{0}\right]$ e complexos de cloro $\left(\mathrm{AuCl}^{2-}\right)$ (Benning e Seward, 1996; Gammons et al., 1994; Hayashi e Ohmoto, 1991). Em Jerimum de Baixo, o minério é do tipo sulfetado (principalmente pirita), sem quantidade relevante de outros minerais de metais de base e formado em temperaturas $<400^{\circ} \mathrm{C}$; a presença de pirrotita em paragênese no minério (partículas de Au em fratura) atesta um caráter redutor para o fluido mineralizante. Esse cenário aponta o $\mathrm{H}_{2} \mathrm{~S}$ (alternativamente $\mathrm{HS}^{-}$) como o principal ligante no fluido mineralizador e o $\mathrm{Au}(\mathrm{HS})^{-2}$ como o complexo transportador primário do ouro.

A precipitação de metais solubilizados ocorre pela desestabilização dos complexos transportadores em resposta à variação de parâmetros físico-químicos como $f \mathrm{O}_{2}$, $\mathrm{pH}$, temperatura, entre outros. Reações de hidrólise (sericitização) consomem $\mathrm{H}^{+}$do ambiente, ao passo que a cristalização de calcita consome $\mathrm{CO}_{2}$ do fluido, ambas de modo que se promovam alterações no $\mathrm{pH}$. A formação de sulfetos nas rochas alteradas sugere uma redução na atividade do enxofre pela interação fluido-rocha (desestabilização dos minerais máficos).

\section{Evolução do sistema hidrotermal no alvo Jerimum de Baixo}

Acerca da fonte dos fluidos no Complexo Mineralizado do Cuiú-Cuiú, estudos de isótopos estáveis de H, O, C e S têm convergido com razoabilidade para uma mesma interpretação (Araújo, 2014; Assunção e Klein, 2014; Silva Junior e Klein, 2015). Dados isotópicos de H e O para o fluido hidrotermal, obtidos em clorita e quartzo, indicam origem a partir de fluidos magmáticos (Tabela 6). A composição isotópica do $\mathrm{C}$ da calcita e de IF com $\mathrm{CO}_{2}$ apresentam composições compatíveis com fontes magmáticas, metamórficas e carbonatos marinhos. A ausência de registros de carbonatos marinhos e de metamorfismo à época da mineralização na PAT limita a uma fonte magmática ( \pm mantélica) para o $\mathrm{CO}_{2}$. A composição do $\mathrm{S}$ na pirita tem sido atribuída à fonte magmática (magmas félsicos ou por lixiviação de sulfetos de rochas ígneas).

Segundo Chi e Xue (2011), a exsolução de fluidos magmáticos na parte externa de intrusões (entre a carapaça solidificada e a parte interna da intrusão subsaturada em água) resulta em uma expansão no volume total e provoca, assim, uma sobrepressão. Quando a resistência da carapaça solidificada é superada pela pressão exercida pelos fluidos confinados, sua consequente fragmentação e das rochas suprajacentes (por hidrofraturamento) gera condutos para os fluidos em exsolução. Essas condições geológicas justificariam a presença de corpos brechoides e veios.

$\mathrm{O}$ fluido $\mathrm{H}_{2} \mathrm{O}-\mathrm{CO}_{2}-\mathrm{NaCl}$ exsolvido precocemente do magma interagiu com as rochas encaixantes graníticas desestabilizando os minerais primários, em especial a biotita e o 
plagioclásio, substituindo-os mais comumente por clorita e fengita. A sílica dissolvida no fluido foi principalmente precipitada como quartzo em espaços abertos. O hidrofraturamento é normalmente acompanhado de despressurização rápida, que é tida como um excelente gatilho para processos de efervescência/ebulição (Jébrak, 1997; Parry e Bruhn, 1990). Quando os fluidos alcançaram o nível de transição rúptil-dúctil $(\sim 6 \mathrm{~km})$, os componentes formadores do minério foram precipitados em resposta ao fraturamento e às flutuações nas condições de pressão, além de reações fluido/ rocha e alterações no $\mathrm{pH}$. Com o resfriamento do sistema, a solubilidade $\mathrm{CO}_{2}$ no fluido decresce (Lowenstern, 2001), resultando em um fluido aquoso mais salino ou, alternativamente, houve um evento de infiltração de um fluido aquoso independente $\left(\mathrm{H}_{2} \mathrm{O}-\mathrm{NaCl} \pm \mathrm{KCl} \pm \mathrm{MgCl}_{2} \pm \mathrm{FeCl}_{2}\right)$. Nos estágios finais da história hidrotermal, o metassomatismo adquire caráter mais cálcico, estabilizando localmente o epídoto e, posteriormente, a calcita venular. Os fluidos com fluxo ascendente, de fonte mais profunda, misturar-se-iam com os fluidos que fluíam descendentemente $\left(\mathrm{H}_{2} \mathrm{O}-\mathrm{NaCl}\right)$.

O fluido do sistema $\mathrm{H}_{2} \mathrm{O}-\mathrm{NaCl}-\mathrm{CaCl}_{2}$ pode estar relacionado em alguma proporção com a precipitação da calcita

Tabela 6. Características geológicas e propriedades físico-químicas dos fluidos disponíveis para os depósitos e alvos do Campo Mineralizado do Cuiú-Cuiú.

\begin{tabular}{|c|c|c|c|c|c|c|c|}
\hline $\begin{array}{l}\text { Depósitos/ } \\
\text { alvos }\end{array}$ & $\begin{array}{c}\text { Moreira } \\
\text { Gomes }\end{array}$ & Central & Guarim & $\begin{array}{c}\text { Pau da } \\
\text { Merenda }\end{array}$ & $\begin{array}{c}\text { Jerimum de } \\
\text { Cima }\end{array}$ & $\begin{array}{c}\text { Jerimum de } \\
\text { Baixo }\end{array}$ & Babi \\
\hline $\begin{array}{l}\text { Rocha } \\
\text { hospedeira } \\
\text { (unidade } \\
\text { estratigráfica) }\end{array}$ & $\begin{array}{c}\text { Tonalito } \\
\text { (Creporizão) }^{(6)}\end{array}$ & $\begin{array}{c}\text { Monzogranito } \\
\text { (Parauari) } \\
(4 \mathrm{e} 7)\end{array}$ & $\begin{array}{c}\text { Diorito, } \\
\text { granodiorito } \\
\text { (Cuiú-Cuiú) } \\
(1 \mathrm{e} \text { 2) }\end{array}$ & $\begin{array}{c}\text { Monzogranito, } \\
\text { granodiorito } \\
\text { (Cuiú-Cuiú) } \\
\text { (3) }\end{array}$ & $\begin{array}{c}\text { Tonalito a } \\
\text { monzogranito } \\
\text { (Cuiú-Cuiú) } \\
(2 \text { e 5) }\end{array}$ & $\begin{array}{c}\text { Monzogranito } \\
\text { (Creporizão) } \\
\text { (8) }\end{array}$ & $\begin{array}{c}\text { Tonalito, } \\
\text { Monzogranito } \\
\text { (Cuiú-Cuiú) } \\
\text { (5) }\end{array}$ \\
\hline $\begin{array}{l}\text { Alteração } \\
\text { hidrotermal }\end{array}$ & $\begin{array}{l}\text { sil, chl, ser, } \\
\text { carb, sulf, ep } \\
\text { (6) }\end{array}$ & $\begin{array}{c}\text { sil, chl, ser, } \\
\text { carb, sulf } \\
(4 \in 7)\end{array}$ & $\begin{array}{c}\text { sil, chl, carb, } \\
\text { ser, sulf } \\
(1 \in 2)\end{array}$ & $\begin{array}{l}\text { sil, chl, ser, } \\
\text { carb, sulf } \\
\text { (3) }\end{array}$ & $\begin{array}{c}\text { sil, chl, ser, } \\
\text { carb, sulf } \\
(2 \text { e } 5)\end{array}$ & $\begin{array}{l}\text { sil, ser, chl, } \\
\text { carb, sulf } \\
\text { (8) }\end{array}$ & $\begin{array}{l}\text { chl, carb, ser, } \\
\text { sulf, sil } \\
\text { (5) }\end{array}$ \\
\hline $\begin{array}{l}\text { Principais } \\
\text { sulfetos }\end{array}$ & $\begin{array}{l}\text { Py } \\
(6)\end{array}$ & $\begin{array}{l}\text { Py } \\
(4 \in 7)\end{array}$ & Py (Ccp) & Py, $\underset{\text { (3) }}{\mathrm{Ccp}}, \mathrm{Po}$ & $\begin{array}{l}\text { Py } \\
(2 \text { e } 5)\end{array}$ & Py, $\underset{(8)}{\mathrm{Po}}(\mathrm{Ccp})$ & $\begin{array}{c}\text { Py } \\
(5)\end{array}$ \\
\hline $\begin{array}{l}\text { Estilo da } \\
\text { mineralização }\end{array}$ & $\begin{array}{c}\text { Vênulas, } \\
\text { fissural } \\
\text { (6) }\end{array}$ & $\begin{array}{c}\text { Vênulas, } \\
\text { fissural } \\
(4 \in 7)\end{array}$ & $\begin{array}{c}\text { Veio maciço, } \\
\text { brecha } \\
(1 \in 2)\end{array}$ & $\begin{array}{l}\text { Vênulas, } \\
\text { fissural } \\
\text { (3) }\end{array}$ & $\begin{array}{c}\text { Vênulas, } \\
\text { disseminado } \\
(2 \text { e } 5)\end{array}$ & $\begin{array}{c}\text { Vênulas, } \\
\text { fissural, } \\
\text { disseminado } \\
\underset{(8)}{ }\end{array}$ & $\mathrm{nm}$ \\
\hline $\begin{array}{l}\text { Idade } \\
\text { estimada (Ma) }\end{array}$ & $\begin{array}{c}1.858 \\
(4)\end{array}$ & $\underset{(4)}{1.886-1.907}$ & nd & $\begin{array}{c}1.862-1.867 \\
(4)\end{array}$ & nd & nd & nd \\
\hline $\begin{array}{l}\text { Tipo de fluido } \\
\text { [Tht] } \\
\text { [Salinidade] }\end{array}$ & $\begin{array}{c}\mathrm{CO}_{2}, \\
\mathrm{H}_{2} \mathrm{O}-\mathrm{CO}_{2}, \\
{[280-350]} \\
{[3,9-7,5]} \\
\mathrm{H}_{2} \mathrm{O} \\
{[110-225]} \\
{[\sim 0-10,1]} \\
(6)\end{array}$ & $\begin{array}{c}\mathrm{CO}_{2}, \\
\mathrm{H}_{2} \mathrm{O}-\mathrm{CO}_{2}, \\
{[280-360]} \\
{[3,9-9,0]} \\
\mathrm{H}_{2} \mathrm{O} \\
{[80-200]} \\
{[3,4-13,9]} \\
(7)\end{array}$ & $\begin{array}{c}\mathrm{CO}_{2}, \\
\mathrm{H}_{2} \mathrm{O}-\mathrm{CO}_{2}, \\
{[270-320]} \\
{[3,9-9,1]} \\
\mathrm{H}_{2} \mathrm{O} \\
{[160-220]} \\
{[3,4-7,9]} \\
\text { (1) }\end{array}$ & $\begin{array}{c}\mathrm{CO}_{2}, \\
\mathrm{H}_{2} \mathrm{O}-\mathrm{CO}_{2}, \\
{[220-320]} \\
{[4,0-8,0]} \\
\mathrm{H}_{2} \mathrm{O} \\
{[100-250]} \\
{[3,0-9,0]} \\
(3)\end{array}$ & $\begin{array}{c}\mathrm{CO}_{2}, \\
\mathrm{H}_{2} \mathrm{O}-\mathrm{CO}_{2}, \\
{[280-400]} \\
{[3,9-6,6]} \\
\mathrm{H}_{2} \mathrm{O} \\
{[130-350]} \\
{[2,6-9,2]} \\
(5)\end{array}$ & $\begin{array}{c}\mathrm{CO}_{2}, \\
\mathrm{H}_{2} \mathrm{O}-\mathrm{CO}_{2}, \\
{[280-340]} \\
{[3,0-8,3]} \\
\mathrm{H}_{2} \mathrm{O} \\
{[140-220]} \\
{[0,9-11,7]} \\
(8)\end{array}$ & $\begin{array}{c}\mathrm{H}_{2} \mathrm{O} \\
{[136-410]} \\
{\left[\begin{array}{c}3,4-8,5] \\
(5)\end{array}\right.}\end{array}$ \\
\hline P (kbar) & $\begin{array}{l}<2,1 \\
(6)\end{array}$ & $\underset{(7)}{0,75-1,5}$ & $\begin{array}{c}0,9-2,9 \\
\text { (1) }\end{array}$ & nd & $\begin{array}{c}1,2-2,0 \\
\text { (5) }\end{array}$ & $\begin{array}{c}0,7-2,1 \\
\text { (8) }\end{array}$ & nd \\
\hline $\begin{array}{l}\text { Profundidade } \\
\text { (km) }\end{array}$ & $\begin{array}{c}<6,0 \\
(6)\end{array}$ & $\begin{array}{c}2,6-5,0 \\
(7)\end{array}$ & $\begin{array}{c}4,0-7,0 \\
\text { (1) }\end{array}$ & nd & $\begin{array}{c}3,3-5,5 \\
(5)\end{array}$ & $\begin{array}{c}1,9-5,8 \\
\text { (8) }\end{array}$ & nd \\
\hline$\delta^{18} \mathrm{O}_{\mathrm{H} 2 \mathrm{O}}(\% \mathrm{o})$ & $\underset{(6)}{0,5}$ a 9,0 & $2,2 \underset{(7)}{\operatorname{a}} 8,0$ & $\begin{array}{l}4,4 \\
\text { (2) }\end{array}$ & nd & $-1,1 \underset{(5)}{\text { a }} 9,6$ & nd & $-1,4 \underset{(5)}{\operatorname{a}} 10,3$ \\
\hline$\delta \mathrm{D}_{\mathrm{H} 2 \mathrm{O}}(\% \circ)$ & $-49 \underset{(6)}{a}-8,0$ & $-35 \underset{(7)}{a}-15$ & $\begin{array}{l}-31 \\
(2)\end{array}$ & nd & nd & nd & $\begin{array}{l}\mathrm{nd} \\
(5)\end{array}$ \\
\hline$\delta^{13} \mathrm{C}_{\mathrm{CO} 2}(\% \circ)$ & $-\underset{(6)}{-23,8 a}-2,8$ & $-18 \underset{(7)}{a}-1,0$ & nd & nd & $-3,2 \underset{(5)}{a}-0,3$ & nd & $-4,3 \underset{(5)}{a}-0,1$ \\
\hline $\begin{array}{l}T \text { composição } \\
\text { isotópica }\left({ }^{\circ} \mathrm{C}\right) \\
\end{array}$ & $\begin{array}{c}280-350 \\
\text { (6) } \\
\end{array}$ & $\begin{array}{c}340 \\
(7) \\
\end{array}$ & $\begin{array}{c}300 \\
\text { (2) }\end{array}$ & nd & $205 \underset{\text { (5) }}{2} 330$ & nd & $205 \underset{(5)}{a} 330$ \\
\hline
\end{tabular}


e até mesmo da fluorita dado o seu registro em eventos tardios na evolução do sistema hidrotermal. Todavia, a ausência de estudos nesses minerais dificulta a confirmação dessa hipótese. Fluidos de composições similares foram registrados em vários depósitos auríferos na PAT. No depósito aurífero de Ouro Roxo, Veloso et al. (2013) atribuíram para esse tipo de fluido uma natureza ligada ao magmatismo Maloquinha. Considerando a possibilidade da existência de elementos como Li para esse tipo de fluido no alvo Jerimum de Baixo, é viável que tal fluido esteja relacionado ao magmatismo Maloquinha.

\section{Estudo comparativo entre Jerimum de Baixo e outros depósitos auríferos}

O CMCC abrange dois depósitos e vários alvos cuja maioria exibe, de maneira geral, características metalogenéticas bastante similares que apontam para um evento mineralizante comum. Em Jerimum de Baixo o que se observa é uma boa correspondência de várias dessas características, que estão sintetizadas na Tabela 6. Embora não haja dados geocronológicos das rochas encaixantes, todavia, petrograficamente, constatam-se rochas monzograníticas e atribuídas por relações de campo à Suíte Intrusiva Creporizão (Moura et al., 2014). A alteração hidrotermal observada em Jerimum de Baixo é, em geral, muito similar ao observado em outros sítios mineralizados no CMCC no que tange ao estilo, intensidade e assembleia mineralógica. Em relação a este último, excetuando-se a fluorita (registrada somente em Jerimum de Baixo), a manifestação de epídoto foi percebida também nos depósitos Moreira Gomes e Central. Na associação metálica em Jerimum de Baixo, a pirrotita assume papel importante na paragênese do minério, embora, aparentemente, não seja ubíqua no CMCC.

Silva Junior e Klein (2015) confrontaram as características dos fluidos nos alvos Jerimum de Cima (mineralizado) e Babi (não mineralizado) e interpretaram os fluidos $\mathrm{H}_{2} \mathrm{O}-\mathrm{CO}_{2}$ - $\mathrm{NaCl}$ como o mais precoce e o mineralizante no sistema hidrotermal. Em Jerimum de Baixo, o sistema de fluidos foi regido inicialmente por soluções aquocarbônicas, provavelmente magmáticas, com infiltrações de fluidos aquosos nos momentos finais da história hidrotermal. Para o fluido $\mathrm{H}_{2} \mathrm{O}$ $\mathrm{CO}_{2}-\mathrm{NaCl}$, é atribuída a condição de fluido mineralizante e foi aprisionado entre 237,0 e $405,0^{\circ} \mathrm{C}$, com pico entre 280,0 e $340,0^{\circ} \mathrm{C}$ e com salinidade baixa a moderada. Para os fluidos aquosos, as temperaturas de homogeneização abrangeram o intervalo total de 80,0 a $249,0^{\circ} \mathrm{C}$, com o pico principal entre $180,0 \mathrm{e} 220,0^{\circ} \mathrm{C}$, em que as maiores salinidades foram observadas em fluidos tardios com $\mathrm{H}_{2} \mathrm{O}-\mathrm{NaCl}-\mathrm{CaCl}_{2}(16,8 \mathrm{a}$ $21,0 \%$ em peso equivalente de $\mathrm{NaCl}$ ). Tais características são bastante semelhantes ao observado nos outros jazimentos no CMCC. Em nível de prospecto, Klein et al. (2001) registraram em Guarim temperaturas de homogeneização que melhor se comparam às verificadas em Jerimum de Baixo. No CMCC, estudos de geotermometria isotópica foram implementados com maior frequência, não havendo informações publicadas sobre temperaturas de formação da clorita por intermédio de sua composição química além do exposto no presente estudo. Considerando os resultados obtidos por Assunção e Klein (2014) no depósito Moreira Gomes $\left(304-359^{\circ} \mathrm{C}\right)$ e assumindo uma boa correspondência paragenética entre a clorita estudada por isótopos estáveis e as cloritas aqui analisadas, observa-se que aquele depósito abrange valores termométricos mais elevados que os observados em Jerimum de Baixo, o que pode sugerir que a mineralização nesse último pode ter ocorrido em temperaturas relativamente mais baixas, ainda que dentro do intervalo térmico comumente identificado no CMCC. De maneira geral, o conjunto de dados apontam para um único evento mineralizador.

Na PAT, depósitos/prospectos rasos (Coringa, Davi, Joel, Chapéu do Sol e Botica) mostram características pouco comparáveis a Jerimum de Baixo quanto à rocha hospedeira, estilo da mineralização e do hidrotermalismo. Ao Depósito Ouro Roxo (orogênico) assemelham-se o conteúdo metalífero e tipos de alteração hidrotermal, embora o último ocorra em estilo diferente. Nos depósitos Batalha e Palito (classe pórfiro), as similaridades são notadas nas rochas hospedeiras e, em parte, nos estilos de alteração e mineralização. Contudo, em Jerimum de Baixo, as alterações sódica e potássica não foram constatadas. Os depósitos São Jorge e Tocantizinho (relacionados à intrusão) compartilham similaridades nas rochas hospedeiras e conteúdo metalífero (embora pirrotita seja importante somente em Jerimum de Baixo). Ao Tocantinzinho, guardase ainda uma melhor correspondência aos estilos e tipos de alteração hidrotermal (exceto a alteração potássica) e condições P-T estimadas para a mineralização.

\section{Modelo de depósito mineral}

Os primeiros estudos realizados no $\mathrm{CMCC}$ apontaram filiação à classe de depósitos de ouro orogênico, baseado nas características físico-químicas dos fluidos (aquocarbônicos e mesotermais) (Klein et al., 2001). Todavia, dados geológicos e geocronológicos mais recentes têm estimado uma idade da mineralização para o CMCC de aproximadamente 1,86 Ga (Araújo, 2014; Silva Junior et al., 2012; Silva Junior et al., 2013), apontando a ausência de evento metamórfico que justifique a formação do minério (o metamorfismo na PAT é inferido por ter ocorrido cerca de 2,0 1,95 Ga; Klein et al., 2002; Santos et al., 2001). Neste aspecto, a mineralização do CMCC pode ser considerada praticamente contemporânea ou um pouco mais jovem do que a granitogênese Maloquinha, conforme a idade de cristalização $\mathrm{Pb}-\mathrm{Pb}$ em zircão de $1880 \pm 9$ Ma obtida por Lamarão et al. (2002).

Não obstante a existência de um litotipo porfirítico no alvo Jerimum de Baixo, os tipos de alteração hidrotermal, o estilo estrutural, o baixo teor de sulfetos e de metais de base e composição dos fluidos dificultam a interpretação de um modelo similar aos sistemas pórfiro-epitermal (Seedorffet al., 2005; Simmons et al., 2005). 
Os dados levantados para o alvo Jerimum de Baixo apontam para um jazimento aurífero regido por um sistema magmático-hidrotermal no qual fluidos aquocarbônicos de baixa salinidade e baixa a moderada densidade foram exsolvidos por magmatismo félsico em profundidades entre $2 \mathrm{e} 6 \mathrm{~km}$. Com o progresso do sistema hidrotermal, ocorrem infiltrações tardias de outros fluidos (magmáticos e superficiais). Embora os tipos de fluidos envolvidos, os tipos e estilos das alterações hidrotermais, o teor de sulfetos baixos e a associação metálica (com destaque para $\mathrm{Au}-\mathrm{Bi}-\mathrm{Te}$ ) sejam características similares ao encontrados nos reduced intrusion-related gold systems (RIRGS; Hart, 2007), tal definição depende das informações do plúton causativo, que ainda não foi devidamente esclarecido no CMCC.

\section{CONSIDERAÇÕES FINAIS}

As rochas hospedeiras em Jerimum de Baixo estão relacionadas à Suíte Intrusiva Creporizão (Figura 2). As características composicionais da biotita remetem a um magma progenitor de natureza cálcio-alcalina a subalcalina. Apesar da compatibilidade, dados geocronológicos devem confirmar tal ligação, uma vez que outras suítes também podem apresentar tais características (Suíte Intrusiva Parauari).

A mineralização de ouro está hospedada em veios/vênulas contendo quartzo \pm clorita \pm sericita \pm pirita \pm pirrotita \pm carbonatos associada a um sistema hidrotermal desenvolvido sobre e nas proximidades de rochas graníticas de composição monzogranítica. O ouro ocorre em fraturas na pirrotita e/ou pirita e como partículas livres em cristais de quartzo.

Os estágios de alteração hidrotermal observados no alvo Jerimum de Baixo são representados por cloritização, sericitização, sulfetação, silicificação, epidotização e carbonatação. A clorita formada - tanto a de substituição quanto a venular - é do tipo chamosítica com elevados teores de $X_{\mathrm{Fe}}$ em que as sutis modificações composicionais são ocasionadas principalmente pela substituição de cátions $\mathrm{R}^{+2}$ por $\mathrm{Al}^{\mathrm{VI}}$ no sítio octaédrico, enquanto a mica branca formada hidrotermalmente pertence à série fengítica. A presença de fluorita em vênulas, associada a idades recentemente obtidas para a mineralização aurífera de depósitos no CMCC, sugerem que o magmatismo Maloquinha nessa região pode ter participado, de alguma forma, nos processos mineralizantes no alvo Jerimum de Baixo.

O sistema hidrotermal foi regido por, inicialmente, fluidos aquocarbônicos de derivação provavelmente magmática de baixa salinidade e densidade baixa a moderada. A principal assembleia hidrotermal foi formada principalmente entre 280 e $340^{\circ} \mathrm{C}$. É provável que a contínua exsolução de fluido pelo magma ocasionou o enriquecimento da fase aquosa nos momentos mais tardios da exsolução e levou, com o resfriamento do sistema, ao predomínio das inclusões aquosas, embora a participação de fluidos externos aquosos por infiltração não possa ser descartada. O sistema aparentemente interagiu nos estágios finais com fluidos superficiais e que promoveram processos de diluição.

O principal mecanismo causador da quebra da estabilidade dos complexos iônicos do tipo $\mathrm{Au}(\mathrm{HS})^{-2}$, considerado como o principal meio transportador do ouro no alvo Jerimum de Baixo, foi o processo de efervescência do fluido aquocarbônico, aprisionado em temperaturas estimadas no intervalo de 250 a $380^{\circ} \mathrm{C}$, com base nos dados microtermométricos obtidos nas IF AC. Outros fatores podem ter se somado a isso, tais como resfriamento contínuo do sistema, flutuações na pressão confinante, alteração na condições redox e pH do ambiente e interações fluido-rocha. As condições de pressão durante o processo de efervescência estimadas entre 0,7 e 2,1 kbars equivalem a profundidades entre $2 \mathrm{e}$ $6 \mathrm{~km}$, remetendo a um regime rúptil a rúptil-dúctil da crosta.

As feições observadas no alvo Jerimum de Baixo não permitem um enquadramento classificatório perfeitamente adequado a nenhum dos modelos tipológicos metalogenéticos clássicos. Características como tipo e estilo da alteração hidrotermal, tipo e teor de sulfetos, tipos de fluidos envolvidos, profundidade de mineralização, associação metálica juntamente com os dados levantados em outros depósitos/alvos no CMCC indicam que o alvo Jerimum de Baixo é um jazimento aurífero com filiação magmática-hidrotermal (RIRGS?).

\section{AGRADECIMENTOS}

O primeiro autor agradece ao Conselho Nacional de Desenvolvimento Científico e Tecnológico (CNPq), a concessão de bolsa de estudo (processo ${ }^{\circ}$ 132180/2015-4). Às integrantes do Laboratório de Microanálises da UFPA A. P. Corrêa e V. M. M. C. de Araújo, o suporte na condução dos estudos de MEV. Aos revisores anônimos, os comentários construtivos, correções e sugestões de suma importância para a melhoria do manuscrito. As amostras de testemunhos de sondagem foram cedidas pela mineradora Magellan Minerals LTDA., no âmbito do projeto Metalogênese do Campo Mineralizado do Cuiú-Cuiú, Província Aurífera do Tapajós, Estado do Pará (Ministério de Ciência e Tecnologia - MCT/CNPq processo ${ }^{\circ}$ 475614/2010-0), sob coordenação do Dr. Evandro Luiz Klein. Este artigo é uma contribuição ao Instituto de Geociências da Amazônia (Instituto Nacional de Ciência e Tecnologia INCT-CNPq/MCT/Fundação Amazônia Paraense de Amparo à Pesquisa — FAPESPA — Processo $n^{\circ}$ 573733/2008-2).

\section{REFERÊNCIAS}

Almeida, F. F. M., Hasui, Y., Brito Neves, B. B., Fuck, R. A. (1981). Brazilian structural provinces: An introduction. Earth-Science Reviews, 17(1-2), 1-29. https://doi. org/10.1016/0012-8252(81)90003-9 
Araújo, A. C. S. (2014). Estudos isotópicos e de inclusões fluidas no Depósito Central do Campo Mineralizado do Cuiú-Cuiú, Província Aurífera do Tapajós, Estado do Pará. Dissertação (Mestrado). Belém: Instituto de Geociências - UFPA, 65 p.

Assunção, R. F. S., Klein, E. L. (2014). The Moreira Gomes deposit of the Cuiú-Cuiú goldfield: Fluid inclusions and stable isotope constraints and implications for the genesis of granite-hosted gold mineralization in the Tapajós Gold Province, Brazil. Journal of South American Earth Sciences, 49, 85-105. https://doi.org/10.1016/j.jsames.2013.11.004

Bahia, R. B. C., Quadros, M. L. E. S. (2000). Geologia e recursos minerais da Folha Caracol (SB.21-X-C): Estado do Pará. Escala 1:250.000. Nota explicativa. Brasília: Programa de Levantamentos Geológicos Básicos do Brasil - PLGB; Projeto Especial Província Mineral do Tapajós - PROMIN Tapajós; CPRM - Serviço Geológico do Brasil, CD-ROM.

Bahia, R. B. C., Quadros, M. L. E. S., Vasquez, M. L., Ricci, P. S. F., Ferreira, A. L. (2001). Formação Buiuçu Descrição das unidades litoestratigráficas e litodêmicas. Folhas Vila Mamãe Anã (SB.21-V-D), Jacareacanga (SB.21Y-B), Caracol (SB.21 X-C), Vila Riozinho (SB.21-Z-A) e Rio Novo (SB.21-Z-C), Estados do Pará e Amazonas. Brasília: Geologia e Recursos Minerais da Província Mineral do Tapajós (Projeto Especial Província Mineral do Tapajós - PROMIN Tapajós), Serviço Geológico do Brasil - CPRM, CD-ROM.

Bailey, S. W. (1988). Chlorites: structures and crystal chemistry. In: S. W. Bailey (Ed.). Hydrous Phyllosilicates (Exclusive of micas). Reviews in Mineralogy and Geochemistry, 19(1), 347-403.

Benning, L. G., Seward, T. M. (1996). Hydrosulphide complexing of $\mathrm{Au}(\mathrm{I})$ in hydrothermal solutions from $150-400^{\circ} \mathrm{C}$ and 500-1500 bar. Geochimica et Cosmochimica Acta, 60(11), 1849-1871. https://doi.org/10.1016/0016-7037(96)00061-0

Bodnar, R. J., Vityk, M. O. (1994). Interpretation of microthermometric data for $\mathrm{H}_{2} \mathrm{O}-\mathrm{NaCl}$ fluid inclusions. In: B. De Vivo, M. L. Frezzotti (Eds.). Fluid inclusions in minerals: methods and applications (117-130). Blacksburg: Virginia Tech.

Boone, G. M. (1969). Origin of clouded feldspars: petrologic contrasts in a granitic porphyry intrusion. American Journal of Science, 267, 633-668. https://doi.org/10.2475/ajs.267.6.633

Borges, R. M. K., Dall'Agnol, R., Lamarão, C. N., Figueiredo, M. A. B. M., Leite, A. A. S., Barros, C. E. M., Costi,
H. T. (2009). Petrografia, química mineral e processos hidrotermais associados ao depósito de ouro São Jorge, Província Aurífera do Tapajós, Cráton Amazônico. Revista Brasileira de Geociências, 39(2), 375-393. https://doi. org/10.25249/0375-7536.2009392375393

Borisenko, A. (1977). Study of the salt composition of solutions in gas-liquid inclusions in minerals by the cryometric method. Soviet Geology and Geophysics, 18(8), 11-19.

Bowers, T. S., Helgeson, H. C. (1983). Calculation of the thermodynamic and geochemical consequences of non-ideal mixing in the system $\mathrm{H}_{2} \mathrm{O}-\mathrm{CO}_{2}-\mathrm{NaCl}$ on phase relations in geological systems: equation of state for $\mathrm{H}_{2} \mathrm{O}-\mathrm{CO}_{2}-\mathrm{NaCl}$ fluids at high pressures and temperatures. Geochimica et Cosmochimica Acta, 47(7), 1247-1275. https://doi.org/10.1016/0016-7037(83)90066-2

Brown, P. E. (1989). Flincor: a microcomputer program for the reduction and investigation of fluid-inclusion data. American Mineralogist, 74(11-12), 1390-1393.

Brown, P. E., Lamb, W. M. (1986). Mixing of $\mathrm{H}_{2} \mathrm{O}$ e $\mathrm{CO}_{2}$ in fluid inclusions; Geobarometry and Archean gold deposits. Geochimica et Cosmochimica Acta, 50(5), 847-852. https:// doi.org/10.1016/0016-7037(86)90360-1

Cathelineau, M. (1988). Cation site occupancy in chlorites and illites as a function of temperature. Clay Minerals, 23(4), 471-485. https://doi.org/10.1180/claymin.1988.023.4.13

Cathelineau, M., Marignac, C. (1994). Use of fluid inclusions for a better understanding of intracontinental geothermal activities. In: B. De Vivo, M. L. Frezzotti (Eds.). Fluid inclusions in minerals: methods and applications (309-326). Blacksburg: Virginia Tech.

Chi, G., Liu, Y., Dubé, B. (2009). Relationship between $\mathrm{CO}_{2}-$ dominated fluids, hydrothermal alterations and gold mineralization in the Red Lake greenstone belt, Canada. Applied Geochemistry, 24(4), 504-516. https://doi.org/10.1016/j.apgeochem.2008.12.005

Chi, G., Xue, C. (2011). An overview of hydrodynamic studies of mineralization. Geoscience Frontiers, 2(3), 423438. https://doi.org/10.1016/j.gsf.2011.05.001

Collins, P. L. F. (1979). Gas hydrates in $\mathrm{CO}_{2}$-bearing fluid inclusions and the use of freezing data for estimation of salinity. Economic Geology, 74(6), 1435-1444. https://doi. org/10.2113/gsecongeo.74.6.1435

Coutinho, M. G. N. (2008). Província Mineral do Tapajós: Geologia, metalogenia e mapa previsional para ouro em SIG. Rio de Janeiro: Serviço Geológico do Brasil - CPRM, 420 p. 
Coutinho, M. G. N., Santos, J. O. S., Fallick, A. E., Lafon, J. M. (2000). Orogenic gold deposits in Tapajós Mineral Province, Amazon, Brazil. 31 International Geological Congress. Rio de Janeiro: SBG, CD-ROM.

Davis, D. W., Lowenstein, T. K., Spencer, R. J. (1990). Melting behavior of fluid inclusions in laboratory-grown halite crystals in the systems $\mathrm{NaCl}-\mathrm{H}_{2} \mathrm{O}, \mathrm{NaCl}-\mathrm{KCl}-\mathrm{H}_{2} \mathrm{O}$, $\mathrm{NaCl}-\mathrm{MgCl}_{2}-\mathrm{H}_{2} \mathrm{O}$, and $\mathrm{NaCl}-\mathrm{CaCl}_{2}-\mathrm{H}_{2} \mathrm{O}$. Geochimica et Cosmochimica Acta, 54(3), 591-601. https://doi. org/10.1016/0016-7037(90)90355-O

De Caritat, P., Hutcheon, I., Walshe, J. L. (1993). Chlorite geothermometry: A review. Clays and Clay Minerals, 41(2), 219-239. https://doi.org/10.1346/CCMN.1993.0410210

Deer, W. A., Howie, R. A., Zussman, J. (1992). An introduction to the rock-forming minerals. 2. ed. Londres: Longman, $696 \mathrm{p}$.

Echeverri-Misas, C. M., Juliani, C., Monteiro, L. V. S., Fernandes, C. M. D. (2013). Mineralização de Au-Cu do tipo pórfiro na Província Aurífera do Tapajós: implicações metalogenéticas. III Simpósio Brasileiro de Metalogenia. Gramado: SBG, CD-ROM.

Gammons, C., Williams-Jones, A., Yu, Y. (1994). New data on the stability of gold (I) chloride complexes at $300^{\circ} \mathrm{C}$. Mineral Mag A, 58, 309-310.

Hart, C. J. (2007). Reduced intrusion-related gold systems. In: W. D. Goodfellow (Ed.). Mineral Deposits of Canada: A synthesis of Major deposit types, district metallogeny, the Evolution of geological provinces, and exploration methods (5,95-112). Canadá: Geological Association of Canada, Mineral Deposits Division.

Hayashi, K. I., Ohmoto, H. (1991). Solubility of gold in $\mathrm{NaCl}$-and $\mathrm{H}_{2} \mathrm{~S}$-bearing aqueous solutions at $250-350^{\circ} \mathrm{C}$. Geochimica et Cosmochimica Acta, 55(8), 2111-2126. https://doi.org/10.1016/0016-7037(91)90091-I

Hollister, L. S. (1990). Enrichment of $\mathrm{CO}_{2}$ in fluid inclusions in quartz by removal of $\mathrm{H}_{2} \mathrm{O}$ during crystal-plastic deformation. Journal of Structural Geology, 12(7), 895-901. https://doi. org/10.1016/0191-8141(90)90062-4

Jacobi, P. (1999). The discovery of epithermal Au-Cu-Mo proterozoic deposits in the Tapajós Province, Brazil. Revista Brasileira de Geociências, 29(2), 277-279. https://doi. org/10.25249/0375-7536.199929277279

Jébrak, M. (1997). Hydrothermal breccias in vein-type ore deposits: a review of mechanisms, morphology and size distribution. Ore Geology Reviews, 12(3), 111-134. https:// doi.org/10.1016/S0169-1368(97)00009-7
Juliani, C., Monteiro, L. V. S., Echeverri-Misas, C. M., Lagler, B., Fernandes, C. M. D. (2012). Gold and base metal porphyry and epithermal mineralization in Paleoproterozoic magmatic arcs in the Amazonian Craton, Brazil. 34 $4^{\text {th }}$ International Geological Congress. Queensland, Austrália: IUGS, CD-ROM.

Juliani, C., Rye, R. O., Nunes, C. M. D., Snee, L. W., Corrêa Silva, R. H., Monteiro, L. V. S., Bettencourt, J. S., Neumann, R., Alcover Neto, A. (2005). Paleoproterozoic high-sulfidation mineralization in the Tapajós gold province, Amazonian Craton, Brazil: Geology, mineralogy, alunite argon age, and stable-isotope constraints. Chemical Geology, 215(1-4), 95-125. https://doi.org/10.1016/j.chemgeo.2004.06.035

Juliani, C., Vasques, M. L., Klein, E. L., Villas, R. N. N., Echeverri Misas, C. M., Santiago, É. S. B., Monteiro, L. V. S., Carneiro, C. C., Fernandes, C. M. D., Usero, C. (2014). Metalogênese da Província Tapajós. In: M. G. Silva, M. B. Rocha Neto, H. Jost, R. M. Kuyumjian (Eds.). Metalogênese das Províncias Tectônicas Brasileiras (229-268). Belo Horizonte: Programa Geologia do Brasil, Recursos Minerais, Serviço Geológico do Brasil - CPRM.

Klein, E. L., Almeida, M. E., Rosa-Costa, L. T. (2012). The 1.89-1.87 Ga Uatumã Silicic Large Igneous Province, northern South America. Large Igneous Provinces Commission. Disponível em: <http://www.largeigneousprovinces. org/12nov>. Acesso em: $1^{\circ}$ mar. 2016.

Klein, E. L., Fuzikawa, K. (2010). Origin of the $\mathrm{CO}_{2}$-only fluid inclusions in the Palaeoproterozoic Carará vein-quartz gold deposit, Ipitinga Auriferous District, SE-Guiana Shield, Brazil: Implications for orogenic gold mineralisation. Ore Geology Reviews, 37(1), 31-40. https://doi.org/10.1016/j.oregeorev.2009.10.001

Klein, E. L., Harris, C., Giret, A., Moura, C. A. (2007). The Cipoeiro gold deposit, Gurupi Belt, Brazil: Geology, chlorite geochemistry, and stable isotope study. Journal of South American Earth Sciences, 23(2-3), 242-255. https:// doi.org/10.1016/j.jsames.2006.09.002

Klein, E. L., Harris, C., Renac, C., Giret, A., Moura, C. A., Fuzikawa, K. (2006). Fluid inclusion and stable isotope (O, $\mathrm{H}, \mathrm{C}$, and S) constraints on the genesis of the Serrinha gold deposit, Gurupi Belt, northern Brazil. Mineralium Deposita, 41(2), 160. https://doi.org/10.1007/s00126-006-0050-1

Klein, E. L., Rodrigues, J. B., Queiroz, J. D. S., Oliveira, R. G., Guimarães, S. B., Chaves, C. L. (2017). Deposition and tectonic setting of the Palaeoproterozoic Castelo dos Sonhos metasedimentary formation, Tapajós Gold Province, Amazonian Craton, Brazil: age and isotopic constraints. International Geology Review, 59(7), 864883. https://doi.org/10.1080/00206814.2016.1237311 
Klein, E. L., Rosa-Costa, L. T., Carvalho, J. M. A. (2004). Estudo de inclusões fluidas em veio de quartzo aurífero do prospecto Patinhas, Província Aurífera do Tapajós, Cráton Amazônico. Revista Brasileira de Geociências, 34(1), 59-66. https://doi.org/10.25249/0375-7536.20043415966

Klein, E. L., Santos, R. A., Fuzikawa, K., Angélica, R. S. (2001). Hydrothermal fluid evolution and estructural control of the Guarim gold mineralisation, Tapajós Province, Amazonian Craton, Brazil. Mineralium Deposita, 36(2), 149-164. https://doi.org/10.1007/s001260050295

Klein, E. L., Vasquez, M. L., Rosa-Costa, L. T., Carvalho, J. M. A. (2002). Geology of paleoproterozoic gneissand granitoid-hosted gold mineralization in Southern Tapajós gold Province, Amazonian Craton, Brazil. International Geology Review, 44(6), 544-558. https:// doi.org/10.2747/0020-6814.44.6.544

Kranidiotis, P., MacLean, W. H. (1987). Systematics of chlorite alteration at the Phelps Dodge massive sulfide deposit, Matagami, Quebec. Economic Geology, 82(7), 1898-1911. https://doi.org/10.2113/gsecongeo.82.7.1898

Lamarão, C. N., Dall'Agnol, R., Lafon, J. M., Lima, E. F. (2002). Geology, geochemistry, and $\mathrm{Pb}-\mathrm{Pb}$ zircon geochronology of the Paleoproterozoic magmatism of Vila Riozinho, Tapajós Gold Province, Amazonian craton, Brazil. Precambrian Research, 119(1-4), 189-223. https:// doi.org/10.1016/S0301-9268(02)00123-7

Lowenstern, J. B. (2001). Carbon dioxide in magmas and implications for hydrothermal systems. Mineralium Deposita, 36(6), 490-502. https://doi.org/10.1007/ s001260100185

McMahon, A. M. P. G. (2011). Resource estimate and technical report for the Cuiú Cuiú Project Tapajos region, north-central Brazil. Relatório interno, $134 \mathrm{p}$. Disponível em: <www.magellanminerals.com>. Acesso em: $1^{\circ}$ jun. 2014.

Monier, G., Robert, J. (1986). Muscovite solid solutions in the system $\mathrm{K}_{2} \mathrm{O}-\mathrm{MgO}-\mathrm{FeO}-\mathrm{Al}_{2} \mathrm{O}_{3}-\mathrm{SiO}_{2}-\mathrm{H}_{2} \mathrm{O}$ : an experimental study at $2 \mathrm{kbar} \mathrm{PH}_{2} \mathrm{O}$ and comparison with natural $\mathrm{Li}$-free white micas. Mineralogical Magazine, 50(356), 257-266. https://doi.org/10.1180/minmag.1986.050.356.08

Moura, E. M., Chaves, C. L., Pinheiro, F. G. R. (2014). Cuiú-Cuiú. Folha SB-21-X-C-IV, Estado do Pará. Escala 1:100.000. Carta Geológica. Belém: Programa Geologia do Brasil - PGB, Serviço Geológico do Brasil - CPRM, mapa colorido $(100 \times 80 \mathrm{~cm})$.
Nachit, H., Razafimahefa, N., Stussi, J. M., Carron, J. P. (1985). Composition chimique des biotites et typologie magmatique des granitoides. Comptes Rendus de l'Académie des Sciences, 301(11), 813-818.

Parry, W., Bruhn, R. (1990). Fluid pressure transients on seismogenic normal faults. Tectonophysics, 179(3-4), 335344. https://doi.org/10.1016/0040-1951(90)90299-N

Queiroz, J. D. S., Klein, E. L. (2012). Estudo de inclusões fluidas em veios de quartzo sulfetado do alvo Pau da Merenda, campo mineralizado do Cuiú-Cuiú, Província Aurífera do Tapajós. XLVI Congresso Brasileiro de Geologia. Santos: SBG, CD-ROM.

Queiroz, J. D. S., Klein, E. L., Rodrigues, J. B. (2015). Rochas intrusivas na Formação Castelo dos Sonhos, Cráton Amazônico: petrografia, geocronologia, geoquímica e implicações para as idades de sedimentação e da mineralização no depósito aurífero Castelo de Sonhos. Boletim do Museu Paraense Emílio Goeldi. Ciências Naturais, 10(3), 341-380.

Queiroz, J. D. S., Villas, R. N. N. (2015). Estudo dos fluidos hidrotermais relacionados ao depósito Tocantinzinho, Província Aurífera do Tapajós (PA), com base em inclusões fluidas. In: P. S. S. Gorayaeb, A. M. M. Lima (Eds.). Contribuições à Geologia da Amazônia (9, 93-117). Belém: SBG-Núcleo Norte.

Ramboz, C., Pichavant, M., Weisbrod, A. (1982). Fluid immiscibility in natural processes: Use and misuse of fluid inclusion data: II. Interpretation of fluid inclusion data in terms of immiscibility. Chemical Geology, 37(1-2), 29-48. https://doi.org/10.1016/0009-2541(82)90065-1

Rieder, M., Cavazzini, G., D’yakonov, Y. S., FrankKamenetskii, V. A., Gottardi, G., Guggenheim, S., Koval, P. V., Müller, G., Neiva, A. M., Radoslovich, E. W., Robert, J.-L., Sassi, F. P., Takeda, H., Weiss, Z., Wones, D. R. (1998). Nomenclature of the micas. Clays and Clay Minerals, 46(5), 586-595. https://doi.org/10.1346/CCMN.1998.0460513

Santos, J. O. S., Groves, D. I., Hartmann, L. A., Moura, M. A., McNaughton, N. J. (2001). Gold deposits of the Tapajós and Alta Floresta domains, Tapajós-Parima orogenic belt, Amazon Craton, Brazil. Mineralium Deposita, 36(3-4), 278299. https://doi.org/10.1007/s001260100172

Santos, J. O. S., Hartmann, L. A., Faria, M. S., Riker, S. R., Souza, M. M., Almeida, M. E., McNaugthon, N. J. (2006). A compartimentação do cráton amazonas em províncias: avanços ocorridos no período 2000-2006. IX Simpósio de Geologia da Amazônia. Belém: SBG-NO. 
Santos, J. O. S., Hartmann, L. A., Gaudette, H. E., Groves, D. I., McNaughton, N. J., Fletcher, I. R. (2000). A New Understanding of the Provinces of the Amazon Craton Based on Integration of Field Mapping and U-Pb and $\mathrm{Sm}-\mathrm{Nd}$ Geochronology. Gondwana Research, 3(4), 453-488. https:// doi.org/10.1016/S1342-937X(05)70755-3

Santos, J. O. S., Hartmann, L. A., McNaughton, N. J., Fletcher, I. R. (2002). Timing of mafic magmatism in the Tapajós Province (Brazil) and implications for the evolution of the Amazon Craton: evidence from baddeleyite and zircon U-Pb SHRIMP geochronology. Journal of South American Earth Sciences, 15(4), 409-429. https://doi.org/10.1016/ S0895-9811(02)00061-5

Santos, J. O. S., Van Breemen, O. B., Groves, D. I., Hartmann, L. A., Almeida, M. E., McNaughton, N. J., Fletcher, I. R. (2004). Timing and evolution of multiple Paleoproterozoic magmatic arcs in the Tapajós Domain, Amazon Craton: constraints from SHRIMP and TIMS zircon, baddeleyite and titanite $\mathrm{U}-\mathrm{Pb}$ geochronology. Precambrian Research, 131(1-2), 73-109. https://doi. org/10.1016/j.precamres.2004.01.002

Santos, M. D., Aquino, L. B. M., Serra, V. F. H., Lima, M. V. G. R., Galarza, M. A., Lafon, J. M. (2013). Geocronologia das rochas hospedeiras e do minério com implicações na gênese do depósito aurífero Palito, Província Tapajós, sudoeste do Pará. XIII Simpósio de Geologia da Amazônia, p. 675-678. Belém: SBG-Núcleo Norte, CD-ROM.

Schmidt-Mumm, A., Oberthür, T., Vetter, U., Blenkinsop, T. G. (1997). High $\mathrm{CO}_{2}$ content of fluid inclusions in gold mineralisations in the Ashanti Belt, Ghana: a new category of ore forming fluids? Mineralium Deposita, 32(2), 107118. https://doi.org/10.1007/s001260050078

Seedorff, E., Dilles, J., Proffett, J., Einaudi, M., Zurcher, L., Stavast, W., Johnson, D., Barton, M. (2005). Porphyry deposits: Characteristics and origin of hypogene features. In: J. W. Hedenquist, J. F. H. Thompson, R. J. Goldfarb, J. P. Richards (Eds.). Economic Geology $100^{\text {th }}$ Anniversary (29, 251-298). Society of Economic Geologists. https://doi. org/10.5382/AV100.10

Silva Junior, C. A. S., Klein, E. L. (2015). Geologia e características do fluido mineralizador dos alvos auríferos Jerimum de Cima e Babi, campo mineralizado do CuiúCuiú, Província Aurífera do Tapajós, Cráton Amazônico, com base em estudos de inclusões fluidas e de isótopos estáveis. Boletim do Museu Paraense Emílio Goeldi. Ciências Naturais, 10(2), 105-136.
Silva Junior, C. A. S., Klein, E. L., Galarza, M. A. (2013). Rochas hospedeiras e estudo de isótopos de chumbo do minério aurífero do alvo Pau da Merenda, Campo Mineralizado do Cuiú-Cuiú, Província Aurífera do Tapajós, Estado do Pará. XIII Simpósio de Geologia da Amazônia, p. 620-622. Belém: SBG-Núcleo Norte.

Silva Junior, C. A. S., Klein, E. L., Galarza, M. A., Borges, R. M. K., Queiroz, J. D. S., Assunção, R. F. S., Araújo, A. C. S., Moore, D. J. (2015). Zircon geochronology and $\mathrm{Pb}$ isotope systematics in sulfides: implications for the genesis of gold mineralization in the Cuiú-Cuiú Goldfield, Tapajós Gold Province, Amazonian Craton, Brazil. In: P. S. S. Gorayaeb, A. M. M. Lima (Eds.). Contribuições à Geologia da Amazônia $(9,453-465)$. Belém: SBGNúcleo Norte.

Silva Junior, C. A. S., Klein, E. L., Galarza, M. A., Moore, D. J. (2012). Petrografia e geocronologia das rochas hospedeiras e do minério aurífero sulfetado no Depósito Central (CuiúCuiú), Província Aurífera do Tapajós, Pará. XLVI Congresso Brasileiro de Geologia. Santos: SBG.

Simmons, S. F., White, N. C., John, D. A. (2005). Geological characteristics of epithermal precious and base metal deposits. In: J. W. Hedenquist, J. F. H. Thompson, R. J. Goldfarb, J. P. Richards (Eds.). Economic Geology $100^{\text {th }}$ Anniversary (29, 485-522). Society of Economic Geologists. https://doi. org/10.5382/AV100.16

Streckeisen, A. (1976). To each plutonic rock its proper name. Earth Science Reviews, 12(1), 1-33. https://doi. org/10.1016/0012-8252(76)90052-0

Stubens, T. C., Hennessey, B. T., Gowans, R. M. (2017). Technical report on the Cuiú Cuiú Project, Pará State, NorthCentral Brazil. Relatório interno, 128 p. Disponível em: $<$ https://www.cabralgold.com/projects/cuiu-cuiu-project/>. Acesso em: 15 set. 2017.

Tokashiki, C. C., Juliani, C., Monteiro, L. V. S., Echeverri Misas, C. M., Aguja, M. A., Arrais, L. B. (2015). Eventos vulcânicos de 1,97 Ga com mineralizações de ouro epitermais low- e intermediate-sulfidation na porção sul da Província Mineral do Tapajós (PA). In: P. S. S. Gorayaeb, A. M. M. Lima (Eds.). Contribuições à Geologia da Amazônia (9, 119-138). Belém, SBG-Núcleo Norte.

Vasquez, M. L. (2014). Contexto Geológico Regional. Geologia e Recursos Minerais das Folhas São Domingos - SA.21.Z-A-II e Jardim do Ouro - SA.21-Z-A-III. Belém: Serviço Geológico do Brasil - CPRM. 
Vasquez, M. L., Chaves, C. L., Moura, E. M., Oliveira, J. K. M. (2014). Folha São Domingos (SA-21-Z-A-II). Escala 1:100.000. Carta geológica. Belém: Serviço Geológico do Brasil - CPRM.

Vasquez, M. L., Klein, E. L., Ricci, P. S. F. (2002). Granitóides pós-colisionais da porção leste da Província Tapajós. In: E. L. Klein, M. L. Vasques, L. T. Rosa-Costa (Eds.). Contribuições à Geologia da Amazônia (3, 67-84). Belém, SBG-Núcleo Norte.

Vasquez, M. L., Klein, E. L., Santos, A., Bahia, R. B. C., Ricci, P. S. F., Quadros, M. L. E. S., Macambira, M. J. B. (2000). Geochronology of granitoids and mafic intrusions of the Tapajós Gold Province - Amazonian Craton - Brazil. 31 International Geological Congress. Rio de Janeiro, CD-ROM.

Vasquez, M. L., Rosa-Costa, L. T., Silva, C. M. G., Klein, E. L. (2008). Compartimentação Tectônica. Geologia e Recursos Minerais do Estado do Pará. Texto explicativo dos mapas geológico e tectônico e de recursos minerais do Estado do Pará. Belém: Serviço Geológico do Brasil - CPRM, 112 p.

Veloso, Â. S. R., Santos, M. D., Rios, F. J. (2013). Evolução dos fluidos mineralizantes e modelo genético dos veios de quartzo auríferos em zona de cisalhamento do depósito Ouro Roxo, Província Tapajós, Jacareacanga (PA), Brasil. Brazilian Journal of Geology, 43(4), 725-744. http://dx.doi. org/10.5327/Z2317-488920130004000011
Villas, R. N. N., Santiago, É. S. B., Castilho, M. P. (2013). Contexto geológico, estudos isotópicos $(\mathrm{C}, \mathrm{O}$ e $\mathrm{Pb})$ e associação metálica do depósito aurífero Tocantinzinho, domínio Tapajós, Província Tapajós-Parima. Geologia USP. Série Cientifica, 13(1), 119-138. https://doi.org/10.5327/ Z1519-874X2013000100008

Walker, R. T., Samson, I. M. (1998). Cryogenic Ramam spectroscopic investigation of fluid inclusion in the system $\mathrm{NaCl}-\mathrm{CaCl}_{2}-\mathrm{H}_{2} \mathrm{O}$. In: E. Schandl (Ed.). 17th General Meeting, Internacional Mineralogical Association, p. A33. Toronto: Internacional Mineralogical Association.

Whitney, D. L., Evans, B. W. (2010). Abbreviations for names of rock-forming minerals. American Mineralogist, 95(1), 185-187. https://doi.org/10.2138/am.2010.3371

Xie, X., Byerly, G. R., Ferrell Jr., R. E. (1997). IIb trioctahedral chlorite from the Barberton greenstone belt: crystal structure and rock composition constraints with implications to geothermometry. Contributions to Mineralogy and Petrology, 126(3), 275-291. https://doi.org/10.1007/s004100050250

Zang, W., Fyfe, W. S. (1995). Chloritization of the hydrothermally altered bedrock at the Igarapé Bahia gold deposit, Carajás, Brazil. Mineralium Deposita, 30(1), 30-38. https://doi.org/10.1007/BF00208874 